\title{
Metal Chalcogenides on Silicon Photocathodes for Efficient Water Splitting: A Mini Overview
}

\author{
Jemee Joe ${ }^{\dagger}$, Hyunwoo Yang ${ }^{\dagger}$, Changdeuck Bae * ${ }^{+}$and Hyunjung Shin *(D) \\ Department of Energy Science, Sungkyunkwan University, Suwon 16419, Korea; konji3024@gmail.com (J.J.); \\ hyunoo0511@naver.com (H.Y.) \\ * Correspondence: changdeuck@skku.edu (C.B.); hshin@skku.edu (H.S.) \\ † These authors contributed equally to this work.
}

Received: 29 November 2018; Accepted: 8 January 2019; Published: 2 February 2019

\begin{abstract}
In the photoelectrochemical (PEC) water splitting (WS) reactions, a photon is absorbed by a semiconductor, generating electron-hole pairs which are transferred across the semiconductor/electrolyte interface to reduce or oxidize water into oxygen or hydrogen. Catalytic junctions are commonly combined with semiconductor absorbers, providing electrochemically active sites for charge transfer across the interface and increasing the surface band bending to improve the PEC performance. In this review, we focus on transition metal (di)chalcogenide [TM(D)C] catalysts in conjunction with silicon photoelectrode as Earth-abundant materials systems. Surprisingly, there is a limited number of reports in $\mathrm{Si} / \mathrm{TM}(\mathrm{D}) \mathrm{C}$ for PEC WS in the literature. We provide almost a complete survey on both layered TMDC and non-layered transition metal dichalcogenides (TMC) co-catalysts on Si photoelectrodes, mainly photocathodes. The mechanisms of the photovoltaic power conversion of silicon devices are summarized with emphasis on the exact role of catalysts. Diverse approaches to the improved PEC performance and the proposed synergetic functions of catalysts on the underlying $\mathrm{Si}$ are reviewed. Atomic layer deposition of TM(D)C materials as a new methodology for directly growing them and its implication for low-temperature growth on defect chemistry are featured. The multi-phase $\mathrm{TM}(\mathrm{D}) \mathrm{C}$ overlayers on $\mathrm{Si}$ and the operation principles are highlighted. Finally, challenges and directions regarding future research for achieving the theoretical PEC performance of Si-based photoelectrodes are provided.
\end{abstract}

Keywords: photoelectrochemical water splitting; silicon/chalcogenide junction; semiconductor photoelectrode; atomic layer deposition; multi-phase metal chalcogenides

\section{Introduction}

Photoelectrochemical (PEC) water splitting (WS) utilizes sunlight to oxidize or reduce water into oxygen and hydrogen. It is a promising concept for clean fuel production in that no energy cost is required when compared with the electrocatalytic (EC) counterparts. The conversion of solar power to feasible gas fuels (hydrogen and oxygen) out of water requires semiconductors as absorbers having suitable band gaps whose position straddles the water redox potential $\left(E^{0}=1.229 \mathrm{eV}\right)$ along with sustainable, Earth-abundant and efficient catalytic overlayers. Silicon (Si) is one of the most intensively studied semiconductors in the field of PEC WS as a light absorber thanks to its suitable band gap $(1.12 \mathrm{eV})$, Earth-abundance and validity in existing electronics industries. The maximum photovoltage $\left(V_{\mathrm{ph}}\right)$ of $\mathrm{Si}$ is in the range of 0.45 to $0.5 \mathrm{~V}$, with a photocurrent density $\left(J_{\mathrm{ph}}\right)$ of approximately $44 \mathrm{mAcm}^{-2}$ [1]. However, Si itself suffers from (photo)corrosion in electrolyte solutions. The surface states of $\mathrm{Si}$ induce surface recombination between the Si/electrolyte interfaces and significantly reduce the surface energetics and kinetics leading to decreases of both $V_{\mathrm{ph}}$ and $J_{\mathrm{ph}}$. This is the result of Fermi-level pinning (FLP) and recombination at the electrode/electrolyte interface, which is already 
prevalent in the metal-semiconductor (MS) junction in solid-state physics [2]. Therefore, the surface modification strategy of applying co-catalysts is necessary, and significant progress has been made in designing efficient photoelectrodes, primarily using the high work function noble metals (platinum (Pt) or Pt-group metals), which have shown the best catalytic activities for hydrogen production to date. To overcome the cost limitation for large-scale production, searching for Earth-abundant and efficient alternatives, such as high work function metals, chalcogenides, nitrides, phosphides, carbides, and metal oxides has received great interest in the field of PEC WS [3,4]. Moreover, the roles of the catalytic effects such as increasing $V_{\mathrm{ph}}$ and efficient charge transfer, and the plausible mechanisms have been studied recently $[5,6]$.

With these efforts, the tandem-structured PEC cells with co-catalysts have been investigated for the purpose of unbiased and unassisted PEC WS. A tandem PEC cell consists of the top cell that absorbs short wavelength light and the bottom cell that absorbs light of a long wavelength that was transmitted after the top one. The two-stage light absorption/conversion is an important strategy for better photovoltage and efficient photoconversion. The Lewis group calculated the optimal band gap of the light absorber and the theoretical solar-to-hydrogen limits for constructing the tandem PEC cell [7]. Si has long been used as a photocathode with variously modified oxide photoanodes to construct PEC-PEC tandem cells for improving the solar-to-hydrogen efficiency. Abdi et al. reported an excellent STH of $5 \%$ through the cobalt phosphate layers on the tandem cell configuration of $\mathrm{W}$-doped $\mathrm{BiVO}_{4}$ photoanode and Si photocathode [8]. Nonetheless, the research activities on the tandem structures with modifying Si remain in their infancy [9]. Therefore, it is highly desired to study the improved cathodic reactions by conjunction with various co-catalytic materials.

Transition metal (di)chalcogenide $[\mathrm{TM}(\mathrm{D}) \mathrm{C}]$ materials are promising due to the unique physical, optical and electronic properties $[10,11]$. Many of the TM(D)Cs are layered materials, consisting of honeycomb transition metal $(\mathrm{M})$ atoms sandwiched by chalcogenide $(\mathrm{X})$ layers. For example, $\mathrm{MoS}_{2}$ is composed of a triple layer of strongly covalent bonding S-Mo-S and weak van der Waals (vdW) bonding S-S. Similarly, the ordered quintuple layers, such as $\mathrm{Te}^{1}-\mathrm{Bi}^{-} \mathrm{Te}^{2}-\mathrm{Bi}^{-} \mathrm{Te}^{1}$ can also constitute a unique layered structure, where the $\mathrm{Te}^{1}-\mathrm{Te}^{1}$ bond is of the van der Waals' type (i.e., $\mathrm{M}_{2} \mathrm{X}_{3}$ type). With the unique bonding properties of $\mathrm{TM}(\mathrm{D}) \mathrm{C}$ that comprise covalent bonding between $\mathrm{M}-\mathrm{X}$ and $\mathrm{vdW}$ interaction between $X-X, T M(D) C$ shows characteristic charge transport and phonon propagation properties. These bonding characters, consequentially, exhibit strong anisotropy which can be utilized in many different applications. They have been applied in the studies from solid lubricant to thermoelectric materials $[12,13]$. In particular, relatively wider vdW gaps than ionic species could be promising as battery materials [14]. TM(D)C materials possessing intrinsic semiconducting properties can be transformed into metal by either distorting the $\mathrm{X}$ structures or intercalating ions into the vdW gap. The layered structures can be easily delaminated into very thin layers by exfoliation and can be used as a charge transport layer of solar cells having excellent mobility values [15]. Moreover, the dangling bonds where the catalytic activity is expected to be high are rare on the basal plane, and thus, more stable against the electrochemical reactions in the electrolyte [16]. The exposed edge sites are proved to be responsible for fast charge transfer kinetics at the electrode/electrolyte interface. Therefore, $\mathrm{MoS}_{2}$ has been studied as one of the most efficient catalysts for EC [17]. TM(D)C materials combined to semiconductor absorbers including Si have been reported for improved PEC performance.

In this review, we introduce the basic mechanisms of Si-based photoelectrodes, focusing mostly on photocathodes with a brief look at the progress achieved so far. Si photocathodes combined with $\mathrm{TM}(\mathrm{D}) \mathrm{C}$ materials will be the main focus of this review. Various synthesis routes of $\mathrm{Si} / \mathrm{TM}(\mathrm{D}) \mathrm{C}$ structures are also summarized, and the atomic layer deposition (ALD) technique is highlighted as the direct growth method at low temperatures. The implications of low-temperature formation on the defect chemistry of chalcogenides are featured. Finally, we highlight the recent reports on the multi-/mixed-phase TM(D)C layers on Si for application in PEC WS. The related energetic and kinematic mechanisms are also discussed for the design of high-performance photoelectrodes. 


\section{Photo-Assisted Electrochemical Water Splitting}

\subsection{Requirements for Semiconductor Photoelectrodes}

The semiconductor absorbers should satisfy the following fundamental conditions for WS: they should have proper conduction and valence band edge positions for water reduction or oxidation. An appropriate band gap and absorption coefficient is needed to include a large portion of the solar spectrum and efficient light absorption. In addition to these conditions, photoelectrodes should have good charge transport characteristic and durability in different operation conditions, such as acidic or basic electrolytes.

Knowing the band edge positions at the surface is important since they determine the maximum redox potentials of the photogenerated electron-hole pairs in a semiconductor [18], although the actual power for reduction or oxidation of electrons or holes is less due to the loss of energy in the space charge region (SCR) layer. The valence band $\left(E_{\mathrm{v}}\right)$ and conduction band $\left(E_{\mathrm{c}}\right)$ edge positions must straddle the water oxidation/reduction potentials. Semiconductors with the valence band maximum (VBM) below the water oxidation potential could be used as a photoanode in the water-splitting reaction and those with the conduction band minimum (CBM) above the hydrogen evolution potential could be used as a photocathode. Figure la shows the band gap and band edge positions of the various semiconductor materials with respect to a normal hydrogen electrode (NHE) and vacuum energy level [3,19-21]. Among group IV, group III-V semiconductors, i.e., Si, GaAs, GaN, GaP, and $\mathrm{GaInP}_{2}$, have feasible potentials for water reduction, and $\mathrm{GaN}$ and $\mathrm{InP}$ have proper potentials for water oxidation.

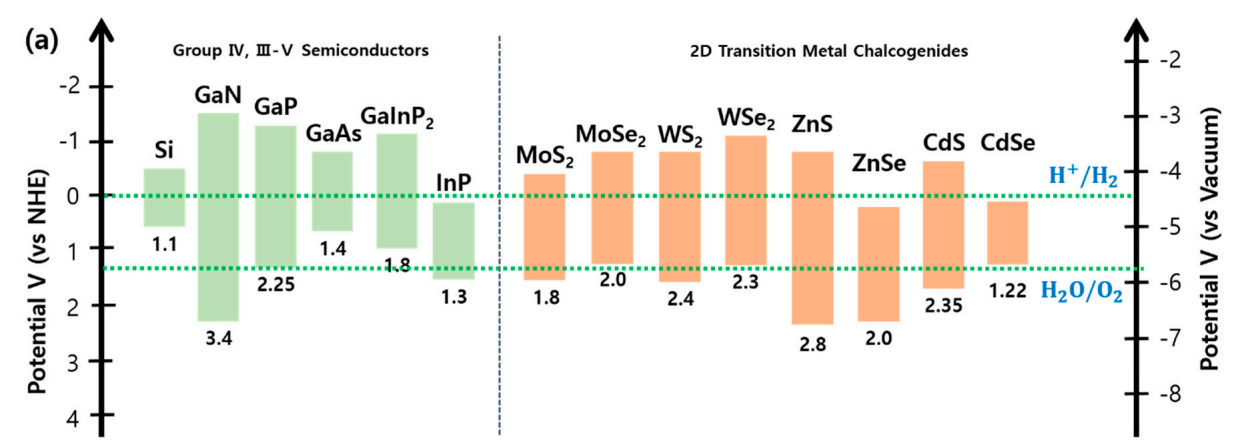

(b)

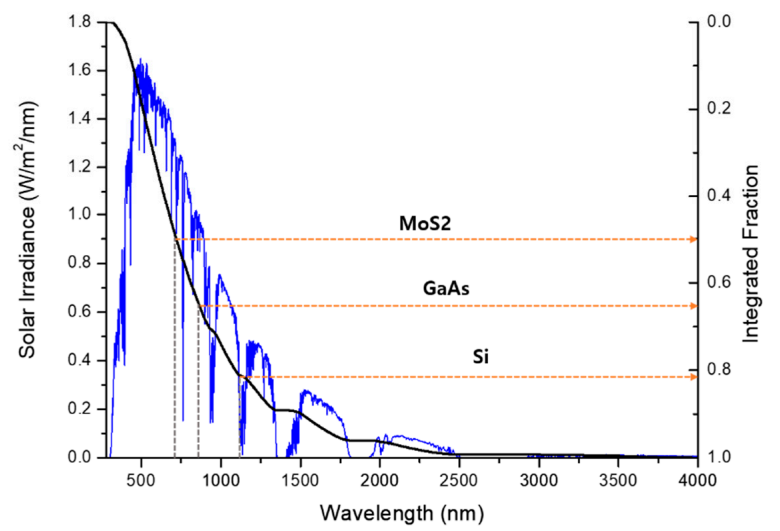

Figure 1. (a) Bandgaps and band edge positions of group IV, III-V semiconductors (green) and transition metal chalcogenides semiconductors (orange) relative to the hydrogen evolution reaction (HER) and oxygen evolution reaction (OER) active potentials (bulk band gaps corresponding to each are indicated in the dotted line below). (b) Solar irradiance spectrum of air mass (AM) $1.5 \mathrm{G}$ for a $37^{\circ}$ tilted surface. The ratio of absorbed solar light irradiance is integrated and is shown on the right-side y-axis of the graph (the blue line represents the irradiance unit of wavelength under 1 sun, and the black line represents the accumulated solar irradiance starting wavelength of $280 \mathrm{~nm}$ ). 
Other semiconducting layered materials, such as $\mathrm{MoS}_{2}, \mathrm{MoSe}_{2}, \mathrm{WS}_{2}, \mathrm{WSe}_{2}$, have appropriate band gap and band edge position for PEC WS, but are normally utilized as co-catalysts to enhance the PEC activities because of extremely short minority diffusion length. Therefore, layered metal chalcogenide materials are used as junction material for enhancing charge transfer or co-catalysts. When utilizing a single semiconductor as an ideal absorber, a $1.6 \mathrm{eV}$ of band gap is needed, and the solar-to-hydrogen (STH) conversion efficiency can reach up to 30\% [22]. However, there exist factors that limit the light absorption, hinder charge separation and injection, making it challenging to find an ideal semiconductor material.

Figure $1 \mathrm{~b}$ illustrates the solar spectrum irradiance at 1 sun and an integrated fraction showing how much solar spectrum the semiconductor can absorb. A semiconductor absorbs shorter wavelength than its band gap, which are the spectrum in the integrated area to the left of the wavelength corresponding to the $\mathrm{x}$-axis. Si has an indirect band gap of $1.12 \mathrm{eV}$, meaning that it can absorb a wavelength shorter than approximately $1127 \mathrm{~nm}$ according to $\lambda=1240 / E_{\mathrm{g}}$ (similarly, GaAs, $1.4 \mathrm{eV} / 886 \mathrm{~nm}$ and single-layer $\mathrm{MoS}_{2} 1.8 \mathrm{eV} / 689 \mathrm{~nm}$ (bulk $1.23 \mathrm{eV} / 1008 \mathrm{~nm}$ ) [23]. We calculated the portion of the solar spectrum that can be absorbed by these three semiconductors by integrating the solar irradiation spectrum above the wavelength. The result showed that among the three semiconductors mentioned above, Si can absorb $80 \%$, GaAs $62 \%$, and $\mathrm{MoS}_{2} 50 \%$ (bulk $\mathrm{MoS}_{2}, 75 \%$ ) of the full solar spectrum. With large absorption portion of the sunlight, $\mathrm{Si}$ has advantages as a promising absorber for the WS reaction, which is long diffusion length and recombination lifetime induced from the indirect band gap.

In addition to the aforementioned requirements, one needs to consider the electrolyte, which can significantly affect the photoelectrochemical performance in the PEC system. According to the Nernst equation, the hydrogen evolution reaction (HER) and oxygen evolution reaction (OER) potential changes are proportional to the $\mathrm{pH}$ by 0.059 at the $1 \mathrm{~atm}$. and $25{ }^{\circ} \mathrm{C}$ (Figure 2). Conversely, the semiconductor used as the photoelectrode might have a different slope compared to that of water. The Munich group revealed the redox shuttle mechanism of the CdS photoelectrode by following its reduction peak (conduction band position of $\mathrm{CdS}$ ) according to the $\mathrm{pH}$ [24]. They illustrated that the rate of change in the reduction peak position of $\mathrm{CdS}$ was different from that of water, and thus showed that at high $\mathrm{pH}$, the inversion of the $\mathrm{CdS}$ valence band edge and the scavenger redox couple occurred, leading to changing the redox mechanisms. Therefore, choosing materials depending on the band gap and band edge position mentioned earlier in Figure 1a may not yield the best performance if the $\mathrm{pH}$ of the electrolyte while operating is not considered. However, there are semiconductors, such as $\mathrm{MoS}_{2}$, and redox couples, such as $\mathrm{Ce}^{3+} / \mathrm{Ce}^{4+}, \mathrm{Ag}^{+} / \mathrm{Ag}$, etc., that do not show $\mathrm{pH}$ dependence $[24,25]$.

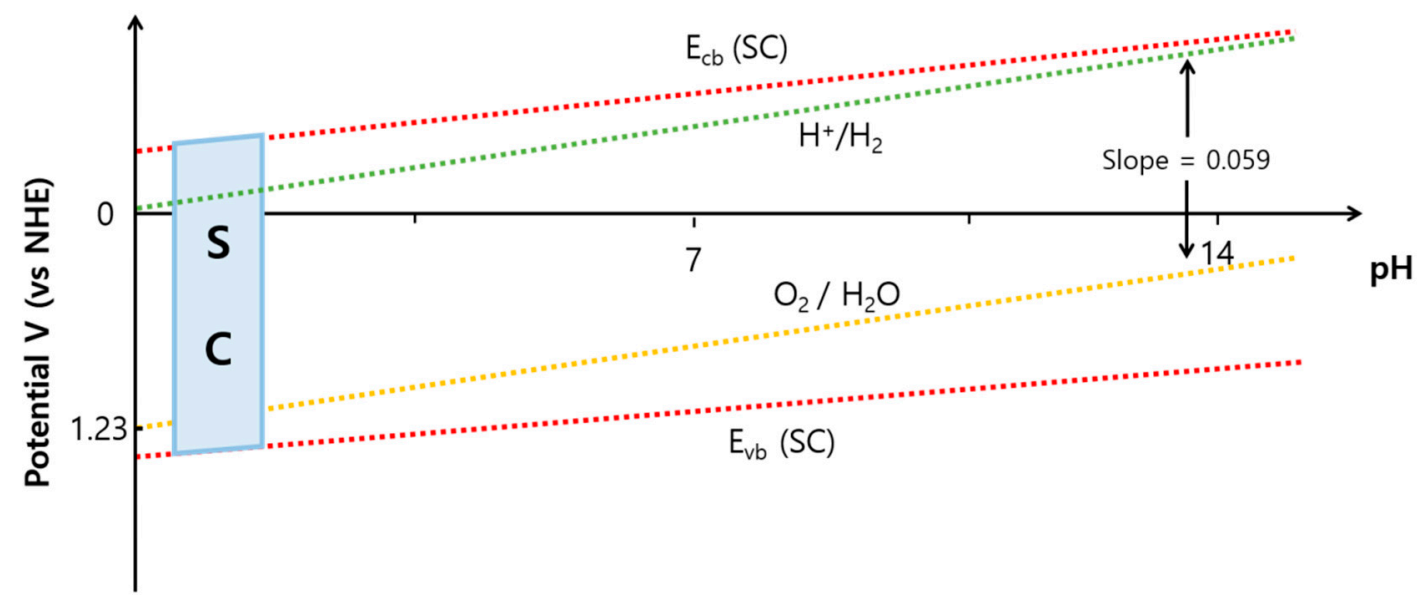

Figure 2. $\mathrm{pH}$ dependence of the band edge positions in an aqueous electrolyte solution. $\mathrm{H}^{+} / \mathrm{H}_{2}$ and $\mathrm{O}_{2} / \mathrm{H}_{2} \mathrm{O}$ potentials follow the Nernstian relation, which has a variation of $0.059 \mathrm{~V} / \mathrm{pH}$ at $25{ }^{\circ} \mathrm{C}$ at $1 \mathrm{~atm}$. Conversely, the slope of the semiconductor band edge position (red dotted line) according to $\mathrm{pH}$ could be different from that of water (green and yellow dotted line). 


\subsection{Properties of Si Photoelectrodes}

Figure 3a illustrates the process of the water redox mechanism of a single $n$-type Si photoelectrode under illumination. Under the dark condition, a dynamic equilibrium is established as the majority carrier transfers from $\mathrm{Si}$ to the electrolyte, changing the electron energy states, and the Fermi level is adjusted, which induces band bending (built-in potential, $\Phi_{b i}$ ) with an energy barrier height $\left(\Phi_{B}\right)$. The potential drop occurs mostly within the semiconductor surface (depletion region), while only a minor portion of the drop appears within the electrolyte, i.e., a voltage drop across the Helmholtz layer. The electrolyte's redox couple energy with respect to the vacuum level is not accurately known but the theoretical and experimental values vary between 4.30 and $4.85 \mathrm{eV}$ [26]. Usually, $4.5 \mathrm{eV}$ is taken.

(a)

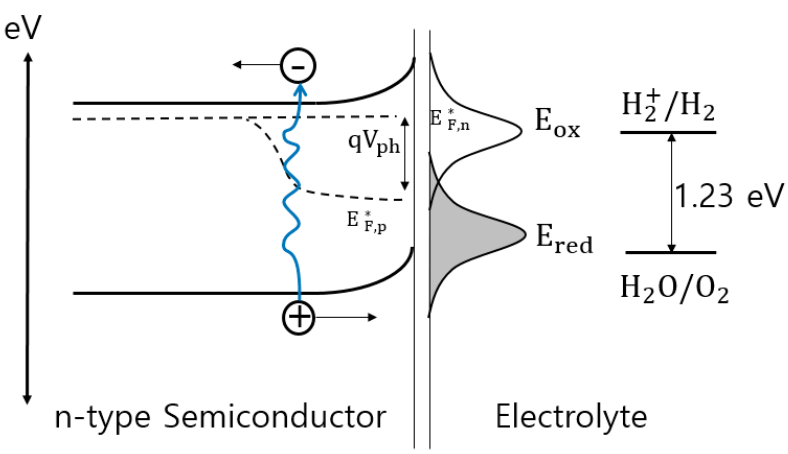

(b)

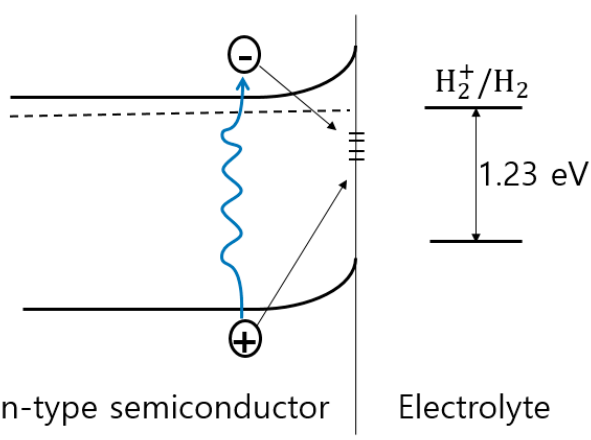

Figure 3. (a) A semiconductor photoanode/electrolyte junction under illumination showing the mechanism of photoelectrochemical (PEC) performance. $E_{\mathrm{F}, \mathrm{P}}{ }^{*}$ and $E_{\mathrm{F}, \mathrm{n}}{ }^{*}$ denote the quasi-Fermi level of Si for the hole and electron under illumination; $E_{\mathrm{Ox}}$ and $E_{\mathrm{red}}$ indicate the energy levels of a redox couple in the electrolyte. (b) Surface recombination of the electron-hole pair induced by the surface states of the semiconductor (i.e., Femi level pinning).

Under light illumination, when energy is larger than the band gap of the semiconductor $(1.12 \mathrm{eV}$ for $\mathrm{Si}$ ), it is absorbed through the semiconductor, electron-hole pairs are generated, which is referred to as minority carrier injection. The minority carriers generated within the depletion region are forced by the inherent potential within the depletion region of Si and are swept away either toward the bulk or electrolyte, respectively. The electron-hole pairs generated within the quasi-neutral region (holes in $n$-type and electrons in $p$-type) diffuse toward the depletion region to be swept by the voltage drop. The driving potential of the depletion region is called a photopotential (i.e., photovoltage, $V_{\mathrm{ph}}$ ) and is induced by the shift of the Fermi-level within the depletion region, which is called the quasi-Fermi level (black dashed line in Figure 3a). The $V_{\mathrm{ph}}$ was demanded to be the band gap of the semiconductor itself, which is $(1 / q) E_{\mathrm{g}}$, where $E_{\mathrm{g}}$ denotes the band gap of a semiconductor and $\mathrm{q}$ is an electronic charge. However, as shown in Figure 3a, the amount of $V_{\mathrm{ph}}$ is smaller than the band gap, which is due to the recombination process. The maximum photovoltage limit $\left(V_{\mathrm{m}}\right)$ of a semiconductor is determined by the intrinsic bulk recombination, which can be expressed as follows [27]:

$$
V_{\mathrm{ph}}=\frac{k T}{q} \ln \left(\frac{J_{\mathrm{ph}} L_{\mathrm{n}} N_{\mathrm{A}}}{q D_{\mathrm{n}} n_{\mathrm{i}}^{2}}\right)=\frac{k T}{q} \ln \frac{J_{\mathrm{ph}}}{J_{\mathrm{sr}}}
$$

where $q$ is the electronic charge $\left(1.6 \times 10^{-19} \mathrm{C}\right), J_{\mathrm{ph}}$ is the photocurrent density, $L_{\mathrm{n}}$ is the minority carrier (here, it is an electron) diffusion length, $N_{\mathrm{A}}$ is the acceptor concentration, $D_{\mathrm{n}}$ is a diffusion coefficient, $n_{\mathrm{i}}$ is the intrinsic carrier concentration, $J_{\mathrm{sr}}$ is the bulk recombination current density. In the case of silicon, the maximum obtainable $V_{\mathrm{ph}}$ is calculated to be $0.48 \sim 0.50 \mathrm{~V}$. However, much less than the maximum $V_{\mathrm{ph}}$ of $\mathrm{Si}$ is easily observed with significant variations of more than $0.30 \mathrm{~V}$, experimentally. This is due to the surfaces states on which the surface recombination takes place [28]. The states presented on the surface pin the Fermi level at the electrode/electrolyte in a dark equilibrium, which is called the Fermi-level pinning (FLP) effect, due to which the band bending is fixed such that no 
additional potential increase occurs under the external electrical field. As a consequence, the energy barrier formed at the electrode/electrolyte interface is lower than the theoretical maximum value $\left(V_{\mathrm{m}}\right)$, hindering efficient PEC operation (Figure 3b). Surface modification by using a catalyst to resolve this issue is thus crucial to enhance the overall cell performance. The role of the catalyst in terms of how it alters the energetics and kinetics of the cell are explained in the next section.

\subsection{Co-Catalyst on $\mathrm{Si}$}

The key motivation of employing a photocatalyst or co-catalyst to $\mathrm{Si}$ is to lower the activation energies for surface electrochemical reactions. Figure $4 \mathrm{c}$ illustrates the thermodynamics of the WS reaction, $2 \mathrm{H}_{2} \mathrm{O} \rightarrow 2 \mathrm{H}_{2}+\mathrm{H}_{2}$. It can be seen that the energy of $\Delta G_{\mathrm{O}}=237 \mathrm{kJmol}^{-1}$ is required to complete the reaction. However, additional activation energy $\left(E_{\mathrm{a}}\right)$ is needed to complete the uphill reaction. By applying the catalyst, the $E_{\mathrm{a}}$ barrier can be lowered (red line) with hinder a number of reaction. Pt has been known for low activation energies in hydrogen evolution reactions and has also proven to be the most efficient photocatalyst when integrated with semiconducting light absorbers [29]. The surface states prevailing on the semiconductor slow down the photogenerated charge transfer reaction, preventing electrons from being efficiently consumed [30]. When a catalyst is applied to the semiconductor (Figure 4a), the surface states remaining on the semiconductor are filled, suppressing the surface recombination, increasing both $V_{\mathrm{ph}}$ and $J_{\mathrm{ph}}$.

(a)

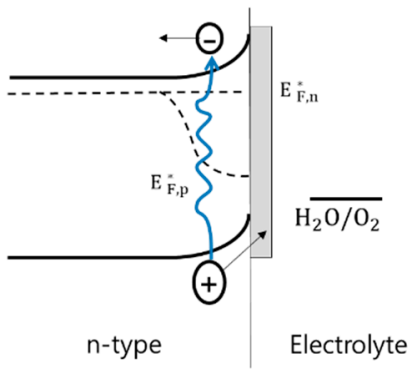

(b)

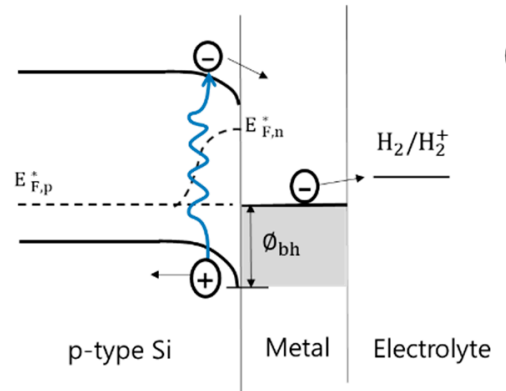

(c)

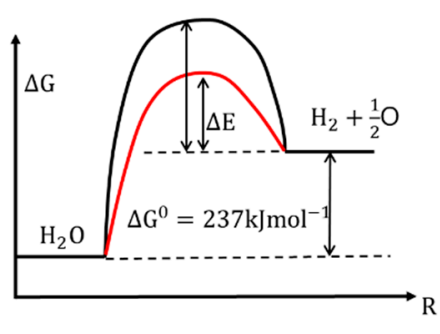

Figure 4. Energy diagram showing the roles of catalysts on Si in PEC performance. (a) Surface passivation of the semiconductor to reduce surface recombination. (b) Metal-semiconductor (MS) junction to enhance the electric field within the depletion region. $\Phi_{\mathrm{ph}}$ denotes the barrier height of Schottky junction. (c) Energy diagram for photocatalytic water splitting. $\Delta G_{0}$ denotes the energy required for the uphill reaction.

In terms of recombination, moreover, the deposited catalyst layer can suppress the minority carrier tunneling through the triangular potential barrier in the semiconductor depletion region. Under the light, the quantitative understanding of the semiconductor/electrolyte junction is critical. For a quantitative understanding, Reichman et al. studied the effect of the surface charge density on the band bending in a semiconductor/electrolyte system, in 1980 [31], and Thorne et al. employed the equation to describe the charge transfer across the electrode/electrolyte interface [5] as follows:

$$
\frac{n_{\mathrm{s}}}{n_{0}}=\exp \left(\frac{q \Phi_{\mathrm{b}}}{k T}\right)=\exp \left[\frac{-q\left(V_{\mathrm{app}}+V_{\mathrm{ph}}-V_{\mathrm{CB}}\right)}{k T}\right]
$$

where $n_{\mathrm{S}}$ and $n_{0}$ are the electron densities under illumination and dark, respectively, $q$ is the electronic charge $\left(1.6 \times 10^{-19} \mathrm{C}\right), k$ is the Boltzmann constant, $T$ is the temperature in $\mathrm{K}, \Phi_{b}$ is the band bending, $V_{\text {app }}$ is the applied potential, $V_{\mathrm{ph}}$ is the photovoltage and $V_{\mathrm{CB}}$ is the conduction band edge. Equation (2) shows that the surface energy induces variation in the Fermi level position of the semiconductor, which largely pertains to the PEC performance, and mainly affects the amount of the onset voltage shift. Such surface band bending is also correlated with the charge transport from the bulk to the 
electrolyte in a complicated fashion [5]. Photo-generated charge kinetics that towards the electrolyte can be explained by the Butler-Volmer equation, as follows:

$$
J_{\mathrm{n}}=J_{\mathrm{n}}^{0}\left\{\frac{n_{\mathrm{s}}}{n_{\mathrm{s}}^{0}} \exp \left(\frac{q \alpha_{\mathrm{p}}}{k T}\right)-\exp \left[\frac{-q\left(1-\alpha_{\mathrm{p}}\right) \eta}{k T}\right]\right\}
$$

where $J_{\mathrm{n}}$ is the electron current density, $J_{\mathrm{n}}^{0}$ is the dark equilibrium current density, $\alpha_{\mathrm{n}}$ is the charge transfer coefficient and $\eta$ is the overpotential. According to Equation (3), both the surface band bending and the kinetic factors affect $J_{\mathrm{ph}}$. The $J_{\mathrm{ph}}$ can also be expressed by using Garner's relation [32], which expresses the current density generated inside the depletion layer and in the adjacent bulk quasi-neutral region.

$$
J_{\mathrm{ph}}=q J_{0}\left[\frac{1-e^{-\alpha W}}{1+\alpha L}\right]-q n_{0} \frac{D_{\mathrm{n}}}{L_{\mathrm{n}}}
$$

Here, $J_{\mathrm{ph}}$ is a photocurrent, $J_{0}$ is a monochromatic photon flux incident on a semiconductor, $\alpha$ is the light absorption coefficient of silicon, $\mathrm{W}$ is the depletion region and $L$ is the bulk diffusion length. To sum, one can conclude that the change in the surface charge density of the semiconductor by catalysts increases the band banding of the surface as well as the kinetics. The physical role of the catalyst is that it serves as a passivation layer from the solution environment of the semiconductor.

As for the metallic catalysts, they form the metal-semiconductor (MS) Schottky junction, whether nanoscale or microscale interfaces are created. If enough light penetration through the semiconductor is secured, this can increase the band bending in the bulk of the Si surface, which facilitates the electron-hole separation. As mentioned above, noble metals, such as $\mathrm{Pt}$, have been considered to be the best candidates due to the lowest activation energy for $\mathrm{H}_{2}$ evolution. In other words, they possess high work function properties, with a greater ability to trap electrons compared to Si. Pt nanoparticles on Si NWs yield energy conversion efficiencies up to $8.14 \%$ [33]. A photoelectrode with Pt on semiconductors, such as a combination with CdS, and Si showed a quantum yield of approximately $60.34 \%$ measured at $420 \mathrm{~nm}$ [34]. In Figure $4 \mathrm{~b}$, the induced barrier height $\left(\Phi_{B}\right)$ due to the metal-semiconductor (MS) Schottky junction formed and this built-in electric field enhances $V_{\mathrm{ph}}$, helping the generated electron to be efficiently transferred to the electrolyte. Despite a number of studies on MS-based WS, the detailed explanations of how photocatalysts affect the PEC performance in terms of $J_{\mathrm{ph}}$ onset potential are still not clear [35]. However, according to recent reports, it is evident that photocatalysts affect the surface energetics and kinetics of the semiconductor, thus enhancing both $V_{\mathrm{ph}}$ the $J_{\mathrm{ph}}[36,37]$. In addition to the solid-state effect of the catalyst explained so far, the properties of the catalyst film itself obtained in the dark condition under HER or OER operation is also important, since a large portion of the kinetic effect stems from the electric and structural properties of the catalyst. In this context, unveiling both solid-state physics and electrochemistry in the co-catalytic systems is essential for the profound understanding of the desired PEC WS.

\subsection{Photoelectrode Half-Cell Configurations}

The energy band diagrams of different types of Si-based photoelectrodes and the operation under illumination are shown in Figure 5. The simplest configurations, which are solely semiconductors, are shown in Figure 5a,b for the photoanode and photocathode, respectively. The driving force of the generated electron-hole pair separation comes from the electric field at the junction formed at the electrode/electrolyte interface. In the photocathode, the generated electrons transport toward the electrolyte for the water reduction, while the generated holes are for the water oxidation in the photoanode. As a solution to overcome the low $V_{\mathrm{ph}}$ induced from the semiconductor surface states, metal layers or islands are commonly deposited on the surface of the semiconductors, which forms Schottky contacts in the micrometer to nanometer scale domain (Figure $5 c$,d), which has been studied as an effective photoelectrode configuration for decades [38]. The deposited metal layer partially or fully protects the semiconductor surface in the physical dimension from the solution 
environment, providing enhanced $V_{\mathrm{ph}}$, which are independent of the redox potential of the ions in the solution [39]. However, for stable and longer time operations, the importance of the stable interface between the semiconductor and the catalyst layer interface has been gradually increased. Researchers started to apply a buried n- $p$ junction with a catalyst deposited (Figure $5 \mathrm{e}, \mathrm{f}$ ), which provides the clean junction interfaces so that the facile electron-hole pair separation can occur. For this reason, multi-junction (both homo and hetero junction) thin film solar cell structures have been studied for over 20 years and have become mainstream in the field [40]. The buried junction configurations show the enhanced performances as photoelectrodes in the field of PEC that has occurred over decades. Further, improvements employing the multi-junction (both homo and heterojunction) thin-film solar cell structures have been studied for twenty years and have become a large research stream in the field. Electron-hole pairs are generated both near the surface and within the junction are depicted in Figure 5e,f. Note that since there is more than one junction presenting depletion layers, there exists a dominating one that determines the photovoltage of the cell [8,41,42]. Other types of cells, such as the PEC cell using organic (organic-inorganic hybrid) absorber [43], and tandem structure cells [44] are not included here.

(a)

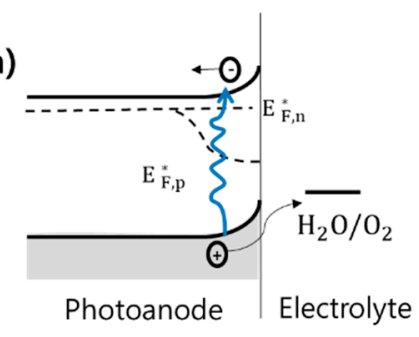

(c)

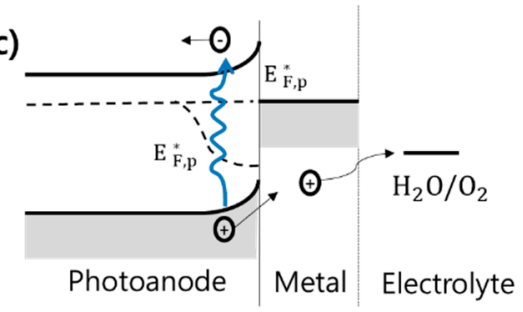

(e)

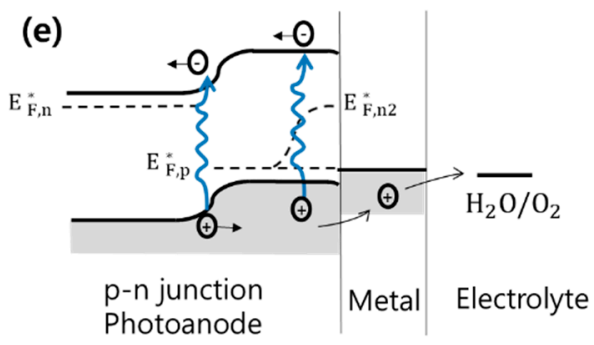

(b)

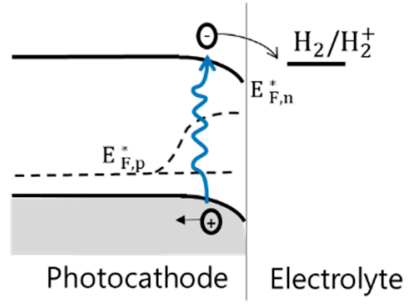

(d)

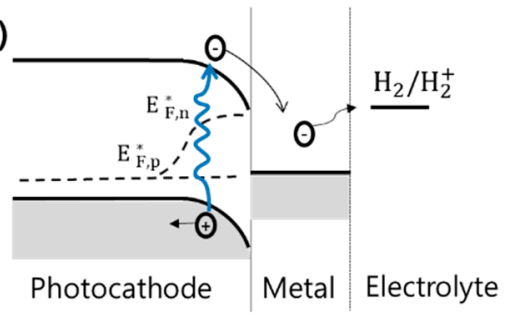

(f)

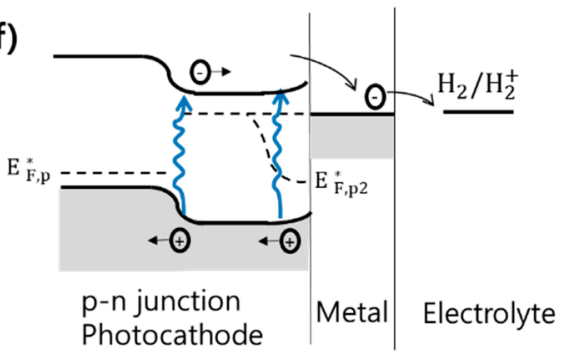

Figure 5. Examples of silicon-based PEC half-cell configurations under illumination. (a) $n$-type $\mathrm{Si}$ photoanode, (b) $p$-type Si photocathode. (c) Photoanode with a catalyst layer on the surface, metal/n-Si (metal-semiconductor, MS) junction. (d) Photocathode with a catalyst layer on the surface, metal $/ p-\mathrm{Si}$ (MS) junction. (e) $p$-n junction photoanode combined with a catalyst layer. (f) $p$-n junction photocathode combined with a catalyst layer. Two depletion layers exist in a sample at the junctions.

\section{Flat-Band Potential Measurement}

\subsection{Concepts of Flat-Band Potential}

Flat-band potential $\left(V_{\mathrm{fb}}\right)$ is an important and direct measure in the understanding of PEC experiments by clarifying the band structure of a semiconductor. The $V_{\mathrm{fb}}$ can be measured if an incident light illumination ( $h v \geq E_{\mathrm{g}}$ ) is sufficiently intense to remove the band bending [45]. Figure 6 
depicts the band banding change with a gradual increase of the induced $V_{\mathrm{ph}}$, where $E_{\mathrm{ox}}$ and $E_{\mathrm{red}}$ are the electrolyte redox potentials and $E_{\mathrm{c}}$ is the conduction band, $E_{\mathrm{v}}$ denotes the balance band and $E_{\mathrm{F}}$ is the Fermi level. Under the dark equilibrium condition, the Fermi level of the electrode is aligned with that of the electrolyte, which induces the band bending of the bulk semiconductors (Figure 6a). In Figure $6 \mathrm{~b}$, when the light is absorbed, the Fermi level splits into the quasi-Fermi level, where the difference is the $V_{\mathrm{ph}}$, and the band bending decreases due to the enhanced energy density states. As the light intensity increases, the band flattens at $V_{\mathrm{ph}}$, which is referred to as the flat-band voltage (Figure 6c). The flat-band potential gives information about the band bending at the dark equilibrium or built-in potential, in the case of a $p$-n junction. There are several methods to measure the flat band potential, some of which will be introduced below.
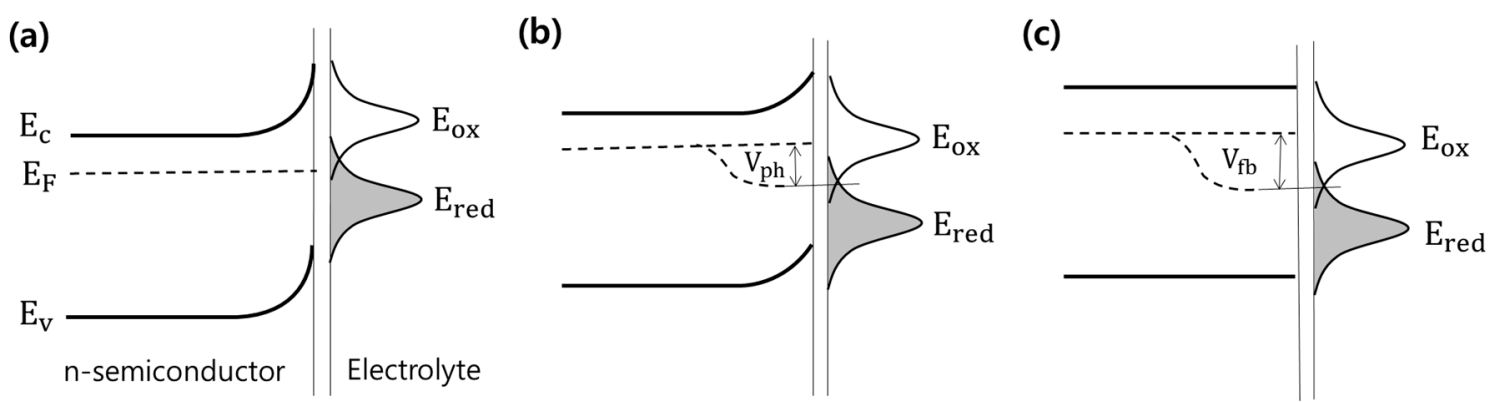

Figure 6. (a) Dark equilibrium condition of the $n$-type Si photoanode immersed in an electrolyte. The Fermi level is aligned with the redox potential of the electrolyte. (b) Photovoltage induced under illumination by creating quasi-Fermi level. (c) Flat-band potential $\left(V_{\mathrm{fb}}\right)$ is the potential at which the band bending flattens under sufficiently intense illumination.

\subsection{Illuminated Open-Circuit Potential (OCP)}

The illuminated open-circuit potential (OCP) is a feasible way for determining $V_{\mathrm{fb}}$ when sufficient light is illuminated to remove band bending. This technique is an effective and convenient way to obtain the $V_{\mathrm{ph}}$ of the electrode and gives useful information about the band bending and is commonly measured by increasing the light intensity until the $J_{\mathrm{ph}}$ saturates [46].

Figure 7 depicts the OCP versus the illumination intensity to the samples of $p$-GaAsPN cell, MDMP-PPV:PCMB (bulk heterojunctions consisting of polyf2-methoxy-5-s38,78-dimethyloctyloxyd-pphenylenevinylene (MDMO-PPV) and 6,6-phenyl C61-butyric acid methyl ester PCBM), dye-sensitized solar cell (DSSC) (ITO/CuPc/ $\left.\mathrm{C}_{60} / \mathrm{BPen} / \mathrm{Al}\right)$ and polycrystalline $\mathrm{Si}$. As the light intensity increases, the OCP value saturates, which means the bands became flatten. Note that the $E_{\mathrm{fb}}$ of many semiconductors follows a Nernstian relationship as a function of $\mathrm{pH}$.

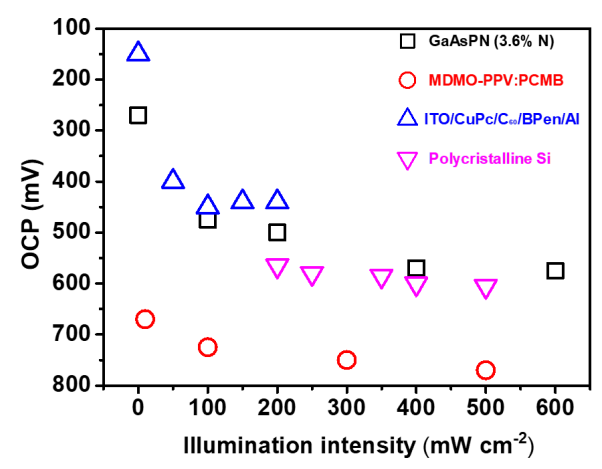

Figure 7. Open-circuit potential (OCP) of different type of solar cells vs illumination intensity: photoelectrode of GaAsPN $(3.6 \% \mathrm{~N}) 3 \mathrm{M} \mathrm{H}_{2} \mathrm{SO}_{4}$ (V vs. Ag/AgCl) [47], MDMO-PPV: PCMB solar cell device [48], DSSC solar cell (ITO/CuPc/ $\mathrm{C}_{60} / \mathrm{BPen} / \mathrm{Al}$ ) [49], polycrystalline Si [50]. 
The photovoltage can be obtained from $V_{\mathrm{ph}}=V_{\text {ocph }}-V_{\text {ocdark }}$. Figure 8 illustrates the flat band potential measurement using the open-circuit potential difference of photoelectrodes in the electrolyte in the literature. The papers containing the measurements of the flat band potential were sorted and the values were grouped into photocathode (top) and photoanode (bottom). Note that the references include other catalytic materials besides transition metal (di)chalcogenide (TMD) materials. The positive shift in OCP upon illumination indicates that the semiconductor is $p$-type, whilst the negative shift in OCP indicates the $n$-type semiconductor. $\mathrm{Yu}, \mathrm{X}$, and Sivula, $\mathrm{K}$ presented a solution-processed multiflake WSe $\mathrm{W}_{2}$ photocathodes coated with $\mathrm{Al}_{2} \mathrm{O}_{3}$ layer showing $\sim 0.3 \mathrm{~V}$ of $V_{\mathrm{ph}}$ [51], which was drawn in the black line indicated with (a). The yellow line marked with (b) shows the $V_{\text {ph }}$ measurement of the CdSe quantum dots with nickel oxide $(\mathrm{NiO})$ engineered by a molecular liner, mercaptoacetic acid (MAA) [52], which is below $0.4 \mathrm{~V}$. For the red line (c), the photoelectrode of $\mathrm{p}-\mathrm{Si} / \mathrm{SiO}_{\mathrm{x}} / \mathrm{MoS}_{2}$ photoelectrode in a $\mathrm{pH}=0.3 \mathrm{H}_{2} \mathrm{SO}_{4}$ also showed significantly high photovoltage of $0.8 \mathrm{~V}$ [53]. The sharp decrease of the photovoltage upon illumination is attributed to bulk recombination within the electrode. The photovoltage is directly correlated with the onset voltage of the J (photocurrent density) - V (voltage) characteristic of the PEC performance). Kornienko et al. developed the growth of InP NWs and demonstrated the integration on Si substrates. With Zn doping, the NWs exhibited $4.0 \%$ of light to hydrogen efficiency in a half-cell configuration, showing $\sim 0.7 \mathrm{~V}$ vs RHE of flat band potential [54]. The high photovoltage of $0.8 \mathrm{~V}$ was obtained by using $p$-type/intrinsic hydrogenated amorphous silicon carbide (a-SiC) photocathode combined with $\mathrm{TiO}_{2}$ (Figure 8e) [55]. The high $V_{\mathrm{ph}}$ was explained by the p-i-n heterojunction structure produces the internal electric field that enhances the photovoltage. As for photoanodes, a well-ordered $\mathrm{TiO}_{2}$ nanotube arrays (TNAs) decorated with graphitic carbon nitride $\left(\mathrm{g}-\mathrm{C}_{3} \mathrm{~N}_{4}\right)$ were fabricated by Liu et al. and the photovoltage was measured to be $0.26 \mathrm{~V}$ under light irradiation [56]. The highest photovoltage was obtained by dos Santos, W.S. et al., who introduced an efficient approach which is coupling ferroelectric materials with semiconductors to boost the photovoltage higher than that obtainable from a conventional p-n heterojunction. The ferroelectric $\mathrm{Bi}_{4} \mathrm{~V}_{2} \mathrm{O}_{11}$ perovskite and $n$-type $\mathrm{BiVO}_{4}$ creates a virtual p-n junction that produces high photovoltage of $1.39 \mathrm{~V}$ (Figure 8j) [46]. The metal-insulator-semiconductor (MIS) photoanode using silicon was fabricated by Digdaya et al. [57]. The n-Si $/ \mathrm{SiO}_{\mathrm{x}} / \mathrm{Al}_{2} \mathrm{O}_{3} / \mathrm{Pt} / \mathrm{Ni}$ photoanode with $0.49 \mathrm{~V}$ of photovoltage was obtained after $18 \mathrm{~h}$ aging, which is indicated in brown color marked (g). The $\mathrm{MoS}_{2} / \mathrm{S}$-doped $\mathrm{g}-\mathrm{C}_{3} \mathrm{~N}_{4}$ heterojunction film for a photoanode was introduced by Ye et al., showing $\sim 0.2 \mathrm{~V}$ of photovoltage [58]. The high photovoltage value of Figure $8 \mathrm{~h}$ demonstrates that hematite photoanode exhibits good PEC performance. Furthermore, the measurement of the OCP decay after the removal of the light source can provide information about the excess carrier lifetime in $p$-n diodes or solar cells $[59,60]$. Using the short-term high frequency measurement and the OCP decay method in a long-term time-scale observation, the OCP decay measurement provides information related to the electrode/surface recombination mechanism along with the minority carrier lifetime in Equation (5) below [61].

$$
\tau_{\mathrm{h}}=-\frac{k T}{q}\left(\frac{d V_{\mathrm{oc}}}{d t}\right)^{-1}
$$

Equation (5) can be applied under the condition of a low-injection level so that the relationship between the Fermi level variations with time and the minority carrier concentrations expand in the first-order linear differential equation [62]. Studies using this technique can be found in other applications in dye-sensitized and perovskite solar cells. 


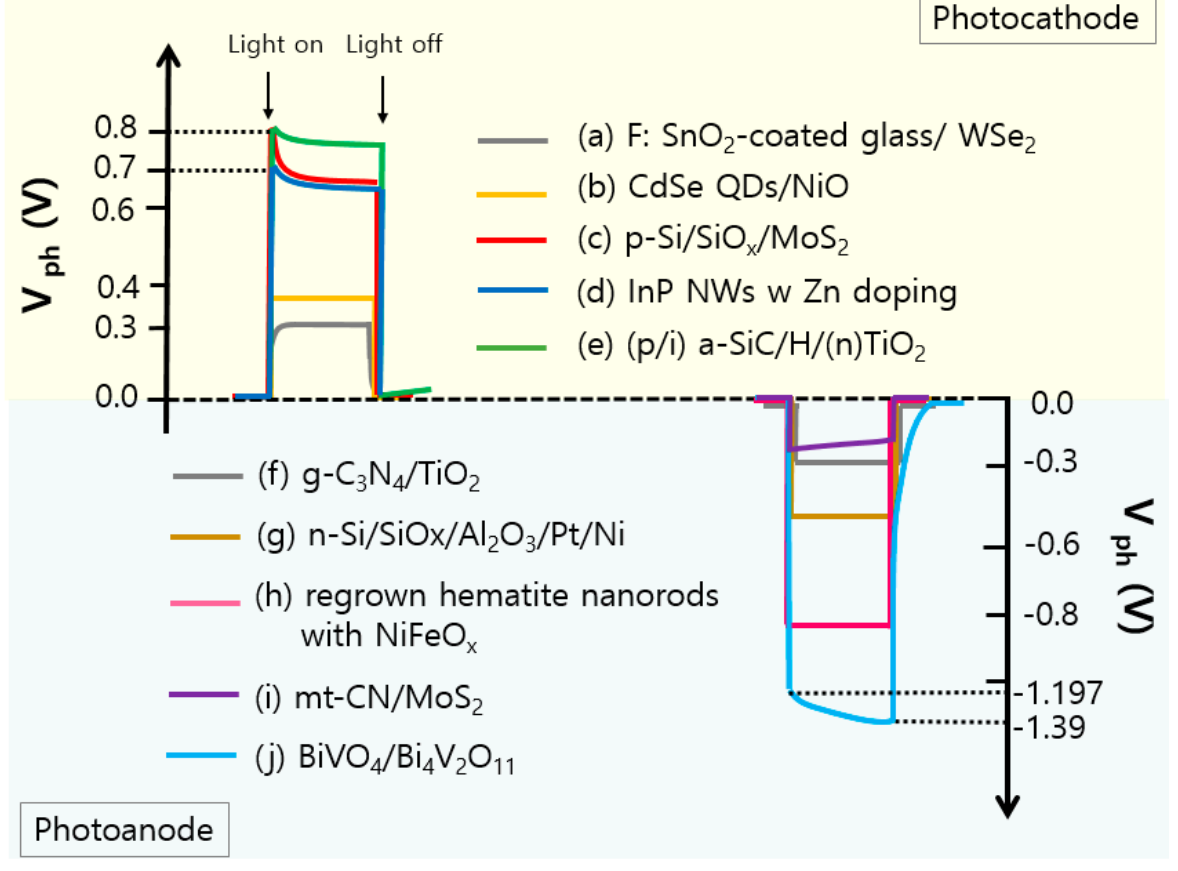

Figure 8. The comparison graphs of open-circuit potential (OCP) difference measurements redrawn based on the $V_{\mathrm{ph}}$ value from the references [5,51-58]. Different type of photocathodes (positive transition) and photoanodes (negative transition) under dark equilibrium and under illumination are shown.

\subsection{Mott-Schottky Analysis}

Another powerful method is a Mott-Schottky (M-S) plot, by which the $V_{\mathrm{fb}}$ or built-in potential for $p$-n or Schottky junction interfaces can be determined. In semiconductor electrochemistry, the M-S plot describes the capacitance value versus the potential difference between bulk semiconductor and the electrolyte. Therefore, from the M-S plot, the qualitative analysis of the conductivity types and the carrier concentration of semiconductors can be obtained [63]. The positive slope in the linear region indicates the $n$-type nature, while the negative slope indicates the $p$-type nature. In accordance with Equation (6), the carrier concentration is derived from the reciprocal of the slope in the plot and the $\mathrm{x}$-intercepts from the linear portion fitted (over $200 \mathrm{mV}$ range minimum) is the flat-band potential induced from the bulk interface between the electrode and electrolyte or bulk built-in potential. $\varepsilon_{r}$ is the relative permittivity of the semiconductor ( $11.7 \mathrm{for} \mathrm{Si}), \varepsilon_{0}$ is the permittivity in vacuum, $A$ is the surface area, e is the electron charge, $N_{\text {dopant }}$ is the carrier density, $k$ is the Boltzmann constant, $T$ is the temperature, and $V$ is the applied voltage. From the slope, the conductivity type, the $N_{\text {dopant }}$ as well as the depletion layer width, which are the surface properties of the semiconductor, can be calculated.

$$
\frac{1}{C_{\mathrm{sc}}^{2}}=\frac{2}{\varepsilon_{\mathrm{r}} \varepsilon_{0} A^{2} e N_{\text {Dopant }}}\left(V-V_{\mathrm{fb}}-\frac{k T}{e}\right)
$$

Figure 9 shows the Mott-Schottky measurement of various types of photoelectrodes to obtain the flab-band potential. Ye et al. reported a $\mathrm{MoS}_{2} / \mathrm{S}$-doped $\mathrm{g}-\mathrm{C}_{3} \mathrm{~N}$ heterojunction film for high visible-light photoelectrochemical (PEC) cell (Figure 9a) [58]. The Mott-Schottky curve was obtained at a frequency of $10 \mathrm{kHz}$, showing the positive slope, an indication of the $n$-type characteristics with the flat-band potential of 1.197 V. A Mott-Schottky plot of the MIS devised with $\mathrm{Pt} / \mathrm{Ni}$ catalyst in $\mathrm{KOH}$ solution is shown in Figure 9e. The flat-band potential of $-0.73 \mathrm{~V}$ was determined [57]. Yua et al. carried out Mott-Schottky measurement in a solution containing $0.5 \mathrm{M} \mathrm{Na}_{2} \mathrm{SO}_{4}$ to determine both flat band potential and donor density at semiconductor/liquid interface. The $n$-type semiconductor properties of CdS/ $\mathrm{MoS}_{2}$ /graphene hollow spheres were confirmed [64]. Photocathode using Zn-doped Indium 
phosphide nanowire arrays showed a flat band potential of $\sim 0.7 \mathrm{~V}$ vs reversible hydrogen electrode (RHE), which was consistent with their OCP measurement [54]. In Figure 9b, $\mathrm{Cu}_{2} \mathrm{O} / \mathrm{CuO}$ bilayer composites were prepared and tested as an efficient photocathode and the M-S plot confirmed $\sim 1 \mathrm{~V}$ of flat band potential, implying a high degree of band bending and a large depletion layer (i.e., SCR) [65]. $p$-type $\mathrm{Si} / \mathrm{SiO}_{\mathrm{x}} / \mathrm{MoS}_{2}$ layer photocathode also revealed significantly high flat band potential of $0.8 \mathrm{~V}$ as shown in the Figure 9c. Considering that the catalyst or co-catalyst modify the surface energetics, the Mott-Schottky technique provides information on the surface energetics of the semiconductor, the effect of the catalyst has been exploited by researchers [66,67], and the Si photoelectrodes decorated with $\mathrm{TM}(\mathrm{D}) \mathrm{C}$ materials to determine the $V_{\mathrm{fb}}$ have also been analyzed and were proven to be informative in understanding the change in surface properties of Si [68-70]. In Figure 9, the change of the surface doping density and the depletion width of the $p$-Si with the $\mathrm{MoS}_{2}$ catalyst layer thickness was observed, which induces the different $V_{\mathrm{fb}}$ potential.

\section{Photocathode}

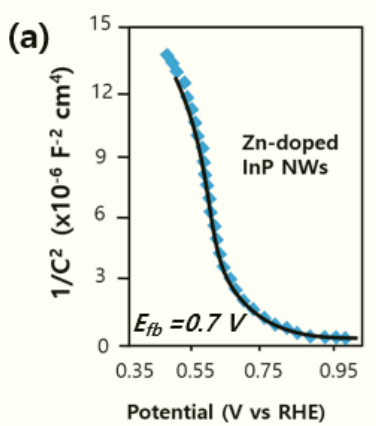

\section{Photocanode}

(d)

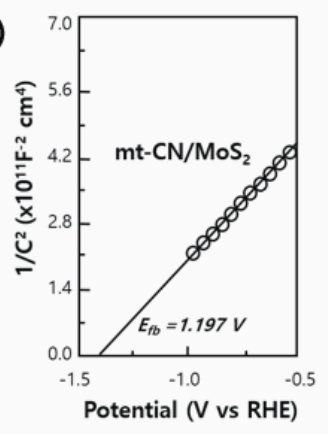

(b)

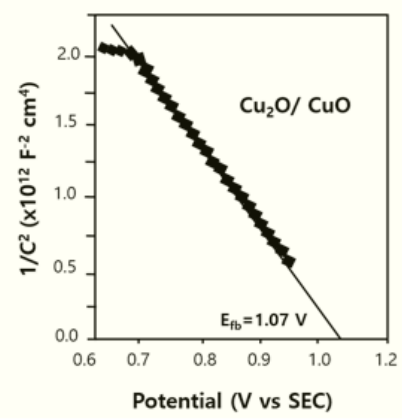

(e)

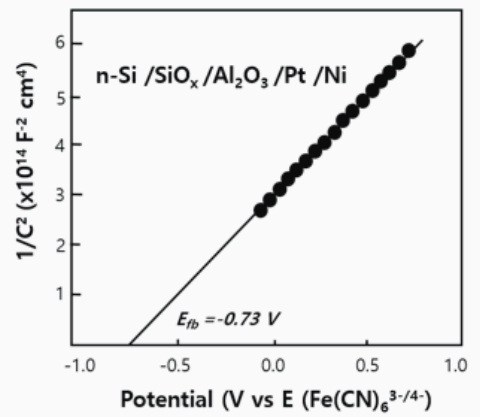

(c)

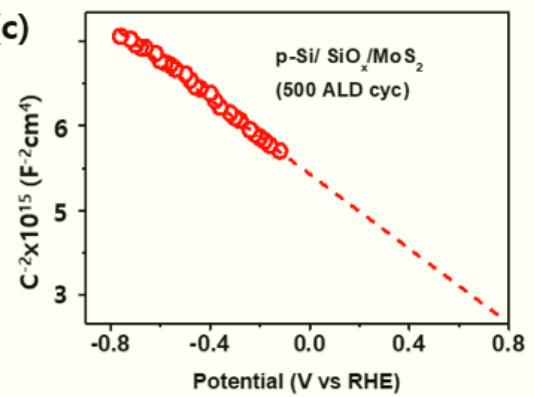

(f)

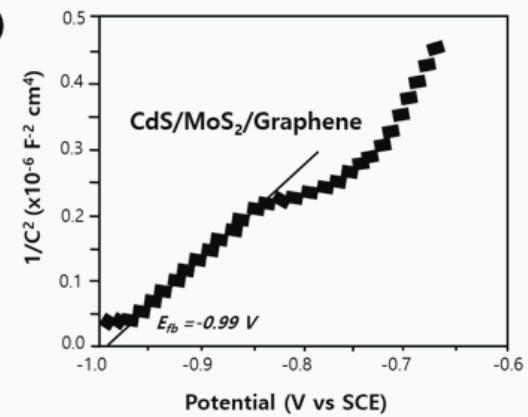

Figure 9. Mott-Schottky plots from various photoelectrodes: (a-c) photocathodes, and (d-f) photo anodes. (a) is adapted from reference [54]. Copyright (2016) American Chemical Society. (b) is adapted from reference [55] with permission from The Royal Society of Chemistry. (c) is adapted from reference [53]. (d) is adapted from reference [58]. Copyright (2016) American Chemical Society. (e) is adapted from reference [57]. (f) is adapted from reference [64] Republished with permission of Elsevier, from Biomolecule-assisted self-assembly of $\mathrm{CdS} / \mathrm{MoS}_{2}$ /graphene hollow spheres as high-efficiency photocatalysts for hydrogen evolution without noble metals, Yu et al., 182, 2016; permission conveyed through Copyright Clearance Center, Inc.

In PEC WS, flat-band potential which can directly identify the band structure of the semiconductor in a junction with the electrolyte can be measured with two powerful methods, OCP and M-S plot. The photovoltage is important because it is directly correlated with the onset voltage of PEC performance characteristic. In the next section, the other important properties including charge transfer dynamics will be discussed with electrochemical impedance spectroscopy as a measurement tool. 


\section{Electrochemical Impedance Spectroscopy (EIS) for Photoelectrochemical (PEC) Cells}

Electrochemical impedance spectroscopy (EIS) is a powerful technique to feature electrochemical behaviors through the whole electrochemical cell including the electrode/electrolyte interface. We could extract meaningful quantitative and qualitative information in terms of impedance sources within the cells such as solution resistance, charge transfer resistance, and mass transfer. There are two main analyses in EIS, i.e., the Bode and the Nyquist plots. The Bode plot shows the response to the frequency in a system, so the magnitude and phase plots can be obtained at the same time. The Nyquist plot, on the other hand, shows gain and frequency at the same time on the graph, explaining gain for all frequencies. Therefore, the information of bulk charge electrochemical reaction at high frequency and interface charge transfer dynamic at low frequency can be obtained through a Nyquist plot. In this section, we explain how to obtain useful information from the Nyquist plot in the simple model of the PEC cell.

Through the measurements, the impedance data measured in the electrochemical cell can be expressed and analyzed by the system of resistors and capacitors in an equivalent circuit [71]. An electrochemical cell consists of an electrolyte solution and electrode. The Faradaic impedance $Z_{\mathrm{f}}$ is the resistance and capacitance acting mutually at the electrode surface and can be divided into the charge transfer resistance $\left(R_{\mathrm{ct}}\right)$ which describes the kinetics of the electrochemical reactions at the electrode/electrolyte, the Warburg impedance $(\mathrm{ZW})$ which represents a mass transfer, and the ohmic resistance of the solution, back contacts, etc. If the solution is not electroactive species, the observed impedance is called the non-Faraday impedance.

The surface kinetics of an electrode can be investigated via the frequency spectra of real and imaginary components of the system in the solution. The two-electrode configuration provides the information of the overall charge transfer occurring from the semiconductor to the counter electrode through the electrolyte, while the three-electrode configuration the information of the semiconductor/electrolyte interface and the double layer [72]. The three-electrode configuration gives a more detailed analysis of the electrode/electrolyte interface compared to the two-electrolyte configuration, since the impedance data of both electrodes can be overlapped in the case of the two-electrode configuration. In the PEC system, the EIS measurements are commonly conducted under dark, illumination, and under applied voltage if needed. The measurement is generally recommended to be carried out by scanning the cell from a high frequency $(50 \sim 100 \mathrm{kHz})$ and sweeping to a lower frequency $(10 \mathrm{mHz})$. With the EIS data, one can identify and separate the two different layers, which respond at different frequencies. The high-frequency range provides information of the effect of the bulk matrix to the electrochemical reaction, while the low frequency range provides information of the double layer capacitance [73]. Figure 10a shows the typical Nyquist plot of the working electrode of three-electrode cell. A semicircle at high frequency and the diffusion process at the low frequency edge appear, the mixed control process model known as Randle's circuit (Figure 9b). From the plot, one can obtain the values for resistance as well as the capacitance which are often replaced by constant phase element (CPE). The capacitive impedance is short-circuited when the $\omega \rightarrow \infty$ so only $R_{\Omega}$ remains at the high frequency plot. EIS of photoelectrodes are measured either in or un-bias within the range from $100 \mathrm{kHz}$ to $10 \mathrm{mHz}$ under the illumination or under dark. It is important to choose the correct model because the semiconductor/electrolyte has a complex system such as capacitance of the SCR, surface states, and the Helmholtz layer (as a constant phase element). Figure 9c illustrates an example of the energy diagram of a photocathode/electrolyte interface with the corresponding electrical equivalent circuit, where $C_{\text {bulk }}$ and $R_{\text {bulk }}$ represent the SC layer components and $C_{\text {cat }}$ and $R_{\text {cat }}$ indicate the charge transfer from the catalyst to the electrolyte. For a Si/TMD photoelectrode, Andoshe et al. deduced the charge transfer resistance from $\mathrm{TiO}_{2}$ thin film to electrolyte through a $\mathrm{MoS}_{2}$ catalyst and found that the value is smaller compared to the charge transfer resistance from $\mathrm{TiO}_{2}$ to electrolytes, confirming that the photogenerated carriers from $p$-Si can effectively be transported to the $\mathrm{TiO}_{2}$ and $3 \mathrm{D} \mathrm{MoS}_{2}$ layers [74]. Thorne et al. utilized intensity modulated photocurrent spectroscopy (IMPS) to investigate the origin of the performance enhancement and observed that the deposition of the $\mathrm{NiFeO}_{\mathrm{x}}$ layer 
suppressed the surface recombination, while there was no contribution by fast hole transfer kinetics [35]. Ding et al. demonstrated the enhanced adhesion between the $\mathrm{MoS}_{2}$ catalyst and Si by measuring the charge resistance of the interface through EIS [75]. More efficient charge transfer characteristics of $1 \mathrm{~T} \mathrm{MoS}$ than $2 \mathrm{H} \mathrm{MoS}_{2}$ was also confirmed. For $\mathrm{MoS}_{2}$ photocatalyst, researchers including Ho et al. observed the correlation between HER activity and exposure level of $\mathrm{MoS}_{2}$ edge site, which helped to embody the effect of $\mathrm{MoS}_{2}$ structural characteristics on HER performance [76]. The charge transfer characteristics and the internal resistance of the TM(D)C material combined with Si have been studied by many researchers [77-79] revealing the relationship between the surface modulation and kinetic enhancement. In the case of $\mathrm{Si}$ photoelectrode modified by $\mathrm{MoS}_{2}$, the performance and catalytic properties tend to be affected by its thickness $[79,80]$.

(a)

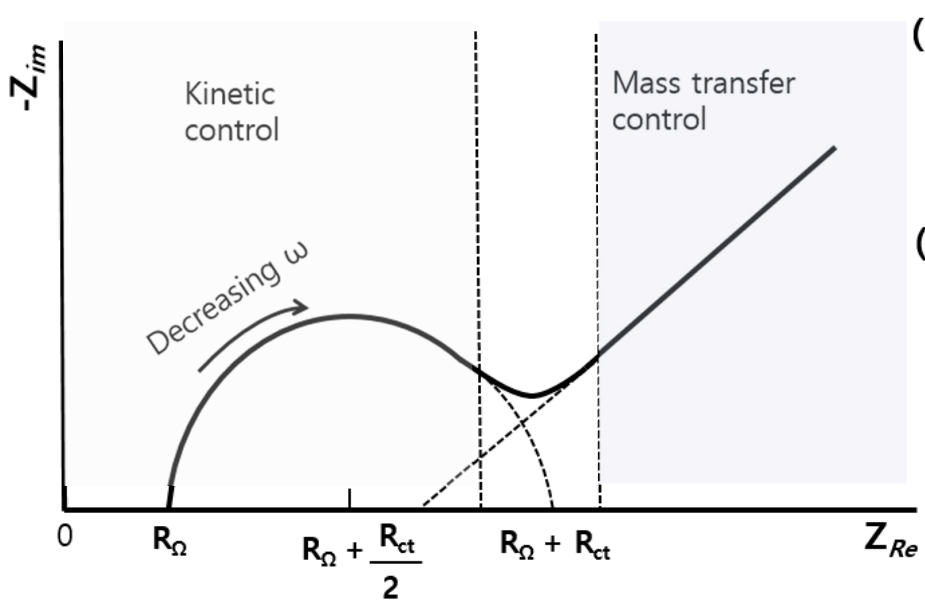

(b)

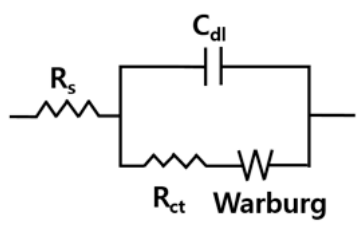

(c)

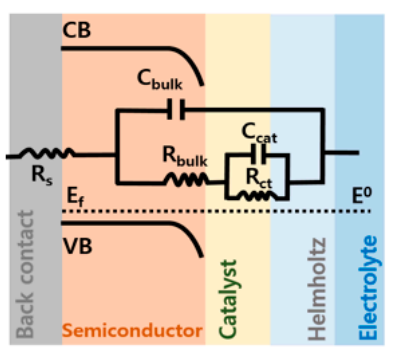

Figure 10. (a) A Nyquist plot for electrochemical cell covering regions of mass-transfer limitations (diffusion, Warburg) and kinetic (from kinetics of the electrochemical reaction, charge-transfer resistance). (b) The corresponding equivalent circuit representing the plot (a). (c) An energy diagram of a semiconductor photocathode/electrolyte interface with the corresponding electrical equivalent circuit.

The EIS analysis also provides relevant information regarding the zone where charge accumulation occurs at the bulk and the electrode/electrolyte interface. Depending on various preparation methods such as annealing and surface treatments, the catalysts may have different or mixed phases. These surface morphology, phase and thickness features of the catalyst can be factors affecting the charge transfer kinetics. The photoelectrode with the thicker layers of TM(D)C materials show higher resistance but can exhibit lower charge transfer resistance values at the electrode/electrolyte interfaces, showing better performances [75,81].

\section{Si/Si/Transition Metal (di)Chalcogenides [TM(D)C] Photocathode}

It is surprising that the number of the studies of PEC WS on the heterostructures of Si/TM(D)C were limited to date although $\mathrm{TM}(\mathrm{D}) \mathrm{C}$ materials and Si photoelectrodes themselves were studied extensively in the literature. The resulting PEC HERs in acidic media show superior performance when compared to those in alkaline media since the kinetics in an alkaline electrolyte is often limited by the sluggish water redox reaction steps [54]. Most Si-based PEC-WS employs overlayers of metals or metal oxides because of the poor stability when operating in aqueous electrolytes. Metal chalcogenides on $\mathrm{Si}$ for PEC-WS has been studied since 2012, when explosive $\mathrm{MoS}_{2}$ research activities as a post-graphene have begun. Narrowing down the scope to $\mathrm{Si}$ as an absorber which is known to be the best and widely used in industry, there was about 10 reports on TMDC on Si, and about 27 papers on Si/TMC until now. Note that only one paper has published for photoanode, and $\mathrm{Si}$ is more suitable for use as a photocathode as in Figure 1a. We categorized all types of the $\mathrm{Si} / \mathrm{TM}(\mathrm{D}) \mathrm{C}$ photoelectrodes published into the following issues: (1) whether they are layered or non-layered; (2) types of $\mathrm{Si}$ such as n, 
$p$-type and $\mathrm{n}^{+} p$ buried junction; (3) employing interlayers between $\mathrm{Si}$ and TM(D)Cs. The results are summarized in Tables 1 and 2.

Tran et al. utilized $\mathrm{MoS}_{2}$ layers on $p$-Si nanowire (NW) arrays where 1-D nanostructures have several advantages for PEC water splitting due to their excellent charge collection efficiency and high surface area [82]. They deposited $\mathrm{MoS}_{2}$ on Si NW by photo-assisted electrodeposition methods. Photoelectrochemical measurement was conducted in $1.0 \mathrm{M} \mathrm{Na}_{2} \mathrm{SO}_{4}$ buffer $(\mathrm{pH}=5.0)$ solutions under 1 sun illumination. It showed $+0.25 \mathrm{~V}$ vs. RHE onset potential which is an anodic shift of $0.55 \mathrm{~V}$ considering bare $p$-Si onset potential ( $-0.3 \mathrm{~V}$ vs. RHE), and photocurrent density was $1 \mathrm{mAcm}^{-2}$ at $0 \mathrm{~V}$ vs. RHE. It was stable during $1 \mathrm{~h}$ of PEC operation. The superior hydrogen generation performance compared to that of a planar Si was attributed to the lower kinetic overpotential induced from the high surface roughness. The Song group studied with chemically exfoliated chemical vapor deposition (CVD) grown $\mathrm{MoS}_{2}$ conjunction with $p$-Si wafer that showed the possibility of $\mathrm{MoS}_{2}$ as a replacement of noble metal like $\mathrm{Pt}$ [75]. $\mathrm{MoS}_{2}$ was deposited by CVD at $475^{\circ} \mathrm{C}$ which is the most popular way to grow $1 \mathrm{~T} \mathrm{MoS}$. The PEC measurement was conducted with the solution of $0.5 \mathrm{M} \mathrm{H}_{2} \mathrm{SO}_{4}(\mathrm{pH}=0.3)$ under 1 sun irradiation and the resulting current density of $17.6 \mathrm{mAcm}^{-2}$ was shown at $0 \mathrm{~V}$ vs. RHE twice higher than that of $2 \mathrm{H}$ phase $\left(9.2 \mathrm{mAcm}^{-2}\right)$. Onset potential of $1 \mathrm{~T} \mathrm{MoS}_{2} / \mathrm{Si}$ was $0.25 \mathrm{~V}$ vs. RHE ( $2 \mathrm{H} \mathrm{MoS}_{2} / \mathrm{Si}$ was $0.23 \mathrm{~V}$ vs. RHE).

$\mathrm{MoS}_{2} / p$-Si structures as ALD-grown $\mathrm{MoS}_{2}$ on $p$-Si were also studied for HER by Oh et al. [78]. They investigated the number of ALD cycles and post-sulfurizing temperatures for crystallization to the resulting PEC performance. The optimum thickness and annealing temperature were $14 \mathrm{~nm}$ (590 cycles) and $600{ }^{\circ} \mathrm{C}$, respectively. With the optimized thickness of $\mathrm{MoS}_{2}$ layers, they obtained $0.23 \mathrm{~V}$ vs. RHE onset potential and $21.7 \mathrm{mAcm}^{-2}$ photocurrent at $0 \mathrm{~V}$ vs. RHE. They also exhibited good stability that only $10 \%$ decrease of current density after $24 \mathrm{~h}$ operation. The Jang group also reported $\mathrm{MoS}_{2} / p$-Si photocathodes which showed the best performance among all. $\mathrm{MoS}_{2}$ was synthesized with spin coating of $\left(\mathrm{NH}_{4}\right)_{2} \mathrm{MoS}_{4}$ and subsequent $\mathrm{CVD}$ process at $950^{\circ} \mathrm{C}$. Onset potential was relatively low ( $+0.17 \mathrm{~V}$ vs. RHE.) but photocurrent at $0 \mathrm{~V}$ vs. RHE was $24.6 \mathrm{mAcm}^{-2}$. It was also stable during 10,000 s during PEC operation [81]. Joe et al., found that the mixed-phase $\mathrm{MoS}_{2}$ could improve the $\mathrm{Si}$ photocathode for PEC WS by regulating the systems impedance [53].

The Liu group fabricated unique structures of $\mathrm{MoS}_{2} / \mathrm{Ag} @ S i$ nanosphere (NS) photocathode. Ag films were deposited on Si and dewetted into spherical shapes, then depositing Si again. Ag@Si NS template improved charge transfer significantly. It showed $0.11 \mathrm{~V}$ vs. RHE onset potential and photocurrent density $-13.4 \mathrm{mAcm}^{-2}$ at $-0.04 \mathrm{~V}$ vs. RHE [83]. The Tsang group utilized $\mathrm{WS}_{2}$ with $\mathrm{Si}$ absorber. The $\mathrm{WS}_{2}$ layers were fabricated by magnetron sputtering on $p$-type $\mathrm{Si}$, followed by annealing at $800{ }^{\circ} \mathrm{C}$. Then $\mathrm{Au}$ was then deposited on $\mathrm{WS}_{2}$ for enhancing photo-activity and stability. They obtained low current density $\left(0.37 \mathrm{mAcm}^{-2}\right.$ at $-1 \mathrm{~V}$ vs. RHE) than $\mathrm{MoS}_{2}$. However, it was much higher than other oxides such as $\mathrm{TiO}_{2}$ or $\mathrm{WO}_{3}$ [84].

In addition to forming heterojunctions on $p$ - or n-Si directly, improved photovoltages via a homojunction of $\mathrm{Si}$ was studied using $\mathrm{n}^{+} p$ type buried junction combined with co-catalyst. In 2014, the Jaramillo group first reported $n^{+} p$ Si conjunction with $\mathrm{MoS}_{2} \cdot \mathrm{Mo}_{3} \mathrm{~S}_{13}$ nanocluster was imposed to enhance the catalytic activity of $\mathrm{MoS}_{2} / \mathrm{n}^{+} p$-Si photocathodes. $\mathrm{MoS}_{2}$ was thermally sulfidized after Mo sputtering on $\mathrm{n}^{+} p$-Si. Onset potential was $0.32 \mathrm{~V}$ (at $-0.5 \mathrm{mAcm}^{-2}$ ) vs RHE. and photocurrent density was $17 \mathrm{mAcm}^{-2}$ at $0 \mathrm{~V}$ vs. RHE. Obviously, onset potential was improved at least $+0.1 \mathrm{~V}$ than $\mathrm{MoS}_{2} / p$-Si configuration [85]. King et al. proved remarkably long duration of 24 days of stable operation under a continuous illumination condition is possible by interfacial engineering between the Si and $\mathrm{MoS}_{2}$ co-catalyst [86].

Huang et al. fabricated sputtered $2 \mathrm{D} \mathrm{MoSe} \mathrm{M}_{2}$ directly on $\mathrm{n}^{+} p$-Si for hydrogen generation. It showed the best onset potential of $+0.40 \mathrm{~V}$ vs. RHE and high saturated current density of $29.3 \mathrm{mAcm}^{-2}$. Their PEC measurement was conducted under 1 sun illumination with the solution of $1.0 \mathrm{M} \mathrm{HClO}_{4}$. It also showed negligible change after $120 \mathrm{~h}$. operation. This result is the only reported Si photocathodes 
with layered $\mathrm{MoSe}_{2}$ [87]. They attributed the PEC properties to the nearly vertically standing two dimensional $\mathrm{MoSe}_{2}$ layer as well as the sharp interface to $\mathrm{Si}$.

To ensure stable operation, protecting Si from degradation in electrolyte is the most important step in the developments of Si-based photoelectrodes. As for protection, metal oxides such as $\mathrm{TiO}_{2}$ were commonly used. In TMDC/Si photocathode, $\mathrm{TiO}_{2}$ interlayer was also used for enhancing stability. The Yang group presented photocathode $\mathrm{MoS}_{2} / p$-type $\mathrm{Si}$ NW with interlayer of $30 \mathrm{~nm}$ ALD-TiO 2 . The $\mathrm{MoS}_{2}$ layer was synthesized with thermolysis method using $\left(\mathrm{NH}_{4}\right)_{2} \mathrm{MoS}_{4}$. They obtained onset potential of $0.30 \mathrm{~V}$ vs. RHE and current density was $15 \mathrm{mAcm}^{-2}$ at $0 \mathrm{~V}$ vs. RHE. It was stable under 1 sun illumination and $0.5 \mathrm{M} \mathrm{H}_{2} \mathrm{SO}_{4}$ acidic condition for an hour [88]. The Jang group also fabricated 3-D $\mathrm{MoS}_{2}$ on $\mathrm{TiO}_{2} / p$-Si by metal-organic CVD (MOCVD) processes. A large fraction of deposited $\mathrm{MoS}_{2}$ was vertically aligned and its grain size was relatively small $(<10 \mathrm{~nm})$. Their cathodic performance was better than their previous results when using $2 \mathrm{D} \mathrm{MoS}_{2}$. It recorded $28 \mathrm{mAcm}^{-2}$ at $0 \mathrm{~V}$ vs. RHE of the highest current density in TMDC/Si photocathode and onset potential was $+0.35 \mathrm{~V}$ vs. RHE. It was stable for $\sim 181 \mathrm{~h}$ in the solution of $0.5 \mathrm{M} \mathrm{H}_{2} \mathrm{SO}_{4}$ due to the role of $\mathrm{TiO}_{2}$ passivation layer [74]. The Zheng group combined both buried $\mathrm{n}^{+} p$-Si and interlayer $\mathrm{Al}_{2} \mathrm{O}_{3}$ for hydrogen evolution. The $\mathrm{MoS}_{2} / \mathrm{Al}_{2} \mathrm{O}_{3} / \mathrm{n}^{+} p$-Si configuration showed the onset potential of $0.40 \mathrm{~V}$ vs. RHE and saturated photocurrent of $35.6 \mathrm{~mA}^{-2}$. Their results exhibited the best onset potential compared to other $\mathrm{TM}(\mathrm{D}) \mathrm{C} / \mathrm{Si}$ photoelectrodes, which came from the presence of $\mathrm{Al}_{2} \mathrm{O}_{3}$ interlayer worked as a protective and passivate layer during $\mathrm{MoS}_{2}$ deposition. It also exhibited best stability about $120 \mathrm{~h}$ operation under $1.0 \mathrm{M} \mathrm{HClO}_{4}(\mathrm{pH}=0)$ acidic condition [77].

In 1995, a group in India reported the first $\mathrm{Si}$ junction with metal sulfides photocathode. A n-Si foil was grounded and mixed with $\mathrm{CdS}$ and $\mathrm{ZnS}$. Metal chalcogenide (CdS and $\mathrm{ZnS}$ ) was made by $\mathrm{Na}_{2} \mathrm{~S}$ and $\mathrm{Cd}\left(\mathrm{CH}_{3} \mathrm{COO}\right)_{2}$ or $\mathrm{Zn}\left(\mathrm{CH}_{3} \mathrm{COO}\right)_{2}$ precipitation method. When $7 \%$ of $\mathrm{CdS}$ mixed with $\mathrm{n}-\mathrm{Si}$, it showed best efficiency of $7.23 \mathrm{mLh}^{-1} \mathrm{~g}^{-1}$ [89]. After this report, the TMC/Si photoelectrode study stopped publishing. Similar with TMDC/Si photoelectrodes, however, reports on the TMC/Si photoelectrodes were also increased after 2011. $\mathrm{Mo}_{3} \mathrm{~S}_{4}$ was synthesized by the drop-casting method on $p$-type $\mathrm{Si}$ wafer and nanopillar (NP). The $p$-Si substrate with $\mathrm{Mo}_{3} \mathrm{~S}_{4}$ photocathodes exhibited the onset potential of $+0.15 \mathrm{~V}$ vs. RHE and photocurrent of $8 \mathrm{mAcm}^{-2}$ at $0 \mathrm{~V}$ vs. RHE. It was increased to $9 \mathrm{mAcm}^{-2}$ at the same potential by changing $p$-Si wafer to $p$-Si nanopillar. The resulting $\mathrm{Mo}_{3} \mathrm{~S}_{4} / p$-Si cells were stable for $60 \mathrm{~min}$ under red light illumination (power density $28.3 \mathrm{mWcm}^{-2}$, wavelength > $620 \mathrm{~nm})$ in $1.0 \mathrm{M} \mathrm{HClO}_{4}(\mathrm{pH}=0)$ [90].

Hou et al. decorated molybdenum-sulfur clusters on $p$-Si NW for hydrogen production. The clusters were synthesized with precipitation method in a chemical bath at $96^{\circ} \mathrm{C}$. This showed great PEC activities in the visible-infrared wavelength regions. The PEC measurements were conducted under $27.3 \mathrm{mWcm}^{-2}$, at wavelengths $>590 \mathrm{~nm}$. It exhibited the photocurrent of $14.3 \mathrm{mAcm}^{-2}$ at $0 \mathrm{~V} \mathrm{vs}$. RHE and onset potential of $0.25 \mathrm{~V}$ vs. RHE. Expanding wavelengths to $\sim 450 \mathrm{~nm}$, photocurrent increased over $30 \mathrm{mAcm}^{-2}$ at $0 \mathrm{~V}$ vs. RHE. It showed stable WS for $\sim 3 \mathrm{~h}$ in $\mathrm{H}_{2} \mathrm{SO}_{4}(\mathrm{pH}=0.3)$ solutions [91]. Si NWs decorated with $\mathrm{MoS}_{3}$ was demonstrated by Huang et al. showing enhanced performance in comparison with SiNWs, with a photocurrent density of $\sim 24.8 \mathrm{mAcm}^{-2}$ and $0.37 \mathrm{~V}$ of onset voltage [92]. The binary and ternary TMCs on $\mathrm{Si}$ are also reported as photocathodes. Photo-assisted electrodeposition of $\mathrm{NiCoSe}_{x}$ on $p$-Si NPs were introduced. The molar ratio of Ni, Co, Se was 1:1:4.5 with amorphous structures. The PEC characteristic of a-NiCoSe $e_{x} / p$-Si NP was the onset potential of $+0.25 \mathrm{~V}$ vs. RHE and the highest photocurrent of $37.5 \mathrm{mAcm}^{-2}$ at $0 \mathrm{~V}$ vs. RHE. After $2 \mathrm{~h}$ of the PEC test, photocurrent density decreased 9\% [93]. The Barber group reported amorphous $\mathrm{CoMoS}_{\mathrm{x}}$ $\left(\mathrm{a}-\mathrm{CoMoS}_{\mathrm{x}}\right) / p$-Si photocathode. $\mathrm{CoMoS}_{\mathrm{x}}$ was synthesized with a photo-assisted electrodeposition method, using $\left[\mathrm{Co}\left(\mathrm{MoS}_{4}\right)_{2}\right]^{2-}$ solution. It showed the photocurrent of $17.5 \mathrm{mAcm}^{-2}$ at $0 \mathrm{~V}$ vs. RHE and onset potential of $0.25 \mathrm{~V}$ vs. RHE under phosphate electrolyte $(\mathrm{pH}=4.25)$. The photocurrents were decreased less than 5\% after $3 \mathrm{~h}$ PEC operation [94]. The n-Si photocathode with TMC was first reported by the Shelke group. The n-Si NW was decorated with CdSe quantum dot (QD) by successive ionic layer adsorption and reaction (SILAR) methods under inert condition. The WS results showed 
size dependency with the CdSe cycles and it showed the maximum current of $6.1 \mathrm{mAcm}^{-2}$ at $1 \mathrm{~V}$ vs. RHE. However, QD coverage was not enough to stabilize n-Si NWs under $0.25 \mathrm{M} \mathrm{Na}_{2} \mathrm{~S}$ and $0.35 \mathrm{M}$ $\mathrm{Na}_{2} \mathrm{SO}_{3}$ electrolytes $(\mathrm{pH}=11.5)$, which significantly degraded in a minute [70].

The Liu group studied Co-based metal chalcogenides on Si photocathode. First, $\mathrm{CoS}_{2}$ co-catalyst on $p$-Si microwire (MW) was introduced for PEC hydrogen evolution. $\mathrm{CoS}_{2}$ was prepared with sulfidation of chemically synthesized $\mathrm{CO}(\mathrm{OH})_{2}$ on $\mathrm{Si} \mathrm{MW}$ at $500{ }^{\circ} \mathrm{C}$. It showed the photocurrent of $3.22 \mathrm{mAcm}^{-2}$ at $0 \mathrm{~V}$ vs. RHE and onset potential of $0.249 \mathrm{~V}$. It maintained photocurrent for $3 \mathrm{~h}$ operation under $0.5 \mathrm{M} \mathrm{H}_{2} \mathrm{SO}_{4}(\mathrm{pH}=0.3)$ solutions and 1 sun illumination [95]. They also compared stability and functionality of co-catalyst $\mathrm{CoS}_{2}, \mathrm{CoSe}_{2} / p$-Si MWs under 1 sun with various $\mathrm{pH}$ of electrolytes, i.e., $0.5 \mathrm{M} \mathrm{H}_{2} \mathrm{SO}_{4}$ ( $\mathrm{pH}=0.3$ ), $1 \mathrm{M}$ phosphate buffered saline (PBS, $\mathrm{pH}=7.4$ ), and $1 \mathrm{M} \mathrm{KOH}$ $(\mathrm{pH}=13) . \mathrm{CoS}_{2}$ was not stable in alkaline solution, but $\mathrm{CoSe}_{2}$ was stable for $50 \mathrm{~min}$. However, both were stable under acidic condition, especially $\mathrm{CoS}_{2}$ was stable for $9 \mathrm{~h} \mathrm{[96].} \mathrm{Improved} \mathrm{photocurrent} \mathrm{of}$ $9 \mathrm{mAcm}^{-2}$ at $0 \mathrm{~V}$ vs. RHE with onset potential of $0.18 \mathrm{~V}$ were obtained from $\mathrm{CoSe}_{2} / p$-Si MW which was prepared in the identical method with $\mathrm{CoS}_{2}$. After stability test of 50 cycles, it showed similar current density [97]. Finally, they prepared $\mathrm{CoTe}_{2} / p-\mathrm{Si}$ MW by drop casting, and $10 \mathrm{~nm}$ of $\mathrm{ALD}-\mathrm{TiO}_{2}$ was deposited on $\mathrm{CoTe}_{2} / p$-Si in order to stabilize $\mathrm{CoTe}_{2}$ which is easily oxidized in ambient condition. It showed the onset potential of $0.17 \mathrm{~V}$ vs. RHE and saturated current density of $24.0 \mathrm{mAcm}^{-2}$ [98].

The interfacial layers of metal oxides were also applied in the TMC/Si photocathodes. Seger et al. studied $\mathrm{MoS}_{\mathrm{x}} / \mathrm{Ti}-\mathrm{TiO}_{\mathrm{x}} / \mathrm{n}^{+} p$-Si where Ti was used as a conductive and protection layer on $\mathrm{Si}$. MoS $\mathrm{x}$ was deposited with the electrodeposition method, Mo and $S$ atomic concentration was similar revealed by XPS. By protecting $\mathrm{Si}$ with Ti layers, the resulting onset potential was reached to $0.33 \mathrm{~V}$ vs. RHE and it showed current density of $12 \mathrm{mAcm}^{-2}$ at $+0.20 \mathrm{~V}$ vs. RHE and was stable for $1 \mathrm{~h} \mathrm{[99].} \mathrm{The} \mathrm{Shen}$ group synthesized $\mathrm{MoS}_{2}$ by photoreduction-annealing method, and $2 \mathrm{~nm}$-thick $\mathrm{Al}_{2} \mathrm{O}_{3}$ was deposited on the $\mathrm{n}^{+} \mathrm{p}$-Si for transparent and protect the $\mathrm{Si}$ surfaces from oxidation. The photoelectrochemical performance was $28.9 \mathrm{mAcm}^{-2}$ at $0 \mathrm{~V}$ vs. RHE in current density and $+0.35 \mathrm{~V}$ onset potential. Due to the $\mathrm{Al}_{2} \mathrm{O}_{3}$ protection layer, $\mathrm{MoS}_{2} / \mathrm{Al}_{2} \mathrm{O}_{3} / \mathrm{n}^{+} p$-Si photocathode was stable for $40 \mathrm{~h}$ [69]. The Huang group also reported photoanodes of $p$-Si with metal sulfides. The $\mathrm{Ag}_{2} \mathrm{~S} / \mathrm{ZnS} / \mathrm{ZnO} / p$-Si nanocones (NCs) were used and compared with $\mathrm{ZnS} / \mathrm{ZnO} / p$-Si and $\mathrm{ZnO} / p$-Si NCs. The $\mathrm{ZnO}$ was prepared with the hydrothermal method at $90^{\circ} \mathrm{C}$, and by sulfidation with thioacetamide in a solution, ZnS was fabricated in the form of film. After then, $\mathrm{Ag}_{2} \mathrm{~S}$ nanoparticles were decorated on top of the cell. Better band alignment with $\mathrm{Ag}_{2} \mathrm{~S} / \mathrm{ZnO}$ resulted photocurrent of $58.8 \mu \mathrm{Acm}^{-2}$ at $2.1 \mathrm{~V}$ vs. RHE and it was 2.5 times higher than $\mathrm{ZnS} / \mathrm{ZnO} / p$-Si NC [100].

The $\operatorname{TM}(\mathrm{D}) \mathrm{C} / \mathrm{Si}$ photoelectrode described above has limitations in terms of instability and low photovoltage. There are possible ways to improve the overall performance (1) by improving the coverage of co-catalysts and (2) by enhancing charge transfer and photovoltage drop through a junction with $\mathrm{TM}(\mathrm{D}) \mathrm{C}$. By analyzing the current trends in $\mathrm{Si} / \mathrm{TM}(\mathrm{D}) \mathrm{C}$ photocathodes, less than 40 studies have been reported so far, which means that there are still so much room to explore in this field. We suspect that one of the reasons why studies on $\mathrm{Si} / \mathrm{TM}(\mathrm{D}) \mathrm{C}$ photocathodes have been limited would be the lack of reliable deposition methodologies. In the next section, we highlight atomic layer deposition techniques as a unique tool for growing $\mathrm{TM}(\mathrm{D}) \mathrm{C}$ on semiconductor absorbers.

\section{Atomic Layer Deposition (ALD) of TM(D)C}

\subsection{Defect Chemistry of $T M(D) C$ and Its Implication on Low-Temperature ALD}

All synthesized materials inevitably include various types of defects at thermal equilibrium although the origins are different from each other. The defects can be divided into three distinctive categories, as follows: 0-D defects (point defects), 1-D defects (line defects), and 2-D defects (surface defects). In particular, point defects are of paramount significance to determine several properties such as conductivity, luminescence and Fermi level. The simplest point defect is caused by missing an atom or ion, called lattice vacancy (also known as Schottky defects). In another case, when the atom missed 
from a lattice site transferred to an interstitial position, we called it a Frenkel pair (i.e., a couple of two point-defects: an interstitial and associated vacancy). The probability of those point defects follows the Boltzmann factor leaving the home lattice-sites at thermal equilibrium: $P=\exp \left(-E_{\mathrm{v}} / k_{\mathrm{B}} T\right)$, where $E_{\mathrm{v}}=$ energy for taking an atom from the lattice site on the surface. Therefore, the equilibrium concentration of point defects often pertains to the synthesis temperatures at the final stages. Controlling point defects is critical in many materials for industrial applications; fine control over the amounts of defects for tuning the electronical and optical properties is greatly important in technological applications. One could create these fine states by additionally doping other elements or by specific synthesis conditions. In $\mathrm{TiO}_{2}$ synthesis, for example, it has $n$-type property due to the energetically favorable formation of oxygen vacancies under ambient conditions [101]. In both anatase and rutile $\mathrm{TiO}_{2}$, the conduction band is predominantly made up from Ti $3 \mathrm{~d}$ states, which are formally unoccupied in the stoichiometric material. These Ti valence states are highly localized, and the formation of intrinsic $n$-type defects donates electrons to the Ti lattice, occupying conduction bands to produce the localized defect states as observed experimentally [102,103].

Note that chalcogenide semiconductors have distinctive point defects such as anti-site defects, because they have a low vacancy formation energy, unlike those of oxide semiconductors. It has been shown that the precise control of conductivity can be achieved through the fundamental differences in the energetics of native defect formation in the Bi-Te-Se ternary system, for example [104]. In such chalcogenides, there are two kinds of charged defects: The substitutionary anti-site defect $\left(B i_{\mathrm{Te}}^{\prime}\right.$ or $\left.B i_{\mathrm{Se}}^{\prime}\right)$ and the vacancy defect $\left(V_{\mathrm{Te}}^{\bullet} / V_{\mathrm{Te}}^{\bullet \bullet}\right.$ or $\left.V_{\mathrm{Se}}^{\bullet} / V_{\mathrm{Se}}^{\bullet \bullet}\right)$. The effective charge carrier density could be expressed by $n_{\mathrm{eff}}=\left[B i_{\mathrm{Te}}^{\prime}\right]-2\left[V_{\mathrm{Te}}^{\bullet \bullet}\right]$ which is distinctive in that the dominant type of defects is determined by the thermodynamically stable anti-site defects when compared with a typical Frenkel pair $\left(T e_{\mathrm{Te}}^{\mathrm{X}} \rightarrow V_{\mathrm{Te}}^{\prime \prime}+T e_{\mathrm{i}}^{\bullet \bullet}\right)$ in accordance with Kröger-Vink notation. In the stoichiometric $\mathrm{Bi}_{2} \mathrm{Te}_{3}, B i_{\mathrm{Te}}^{\prime}$ has the theoretically lowest formation energy to be $0.4-0.5 \mathrm{eV}$ among the charged defects. Therefore, the stoichiometric $\mathrm{Bi}_{2} \mathrm{Te}_{3}$ is the nominal $p$-type semiconductor. The stoichiometric $\mathrm{Bi}_{2} \mathrm{Se}_{3}$ has the vacancy defects of $V_{\mathrm{Se}}^{\bullet} / V_{\mathrm{Se}}^{\bullet \bullet}$ that are thermodynamically stable charged defects, resulting in $n$-type properties.

In practice, however, the most popular synthetic method, CVD (as shown in Table 2) employ high growth temperatures of at least $600{ }^{\circ} \mathrm{C}$, and the precise controls over the number and the type of point defects are very difficult. The amounts of point defects are exponentially affected by the Arrhenius equation in terms of temperature, $\mathrm{K}$. The representative example is that the stoichiometric $\mathrm{Bi}_{2} \mathrm{Te}_{3}$ (as mentioned above, nominal $p$-type) has been reported as $n$-type semiconductor as a result of high growth temperature. As for the TM(D)C materials, therefore, understanding and controlling defects and defect processes is of significance at low temperatures. 
Table 1. Summary of the literature papers on the heterostructures of Si/TM(D)Cs for application in PEC water splitting (WS). Analyzed from Refs. [53,68-70,74,75,77,78,81-100].

\begin{tabular}{|c|c|c|c|c|c|c|c|c|c|c|}
\hline & PEC Process & Cell Type & Configuration & $\begin{array}{c}\mathrm{MX}_{2} \\
\text { Compound }\end{array}$ & Experimental Condition & $\begin{array}{c}\text { Current Density } \\
\left(\mathrm{mAcm}^{-2}\right)\end{array}$ & $\begin{array}{c}\text { Onset Potential } \\
\text { (V vs RHE) }\end{array}$ & $\begin{array}{l}\text { Light Source } \\
\left(\mathrm{mWcm}^{-2}\right)\end{array}$ & $\begin{array}{c}\text { Stability } \\
(\text { min) }\end{array}$ & Ref. \\
\hline \multirow{14}{*}{ TMDC } & \multirow{14}{*}{ Photocathode } & \multirow{8}{*}{$\mathrm{TMDC} / \mathrm{Si}$} & $\mathrm{MoS}_{2} / \mathrm{p}-\mathrm{Si}$ & \multirow{7}{*}{$\mathrm{MoS}_{2}$} & $\begin{array}{c}0.5 \mathrm{M} \mathrm{H}_{2} \mathrm{SO}_{4}(\mathrm{pH}=0.3) / \mathrm{SCE} \text { Ref./Pt plate } \\
\text { Counter }\end{array}$ & 24.6 (0V vs RHE) & +0.17 & $\begin{array}{l}\text { Xe Lamp } \\
(100)\end{array}$ & $\begin{array}{c}1666.7 \\
(10000 s)\end{array}$ & [81] \\
\hline & & & $\mathrm{MoS}_{2} / \mathrm{p}-\mathrm{Si}$ & & $\begin{array}{c}0.5 \mathrm{M} \mathrm{H}_{2} \mathrm{SO}_{4}(\mathrm{pH}=0.3) / \mathrm{Ag} / \mathrm{AgCl} / 1 \mathrm{M} \mathrm{KCl} \\
\text { Ref./Graphite rod Counter }\end{array}$ & 17.6 (0V vs RHE) & +0.23 & $\begin{array}{l}1 \text { sun } \\
(100)\end{array}$ & 180 & [75] \\
\hline & & & $\mathrm{MoS}_{2} / \mathrm{p}-\mathrm{Si}$ & & $\begin{array}{c}0.5 \mathrm{M} \mathrm{H}_{2} \mathrm{SO}_{4}(\mathrm{pH}=0.3) / \mathrm{Ag} / \mathrm{AgCl} / 3 \mathrm{M} \mathrm{KCl} \\
\text { Ref./Pt wire Counter }\end{array}$ & 21.7 (0V vs RHE) & +0.23 & $\begin{array}{l}1 \text { sun } \\
(100)\end{array}$ & 1440 & [78] \\
\hline & & & $\mathrm{MoS}_{2} / \mathrm{p}$-Si NW & & $1.0 \mathrm{M} \mathrm{Na}_{2} \mathrm{SO}_{4}$ buffer $(\mathrm{pH}=5.0) /$ Not available & 1 (0V vs RHE) & +0.25 & $\begin{array}{l}\text { Xe Lamp } \\
(100)\end{array}$ & 60 & [82] \\
\hline & & & & & $\begin{array}{c}0.5 \mathrm{M} \mathrm{H}_{2} \mathrm{SO}_{4}(\mathrm{pH}=0.3) / \mathrm{Ag} / \mathrm{AgCl} \text { Ref. } / \mathrm{Pt} \\
\text { wire Counter }\end{array}$ & 16.5 (0V vs RHE) & +0.26 & $\begin{array}{c}\text { Xe Lamp } \\
(100)\end{array}$ & 2880 & [68] \\
\hline & & & $\mathrm{MoS}_{2} / \mathrm{Ag} @ \mathrm{Si} \mathrm{NS}$ & & $\begin{array}{c}0.5 \mathrm{M} \mathrm{H}_{2} \mathrm{SO}_{4}(\mathrm{pH}=0.3) / \mathrm{Ag} / \mathrm{AgCl} \text { Ref. } / \mathrm{Pt} \\
\text { wire Counter }\end{array}$ & 33.3 (Saturated) & +0.11 & $\begin{array}{l}1 \text { sun } \\
(100)\end{array}$ & 720 & [83] \\
\hline & & & $\mathrm{p}-\mathrm{Si} / \mathrm{SiOx} / \mathrm{MoS}_{2}$ & & $\begin{array}{c}0.5 \mathrm{M} \mathrm{H}_{2} \mathrm{SO}_{4}(\mathrm{pH}=0.3) / \mathrm{Ag} / \mathrm{AgCl} \text { Ref. } / \mathrm{Pt} \\
\text { wire Counter }\end{array}$ & 30(Saturated) & +0.35 & $\begin{array}{l}\text { Xe Lamp } \\
(100)\end{array}$ & 4320 & [53] \\
\hline & & & $\mathrm{Au} / \mathrm{WS}_{2} / \mathrm{Si}$ & $\mathrm{WS}_{2}$ & $\begin{array}{c}0.5 \mathrm{M} \mathrm{H}_{2} \mathrm{SO}_{4}(\mathrm{pH}=0.3) / \mathrm{Ag} / \mathrm{AgCl} \text { Ref. Pt } \\
\text { Counter }\end{array}$ & $\begin{array}{l}0.37 \text { (-1.0V vs } \\
\text { RHE) }\end{array}$ & Not Available & Not Available & 50 & [84] \\
\hline & & \multirow{3}{*}{$\begin{array}{c}\text { TMDC/ } \\
\mathrm{n}+\mathrm{p}-\mathrm{Si}\end{array}$} & $\begin{array}{l}\mathrm{MoS}_{2} / \mathrm{Mox}_{\mathrm{x}} \mathrm{Si} \\
\mathrm{Mo} / \mathrm{n}+\mathrm{p} \mathrm{Si}\end{array}$ & \multirow{2}{*}{$\mathrm{MoS}_{2}$} & $\begin{array}{l}0.5 \mathrm{M} \mathrm{H}_{2} \mathrm{SO}_{4}(\mathrm{pH}=0.3) / \mathrm{Hg} / \mathrm{Hg}_{2} \mathrm{SO}_{4} \text { in } \\
\text { saturated } \mathrm{K}_{2} \mathrm{SO}_{4} \text { Ref./Ir Counter }\end{array}$ & 17 (0V vs RHE) & +0.32 & \multirow{2}{*}{$\begin{array}{l}1 \text { sun } \\
(100)\end{array}$} & 6000 & [85] \\
\hline & & & $\begin{array}{c}\mathrm{MoS}_{2} / \mathrm{Mox}_{\mathrm{x}} \mathrm{Si} \\
\mathrm{Mo} / \mathrm{n}+\mathrm{pSi}\end{array}$ & & $\begin{array}{l}0.5 \mathrm{M} \mathrm{H}_{2} \mathrm{SO}_{4}(\mathrm{pH}=0.3) / \mathrm{Hg} / \mathrm{Hg}_{2} \mathrm{SO}_{4} \text { in } \\
\text { saturated } \mathrm{K}_{2} \mathrm{SO}_{4} \text { Ref./Ir Counter }\end{array}$ & 19 (0V vs RHE) & +0.28 & & $\begin{array}{l}36360 \\
(606 \mathrm{~h})\end{array}$ & [86] \\
\hline & & & $\mathrm{MoSe}_{2} / \mathrm{n}+\mathrm{p}-\mathrm{Si}$ & $\mathrm{MoSe}_{2}$ & $\begin{array}{c}1.0 \mathrm{M} \mathrm{HClO}_{4}(\mathrm{pH}=1.0) / \mathrm{Ag} / \mathrm{AgCl} / 3 \mathrm{M} \mathrm{KCl} \\
\text { Ref./Pt Counter }\end{array}$ & 29.3 (Saturated) & +0.40 & $\begin{array}{c}\text { Xe Lamp } \\
(100)\end{array}$ & 7200 & [87] \\
\hline & & \multirow{2}{*}{$\begin{array}{l}\text { TMDC/Interlayer/ } \\
\mathrm{Si}\end{array}$} & $\begin{array}{l}\mathrm{MoS}_{2} / \mathrm{ALD} \\
\mathrm{TiO}_{2} / \mathrm{p}-\mathrm{Si} \mathrm{NW}\end{array}$ & \multirow{2}{*}{$\mathrm{MoS}_{2}$} & $\begin{array}{c}0.5 \mathrm{M} \mathrm{H}_{2} \mathrm{SO}_{4}(\mathrm{pH}=0.3) / \mathrm{Ag} / \mathrm{AgCl} / 1 \mathrm{M} \mathrm{NaCl} \\
\text { Ref. }\end{array}$ & 15 (0V vs RHE) & +0.30 & $\begin{array}{l}1 \text { sun } \\
(100)\end{array}$ & 75 & [88] \\
\hline & & & $3 \mathrm{D} \mathrm{MoS}_{2} / \mathrm{TiO}_{2} / \mathrm{p}-\mathrm{Si}$ & & $\begin{array}{c}0.5 \mathrm{M} \mathrm{H}_{2} \mathrm{SO}_{4}(\mathrm{pH}=0.3) / \mathrm{SCE} \text { Ref. / Graphite } \\
\text { Counter }\end{array}$ & 28 (0V vs RHE) & +0.35 & $\begin{array}{l}\text { Xe Lamp } \\
(100)\end{array}$ & 6000 & [74] \\
\hline & & TMDC/Interlayer $/ \mathrm{n}+\mathrm{p}-\mathrm{Si}$ & $\begin{array}{l}\mathrm{MoS}_{2} / \mathrm{Al}_{2} \mathrm{O}_{3} \\
\text { n+p-Si }\end{array}$ & $\mathrm{MoS}_{2}$ & $\begin{array}{c}1.0 \mathrm{M} \mathrm{HClO}_{4}(\mathrm{pH}=1.0) / \mathrm{Ag} / \mathrm{AgCl} / 3 \mathrm{M} \mathrm{KCl} \\
\text { Ref./Pt wire Counter }\end{array}$ & 35.6 (Saturated) & +0.40 & $\begin{array}{l}\text { sun } \\
(100)\end{array}$ & 7200 & [77] \\
\hline
\end{tabular}


Table 1. Cont.

\begin{tabular}{|c|c|c|c|c|c|c|c|c|c|c|}
\hline & PEC Process & Cell Type & Configuration & $\begin{array}{c}\mathrm{MX}_{2} \\
\text { Compound }\end{array}$ & Experimental Condition & $\begin{array}{l}\text { Current Density } \\
\left(\mathrm{mAcm}^{-2}\right)\end{array}$ & $\begin{array}{l}\text { Onset Potential } \\
\text { (V vs RHE) }\end{array}$ & $\begin{array}{l}\text { Light Source } \\
\left(\mathrm{mWcm}^{-2}\right)\end{array}$ & $\begin{array}{c}\text { Stability } \\
(\text { min) }\end{array}$ & Ref. \\
\hline \multirow{13}{*}{ TMC } & \multirow{12}{*}{ Photocathode } & \multirow{9}{*}{$\mathrm{TMC} / \mathrm{Si}$} & $\begin{array}{c}\text { CdS, ZnS/ } \\
\text { n-Si powder }\end{array}$ & $\mathrm{CdS}, \mathrm{ZnS}$ & $\begin{array}{c}0.24 \mathrm{M} \mathrm{Na}_{2} \mathrm{~S}+0.35 \mathrm{M} \mathrm{Na}_{2} \mathrm{SO}_{3}(\mathrm{pH}= \\
\text { 11.5)/Not Available }\end{array}$ & $\begin{array}{l}\text { Not Available } \\
\text { (7.23mL/gh) }\end{array}$ & Not Available & (25) & $\begin{array}{c}\text { Not } \\
\text { Available }\end{array}$ & [89] \\
\hline & & & $\mathrm{Mo}_{3} \mathrm{~S}_{4}$ cluster $/ \mathrm{Si} \mathrm{NP}$ & $\mathrm{Mo}_{3} \mathrm{~S}_{4}$ & $\begin{array}{c}1.0 \mathrm{M} \mathrm{HClO}_{4}(\mathrm{pH}=1.0) / \mathrm{Hg} / \mathrm{HgSO}_{4} \text { Ref./Pt } \\
\text { mesh Counter }\end{array}$ & 9 (0V vs RHE) & +0.15 & $\begin{array}{l}\text { Xe Lamp } \\
(28.3)\end{array}$ & 60 & [90] \\
\hline & & & $\mathrm{MoS}_{x} / \mathrm{P}-\mathrm{Si}$ & $\operatorname{MoS}_{x}$ & $\begin{array}{c}0.5 \mathrm{M} \mathrm{H}_{2} \mathrm{SO}_{4}(\mathrm{pH}=0.3) / \mathrm{SCE} \text { Ref./Pt mesh } \\
\text { Counter }\end{array}$ & 14.3 (0V vs RHE) & +0.25 & $\begin{array}{l}\text { Xe Lamp } \\
(27.3)\end{array}$ & 180 & [91] \\
\hline & & & $\begin{array}{l}\text { a-NiCoSe } / \\
\text { p-Si NP }\end{array}$ & $\mathrm{NiCoSe}_{\mathrm{x}}$ & $\begin{array}{c}0.5 \mathrm{M} \mathrm{H}_{2} \mathrm{SO}_{4}(\mathrm{pH}=0.3) / \mathrm{SCE} \text { Ref. } / \mathrm{Pt} \text { wire } \\
\text { Counter }\end{array}$ & 37.5 (0V vs RHE) & +0.25 & $\begin{array}{l}\text { sun } \\
(100)\end{array}$ & 120 & [93] \\
\hline & & & $\mathrm{a}-\mathrm{CoMoS}_{\mathrm{x}} / \mathrm{Si}$ & $\operatorname{coMos}_{x}$ & $\begin{array}{c}\text { Phosphate }(\mathrm{pH}=4.25) / \mathrm{Ag} / \mathrm{AgCl} / 3 \mathrm{M} \mathrm{KCl} \\
\text { Ref./Pt wire Counter }\end{array}$ & $\begin{array}{l}17.5 \mathrm{vs}(0.25 \mathrm{~V} \text { vs } \\
\text { RHE) }\end{array}$ & 0.25 & $\begin{array}{l}\text { Xe Lamp } \\
(100)\end{array}$ & 180 & [94] \\
\hline & & & $\begin{array}{l}\text { CdSe QD/ } \\
\text { n-Si NW }\end{array}$ & CdSe & $\begin{array}{c}0.25 \mathrm{M} \mathrm{Na}_{2} \mathrm{~S}+0.35 \mathrm{M} \mathrm{Na}_{2} \mathrm{SO}_{3}(\mathrm{pH}= \\
11.5) / \mathrm{Hg} / \mathrm{HgO} \text { Ref./ } \\
\text { Pt foil Counter }\end{array}$ & 6.1 (1.0V vs RHE) & Not Available & $\begin{array}{l}1 \text { sun } \\
(100)\end{array}$ & $<1$ & [70] \\
\hline & & & $\mathrm{CoS}_{2} / \mathrm{p}$-Si MW & $\mathrm{CoS}_{2}$ & $\begin{array}{c}0.5 \mathrm{M} \mathrm{H}_{2} \mathrm{SO}_{4}(\mathrm{pH}=0.3) / \mathrm{Ag} / \mathrm{AgCl} \text { Ref. } / \mathrm{Pt} \\
\text { plate Counter }\end{array}$ & 3.22 (0V vs RHE) & 0.249 & $\begin{array}{c}\text { Xe Lamp } \\
(100)\end{array}$ & 180 & [94] \\
\hline & & & $\begin{array}{l}\mathrm{CoS}_{2}, \mathrm{CoSe}_{2} / \mathrm{p}-\mathrm{Si} \\
\mathrm{MW}\end{array}$ & $\mathrm{CoS}_{2}, \mathrm{CoSe}_{2}$ & $\begin{array}{c}0.5 \mathrm{M} \mathrm{H}_{2} \mathrm{SO}_{4}(\mathrm{pH}=0.3) / \mathrm{Ag} / \mathrm{AgCl} \mathrm{Ref.} / \mathrm{Pt} \\
\text { plate Counter }\end{array}$ & $\begin{array}{l}3.22\left(\mathrm{CoS}_{2}\right), 2.55 \\
\left(\mathrm{CoSe}_{2}\right)\end{array}$ & $\begin{array}{r}0.248\left(\mathrm{CoS}_{2}\right) \\
0.137\left(\mathrm{CoSe}_{2}\right)\end{array}$ & $\begin{array}{c}\text { Xe Lamp } \\
(100)\end{array}$ & $\begin{array}{c}\text { Not } \\
\text { Available }\end{array}$ & [96] \\
\hline & & & $\mathrm{CoSe}_{x} / \mathrm{Si} \mathrm{MW}$ & $\mathrm{CoSe}_{x}$ & $\begin{array}{c}0.5 \mathrm{M} \mathrm{Na}_{2} \mathrm{SO}_{4}(\mathrm{pH}=1) / \mathrm{Ag} / \mathrm{AgCl} \text { Ref. } / \mathrm{Pt} \text { foil } \\
\text { Counter }\end{array}$ & $9(-0.14 \mathrm{~V}$ vs RHE $)$ & 0.18 & $\begin{array}{l}\text { Xe Lamp } \\
(100)\end{array}$ & 50 cycles & [97] \\
\hline & & $\mathrm{TMC} /$ Interlayer/Si & $\begin{array}{l}\mathrm{CoTe}_{x} / \mathrm{ALD}^{\mathrm{LLO}}-\mathrm{TiO}_{2} / \mathrm{Si} \\
\text { MW }\end{array}$ & CoTe $_{x}$ & $\begin{array}{c}0.5 \mathrm{M} \mathrm{H}_{2} \mathrm{SO}_{4}(\mathrm{pH}=0.3) / 0.5 \mathrm{M} \mathrm{Ag} / \mathrm{AgCl} \\
\text { Ref./Pt foil Counter }\end{array}$ & 24.0 (Saturated) & 0.17 & $\begin{array}{c}\text { Xe Lamp } \\
(100)\end{array}$ & $\begin{array}{c}66.7 \\
(4000 \mathrm{~s})\end{array}$ & [98] \\
\hline & & \multirow{2}{*}{ TMC/Interlayer/n+p Si } & $\mathrm{MoS}_{x} / \mathrm{Ti}^{-T i O} / \mathrm{n}+\mathrm{p}-\mathrm{Si}$ & $\operatorname{MoS}_{x}$ & $\begin{array}{c}1.0 \mathrm{M} \mathrm{HClO}_{4}(\mathrm{pH}=1.0) / \mathrm{Hg} / \mathrm{HgSO}_{4} \text { Ref./Pt } \\
\text { mesh Counter }\end{array}$ & 12 (0.2V vs RHE) & +0.20 & (38.6) & 60 & [99] \\
\hline & & & $\mathrm{a}-\mathrm{MoS}_{2} / \mathrm{Al}_{2} \mathrm{O}_{3} / \mathrm{n}+\mathrm{p}-\mathrm{Si}$ & $\mathrm{MoS}_{2}$ & $\begin{array}{c}1.0 \mathrm{M} \mathrm{HClO}_{4}(\mathrm{pH}=1.0) / \mathrm{Ag} / \mathrm{AgCl} \text { Ref. } / \mathrm{Pt} \\
\text { wire Counter }\end{array}$ & 34.5 (Saturated) & +0.35 & $\begin{array}{l}\text { Xe Lamp } \\
(100)\end{array}$ & 2400 & [69] \\
\hline & Photoanode & $\mathrm{TMC} /$ Interlayer/Si & $\begin{array}{l}\mathrm{Ag}_{2} \mathrm{~S} \\
\mathrm{NP} / \mathrm{ZnS} / \mathrm{ZnO} / \mathrm{p}-\mathrm{Si} \\
\mathrm{NC}\end{array}$ & $\mathrm{Ag}_{2} \mathrm{~S}, \mathrm{ZnS}$ & $\begin{array}{c}0.2 \mathrm{M} \mathrm{Na}_{2} \mathrm{SO}_{4}+\mathrm{PBS}(\mathrm{pH}=7.25) / \mathrm{Ag} / \mathrm{AgCl} \\
\text { Ref./Pt foil Counter }\end{array}$ & $\begin{array}{l}0.0588 \text { vs (2.1V vs } \\
\text { RHE) }\end{array}$ & Not Available & Not Available & $\begin{array}{c}\text { Not } \\
\text { Available }\end{array}$ & [100] \\
\hline
\end{tabular}


Table 2. Various synthesis routes of TM(D)Cs on Si photoelectrode.

\begin{tabular}{|c|c|c|c|}
\hline Methods & Compounds & Specific Processes & Ref. \\
\hline CVD & $\mathrm{MoS}_{2}$ & $\begin{array}{c}\mathrm{MoS}_{2}:\left(\mathrm{NH}_{4}\right)_{2} \mathrm{MoS}_{4}+\mathrm{H}_{2} \text { at } 500{ }^{\circ} \mathrm{C} \sim 950^{\circ} \mathrm{C} \\
\mathrm{MoS}_{2}: \mathrm{Mo}\left(\mathrm{MoCl}_{5}, \mathrm{MoO}_{3}\right)+\mathrm{S} \text { (Sulfur powder) from } 475^{\circ} \mathrm{C} \text { to } 730^{\circ} \mathrm{C}\end{array}$ & {$[68,74,75,81,83]$} \\
\hline Sputtering & $\mathrm{MoSe}_{2}, \mathrm{WS}_{2}$ & $\begin{array}{l}\text { MoSe }_{2} \text { : } \text { MoSe }_{2} \text { target Sputtering }\left(400^{\circ} \mathrm{C}, 50 \mathrm{~W}\right) \\
\mathrm{WS}_{2} \text { : target Sputtering }\end{array}$ & {$[84,87]$} \\
\hline Photo-electrodeposition & $\mathrm{MoS}_{2}, \mathrm{NiCoSe}$ & $\begin{array}{c}\mathrm{MoS}_{2}:\left(\mathrm{NH}_{4}\right)_{2}\left[\mathrm{MoS}_{4}\right] /\left(\mathrm{NH}_{4}\right)_{2} \mathrm{MoS}_{4}+\mathrm{NaClO}_{4} \\
\mathrm{NiCoSe}_{\mathrm{x}}: \mathrm{NiCl}+\mathrm{CoCl}+\mathrm{SeO}_{2}\end{array}$ & {$[77,82,89,93]$} \\
\hline ALD (PLD) & $\mathrm{MoS}_{2}$ & $\mathrm{MoS}_{2}: 200^{\circ} \mathrm{C} \mathrm{PLD}, \mathrm{Mo}(\mathrm{CO})_{6}+\mathrm{H}_{2} \mathrm{~S}$, annealing in $500 \sim 700^{\circ} \mathrm{C} \mathrm{H}_{2} \mathrm{~S}$ condition & {$[53,78]$} \\
\hline Hydrothermal & $\begin{array}{l}\mathrm{WS}_{2}, \mathrm{MoS}_{\mathrm{x}} \\
\mathrm{CoSe}_{\mathrm{x}}, \mathrm{ZnS}\end{array}$ & $\begin{array}{c}\mathrm{MoS}_{\mathrm{x}}:\left(\mathrm{NH}_{4}\right)_{6} \mathrm{Mo}_{7} \mathrm{O}_{24} \cdot 4 \mathrm{H}_{2} \mathrm{O}+\text { ammonium polysulfide }\left(96^{\circ} \mathrm{C}, 120 \mathrm{~h}\right) \\
\mathrm{CoSe}_{\mathrm{x}}: \mathrm{EDTA}+\mathrm{CoCl}_{2} \cdot 6 \mathrm{H}_{2} \mathrm{O}+\text { Se Powder }+\mathrm{NaOH}\left(180^{\circ} \mathrm{C}, 18 \mathrm{~h}\right) \\
\mathrm{ZnS}_{2}: 0.2 \mathrm{M} \text { thioacetamide }+\mathrm{ZnNO}_{3}\left(90^{\circ} \mathrm{C}\right)\end{array}$ & {$[91,96,97,100]$} \\
\hline Drop-casting & $\mathrm{Mo}_{3} \mathrm{~S}_{4}, \mathrm{CoTe}_{2}$ & $\begin{array}{l}\mathrm{Mo}_{3} \mathrm{~S}_{4}: \text { methylcyclopentadienyl ligands } \\
\mathrm{CoTe}_{2}: \mathrm{Co}\left(\mathrm{NO}_{3}\right)_{2} \cdot 6 \mathrm{H}_{2} \mathrm{O}+\mathrm{Na}_{2} \mathrm{TeO}_{4} \text { in methanol }\end{array}$ & {$[90,92,98]$} \\
\hline Electrodeposition & a-MoS 2 , a-CoMoS & $\begin{array}{l}\text { a-MoS } 2:\left(\mathrm{NH}_{4}\right)_{2} \mathrm{MoS}_{4}+\mathrm{NaClO}_{4} /\left(\mathrm{NH}_{4}\right)_{2} \mathrm{MoS}_{4}+\mathrm{DMF} \\
\text { a-CoMoS: } 0.25 \mathrm{mM}\left[\mathrm{Co}\left(\mathrm{MoS}_{4}\right)_{2}\right]^{2-}\end{array}$ & {$[69,94,99]$} \\
\hline SILAR & CdSe & CdSe: $\mathrm{Cd}\left(\mathrm{NO}_{3}\right)_{2}+\mathrm{NaHSe}+\mathrm{NaBH}_{4}+\mathrm{SeO}_{2}$ & [70] \\
\hline Thermal Sulfidation & $\mathrm{MoS}_{2}, \mathrm{CoS}_{2}, \mathrm{CoSe}_{2}$ & $\begin{array}{c}\mathrm{MoS}_{2}: \text { Mo Sputtering/Sulfidize }\left(250^{\circ} \mathrm{C}, \mathrm{H}_{2} \mathrm{~S} \text { gas, } 1 \mathrm{~h}\right) \\
\mathrm{CoS}_{2}: \mathrm{Co}(\mathrm{OH})_{2}+\text { Sulfur powder }\left(500^{\circ} \mathrm{C}, 1 \mathrm{~h}\right) \\
\mathrm{CoSe}_{2}: \mathrm{Co}(\mathrm{NO})_{3} \cdot 6\left(\mathrm{H}_{2} \mathrm{O}\right)+\mathrm{S} \text {, Se powder }\end{array}$ & {$[85,86,95]$} \\
\hline Thermolysis & $\mathrm{MoS}_{2}$ & $\mathrm{MoS}_{2}:\left(\mathrm{NH}_{4}\right)_{2} \mathrm{MoS}_{4}\left(573-673 \mathrm{~K}, \mathrm{~N}_{2} / \mathrm{H}_{2}\right)$ & [88] \\
\hline
\end{tabular}


Indeed, the perfect stoichiometric $\mathrm{Bi}_{2} \mathrm{Te}_{3}$ as a binary end compound is a representative example of $\operatorname{TM}(D) C$ s that should be $p$-type [105] because of the low formation energy of anti-site defects, $B i_{\mathrm{Te}}^{\prime}$ [106]. Like a number of TM(D)C materials, it is difficult to find the successful growth of intrinsic $p$-type $\mathrm{Bi}_{2} \mathrm{Te}_{3}$ in the literature because most of the system is prepared at high temperatures and $\mathrm{Te}$ vacancies are created easily. The migration energy for the Te vacancy is also quite low $\left(E_{\mathrm{Te}}=\sim 1 \mathrm{eV}\right)$, indicative of a high vapor pressure [107]. Recently, some of the authors reported that $\mathrm{Bi}_{2} \mathrm{Te}_{3}$ can be synthesized at temperatures as low as $100{ }^{\circ} \mathrm{C}\left(100-250{ }^{\circ} \mathrm{C}\right)$ through ALD chemistry and synthesis conditions. By varying the growth temperature, remarkably, Bae et al. observed the gradual defect activation from the nominal $p$-type to $n$-type in $\mathrm{Bi}_{2} \mathrm{Te}_{3}$ without any alloying, as shown in Figure 11 [13]. This result provides an insight on the understanding of doping properties by both nanostructuring (i.e., phonon engineering) and control of defect activation (i.e., electron engineering). Defect control activation with growth temperature can be adjusted to the PEC WS systems. By controlling defects and doping mechanism with temperature, we can control the charged point defect which can provide a recombination center and catalytically active sites. In conclusion, TM (D) C synthesis, which can show critical functions on the surface, is suitable for low temperature synthesis ALD process which can control defect rather than high temperature synthesis which defect control is impossible.
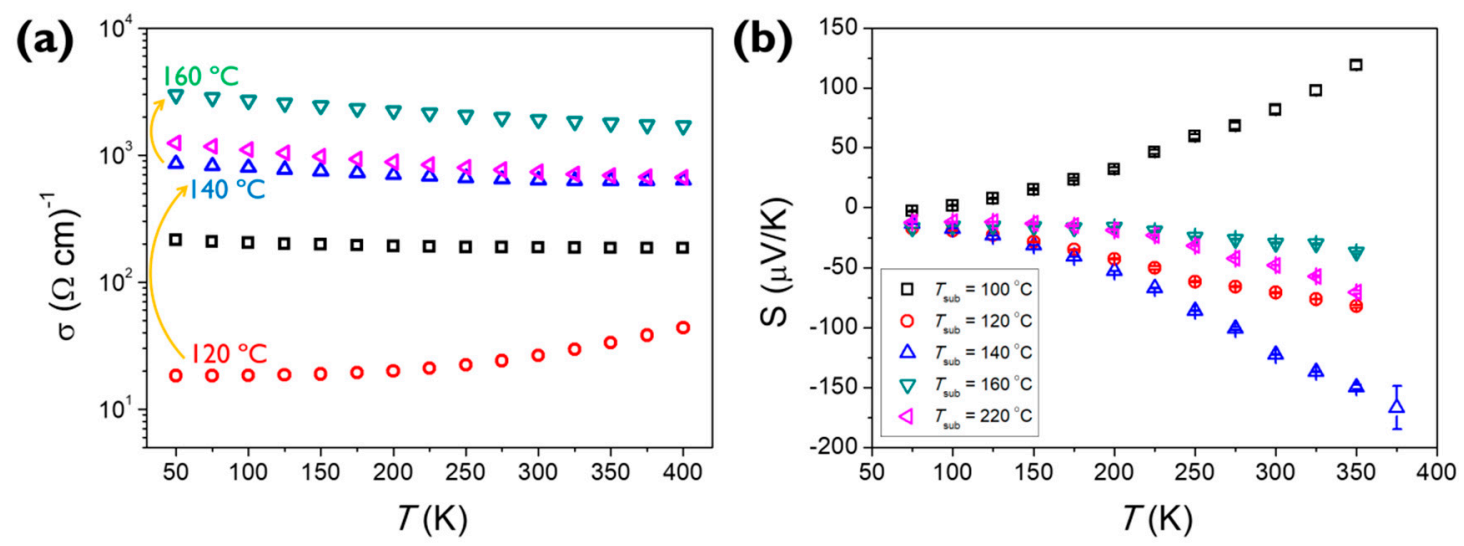

Figure 11. Electrical and thermoelectric characterization of $\mathrm{Bi}_{2} \mathrm{Te}_{3}$ thin films grown at different $T_{\text {sub }}$. (a) The electrical conductivity, $\sigma$. (b) The Seebeck coefficient, S. Adapted from reference [13].

\subsection{Growth Mechanisms of $T M(D) C$ in $A L D$}

ALD is advantageous because it provides (i) control over film thicknesses at the level of atomic layers, and (ii) the capability of conformal coating on many different substrates once the surface chemistries have been well established $[108,109]$. Considering the intrinsic limitations of Si photoelectrode, conformal surface coating with a thin layer and controlling charge transfer from $\mathrm{Si}$ to catalyst surface is highly desired. Therefore, the ALD strategy to the efficient energy transfer in PEC systems should be a powerful tool not only for coating functional materials such as metals, semiconductors, and insulators but also for incorporating dopant elements in a controlled fashion. Recently, along with the explosive interest in monolayer and few-layer TM(D)Cs, the synthesis of $\mathrm{TM}(\mathrm{D}) \mathrm{C}$ by the ALD processes has also received huge attention. Most ALD chemistries so far have been focused on amorphous and nanocrystalline materials where anisotropy in the crystalline structures was ignored. Moreover, the direct formation of crystalline $\mathrm{MX}_{2}$ by ALD is difficult and whether ALD operates well for layered materials has not yet been answered $[110,111]$. An important question was how the ALD of layered materials works if a directional component predominates over the others, or in other words, how to control anisotropic growth during ALD [76]. This would allow for a general understanding of ALD for layered materials. Figure 11 illustrates two distinctive growth modes of layered materials by ALD. Figure 11a highlights highly textured in-plane growth via van der Waals $(\mathrm{vdW})$ attachments when growing layered materials by ALD. In contrast, Figure $12 \mathrm{~b}$ represents a vertical growth mode where layer-by-layer growths along the basal plane with strong covalent bonding 
of $\mathrm{MoS}_{2}$ is common. Note that both are the result of the identical ALD chemistry where the ALD reactions contribute the crystal growth along the basal plane and the vdW secondary nucleation does not take place (see the upper row of Figure 11). However, each growth mode determines the final growth rate by which the mode operates, even though an identical chemistry is employed (see graphs of panels $a$ and $b$ ). This understanding is distinctive when compared with the conventional ALD growths. By controlling the growth mode in the form of Figure 11a, therefore, the highly textured growth of $\operatorname{TM}(\mathrm{D}) \mathrm{C}$ materials is possible, and with appropriate single-crystal substrates, the epitaxial heterojunction growth of TM(D)C layers could be realized.

(a)

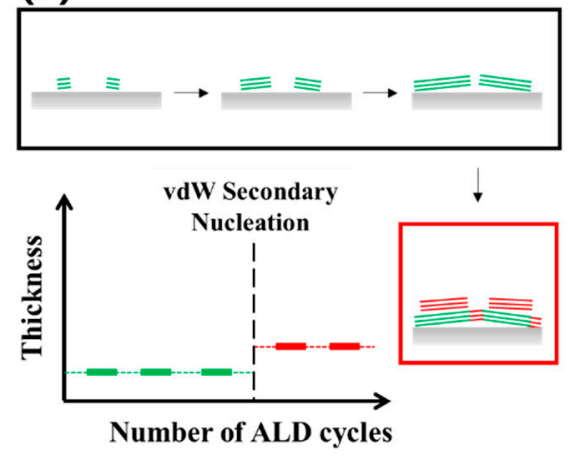

(b)

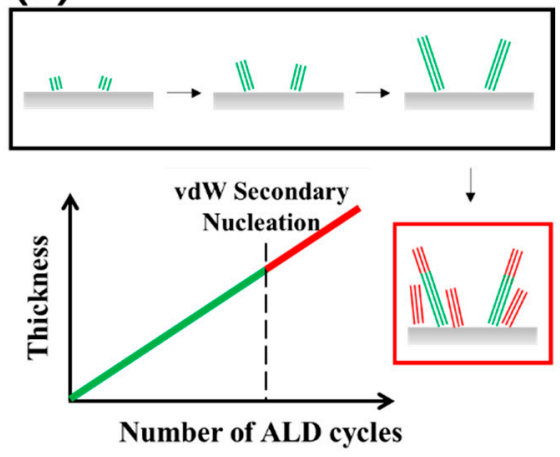

(c)

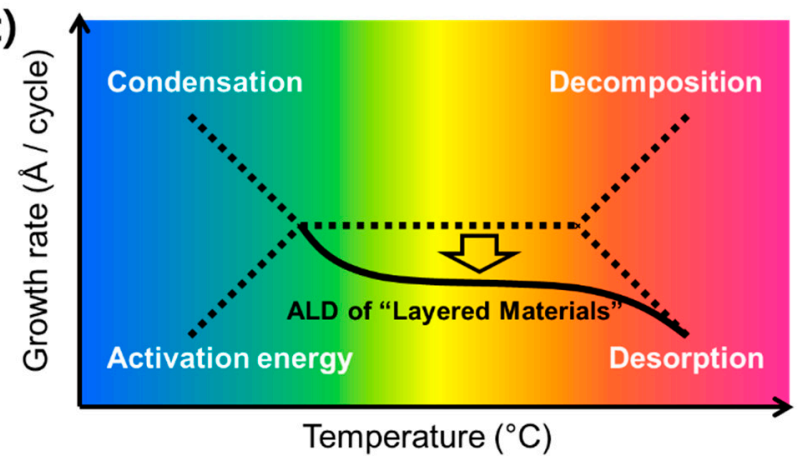

Figure 12. (a,b) Two distinctive growth modes of layered materials, such as $\mathrm{MoS}_{2}$ grown by atomic layer deposition (ALD). (c) Plot of the so-called "ALD window" with four factors affecting the nonideality of the ALD processes (i.e., condensation, decomposition, activation energy, and desorption). An incomplete reaction occurs because the activation energy for the reaction is not reached; adsorbed precursors on the surface react with the next precursor and remove the residue. However, there is not enough heat energy due to low chamber temperature so residues cannot be removed and remain as condensation; high temperature decomposes the precursor even before absorbing on the surface, and causes CVD-like deposition; the deposited compounds are desorbed because of excessive heat energy in the chamber). This plot revisits the ALD process of layered materials by adding an additional factor, i.e., strong structural anisotropy (see solid black line). Adapted from reference [76]. Copyright (2017) American Chemical Society.

\section{Measurement Tools for Understanding Operation Mechanisms}

There are various measurement tools to analyze the efficiency and characteristics of PEC WS using semiconductors. It is important not only to measure flat-band potential or impedance, but also to analyze surfaces/heterojunctions formed with the different materials. In this section, Kelvin probe force microscopy (KPFM), ultraviolet photoelectron spectroscopy (UPS) and transient absorption spectroscopy (TAS) are introduced as tools for analyzing the roles of TM(D)C co-catalysts on Si photoelectrodes. 


\subsection{Kelvin Probe Force Microscopy (KPFM)}

KPFM or Kelvin force microscopy (KFM) and spectroscopy (KPFS) are variants of atomic force microscopy (AFM) by using a Kelvin probe method and are capable of directly imaging the charge separation/transfer phenomena on the surfaces of the materials because of the nanometer scale spatial resolution and few $\mathrm{mV}$ sensitivity in the surface potential. From the vacuum level variation measurement at a material surface, KPFM is, therefore, suited to examine the band offsets (bending) of heterojunctions, especially 2D materials, as well as the mechanism of the photoinduced charge separation.

During KPFS measurement, the cantilever is approached on the sample and the mechanical vibration for the non-contact approach is stopped. The AC bias is applied between the tip and the sample to make the harmonic oscillation of the cantilever caused by an induced Coulombic force. Then, the voltage that minimizes the $\omega$ term (first-harmonic) of harmonic oscillation is measured as a contact potential difference (CPD) while sweeping the DC bias. CPD is described as follows:

$$
C P D(V)=\frac{\Phi_{\text {tip }}-\Phi_{\text {sample }}}{-q}
$$

where $\Phi_{\text {tip }}$ is the work function of the cantilever, $\Phi_{\text {sample }}$ is the work function of the sample, and $q$ is the electron charge. If we simplify the interaction between the tip and the sample as a two-parallel-plate capacitor model, the total energy $(\mathrm{U})$ can be expressed as follows,

$$
U=\frac{1}{2} C \Delta V^{2}
$$

where $C$ is the total capacitance and $V$ is the applied bias between the two plates. If we simultaneously apply alternating current (AC) bias and direct current (DC) bias $\left(V=V_{\mathrm{DC}}+V_{\mathrm{AC}} \sin (\omega t)\right)$ between the tip and the sample, the force is expressed as follows (Ref):

$$
\begin{gathered}
F=-\frac{\partial U}{\partial z}=-\frac{1}{2} \frac{\partial C}{\partial Z} V^{2}=F_{d c}+F_{\omega}+F_{2 \omega} \\
F_{d c}=-\frac{1}{2} \frac{\partial C}{\partial z}\left[\left(V_{d c}-\Delta \Phi\right)^{2}+\frac{V_{a c}^{2}}{2}\right] \\
F_{\omega}=-\frac{\partial C}{\partial z}\left[\left(V_{d c}-\Delta \Phi\right) V_{a c} \sin (\omega t)\right] \\
F_{2 \omega}=\frac{1}{4} \frac{\partial C}{\partial z}\left[\left(V_{a c}^{2} \cos (2 \omega t)\right]\right.
\end{gathered}
$$

When the $\omega$ component of the force (Equation (11)) is zero, then $V_{\mathrm{DC}}$ is equal to the work function difference between the tip and the sample. Therefore, one can measure the work function difference by sweeping the DC bias and calibration with the well-known standard sample to find the nullifying value of the first harmonic term.

It is also possible to study charge transfer and charge separation in a nanostructure via surface potential differences, $\Delta V=\left(V_{\text {sample }}-V_{\text {substrate }}\right)_{\mathrm{uv}}-\left(V_{\text {sample }}-V_{\text {substrate }}\right)_{\text {dark}}$, which are displayed by area-averaging each micrograph. Some results of investigating the characteristics of semiconductor and semiconductor/metal heterojunction used in a photoelectrode using KPFM are as follows. Yoo et al. measured the Schottky barrier height by mapping the co-catalyst-decorated oxide semiconductor junctions under ultraviolet (UV) light illumination [112]. Under UV illumination, the authors directly observed the charge separation phenomena at the Au-nanoparticle/ $\mathrm{TiO}_{2}$-nanotube interfaces. They observed that in a steady state, approximately 0.3 of an electron per Au particle of approximately $4 \mathrm{~nm}$ in diameter is effectively charged and consequently screens the surface potential of the underlying $\mathrm{TiO}_{2}$ nanotubes (see Figure 13b). Polak et al. visualized the CPD after UV light illumination and confirmed the presence of a trap state using $\mathrm{NaTaO}_{3}$, which was utilized as the photoanode [113]. 
In a recent report, the measured surface potential of the photoanode $\mathrm{BiVO}_{4}$ and the heterojunction of $\mathrm{BiVO}_{4}$ with electrodeposited $\mathrm{AgO}_{\mathrm{x}}$ and $\mathrm{NiO}_{\mathrm{x}}$ is higher than $\mathrm{BiVO}_{4} / \mathrm{AgO}_{\mathrm{x}}$ and $\mathrm{BiVO}_{4} / \mathrm{NiO}_{\mathrm{x}}$ [114].

(a)

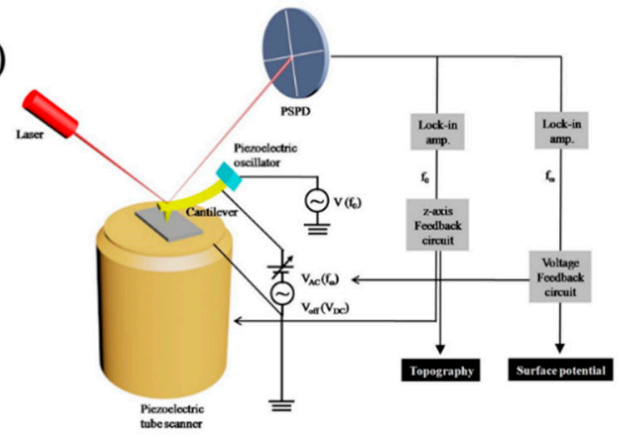

(b)

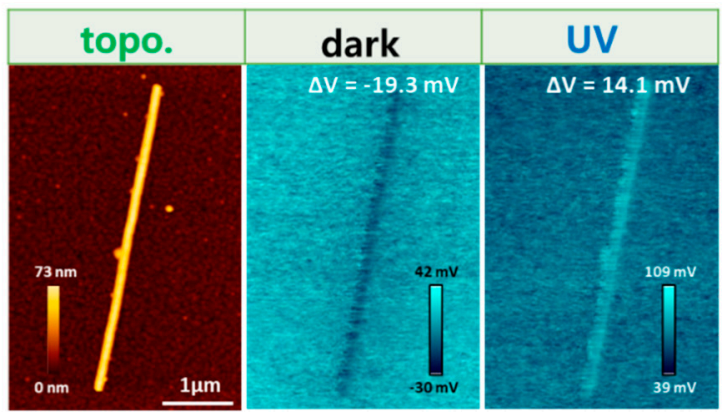

Figure 13. (a) Operation mechanism of Kelvin probe force microscopy (KPFM). (b) The representative surface potential images of an Au/TNT on a Pt substrate before and after ultraviolet (UV) illumination. Adapted from reference [112]. Copyright (2014) American Chemical Society.

Almadori el al. measured the surface potential image of the $\mathrm{WSe}_{2} / \mathrm{MoS}_{2}$ van der Waals heterojunction using KPFM, from which the band alignment at the monolayer interface was obtained. They confirmed the impact of the defects to the photocarrier generation and the diffusion of negative charges near the heterojunction as well as the OCP value [115], by the surface photovoltage (SPV) image observation. Li et al. demonstrated the more efficient charge separation of photogenerated carriers in $\mathrm{n}-\mathrm{Si} / \mathrm{MoS}_{2}$ compared to that in $p-\mathrm{Si} / \mathrm{MoS}_{2}$ by using KFM. The measured KFM results under dark and illumination condition also yielded the band alignment of $\mathrm{Si} / \mathrm{MoS}_{2}$ heterojunctions and the separation of photogenerated excitons [116]. The analysis of the surface potential with photoassisted KPFM can also provide the information regarding the composition and electronic state of the local structures and the potential difference caused by the mixed-phase under illumination on the surface of a solid. Kim et al. conducted a KPFM measurement for two samples which are $\mathrm{FeS}_{2}$ thin films grown at 350 and $400{ }^{\circ} \mathrm{C}$, respectively, to obtain the work function for each. $\mathrm{FeS}_{2}$ thin films grown at $350{ }^{\circ} \mathrm{C}$ showed multiple sharp work function peaks between 4.4 to $4.7 \mathrm{eV}$, meaning that several different phase, such as pyrrhotite phases and marcasite exist on the surface. The $400{ }^{\circ} \mathrm{C}$-grown $\mathrm{FeS}_{2}$ thin film showed a smooth work function distribution, indicating that a single pyrite phase was developed [117].

\subsection{Optical Spectroscopy}

Ultraviolet photoelectron spectroscopy (UPS): UPS has long been used to identify the band structure of semiconductors. The operation principle of UPS is analyzing the ejected photoelectron energy when the photon energy of $h v$ is irradiated on the surface. UPS normally utilizes a gas source of Helium, which has an energy of $21.21 \mathrm{eV}$ (He I) or $40.82 \mathrm{eV}$ (He II) with very narrow linewidths $(\approx 20$ $\mathrm{meV}$ ). This energy is much lower than the source of X-ray photoelectron spectroscopy (XPS) and Auger electron spectroscopy (AES). The equation to calculate the ejected electron energy is similar to the XPS equation, $E_{\mathrm{kin}}=h v-E_{\mathrm{B}}-\Phi_{\mathrm{S}}$. Due to low excitation energy in UPS, the binding energy $\left(E_{\mathrm{B}}\right)$ cannot reach the core level, but to shallow valence band or adsorbates on the surface. With these characteristics, UPS has been employed to study the surface-associated band structure and interactions of gaseous molecules with surfaces. Not only to determine the band-edge levels of semiconducting absorbers but to study even cascade electrode having multiple interfaces of thin film and catalyst layers are possible. Chi et al. utilized UPS measurement to determine the energy level alignment of CdSe, CdS, and $\mathrm{TiO}_{2} / \mathrm{CdS} / \mathrm{CdSe}$ electrodes to analyze the outperformance of $\mathrm{TiO}_{2} / \mathrm{CdS} / \mathrm{CdSe}$ electrode [118]. They confirmed the stepwise energy level of the electrode and the conduction band minimum (CBM) position shift of the materials. Fingerle et al. made a schematic model interface model of nickel oxide/water to investigate the role of nickel oxide as an OER catalyst and water adsorption surface chemistry from the results of XPS core level and UPS valence band analysis [119] Wan et al. analyzed 
the Fermi level of $\mathrm{SrNbO}_{3}$ with a $1 \mathrm{wt} \%$ of platinum powder co-catalyst with UPS analysis [120]. Liu et al. used He I source (21.22 eV) UPS to determine the ionization potential (equivalent to the valence band energy) of $\mathrm{C}_{3} \mathrm{~N}_{4}$ [121]. With the UPS analysis, important physical measures such as conduction band edge position or surface modified properties are efficiently estimated.

Transient absorption spectroscopy (TAS): in many photophysical and photochemical reactions, information regarding time-resolved carrier dynamics within nanoseconds or even picoseconds is critical. This becomes far more important for $\mathrm{Si}$ and $\mathrm{TM}(\mathrm{D}) \mathrm{C}$ heterojunction structures, and TAS is one of the most useful analytic tool to understand the charge transfer dynamics affected by the co-catalytic TM(D)C in PEC WS. TAS is well known pump-probe spectroscopy, which uses two extremely short pulses of light from a laser to excite (or pump) a molecule, and then probe it. The pulse of the pump pulse is tunable from the microsecond to the femtosecond, allowing us to excite materials of interest to a desired excited state. By varying the arrival time difference of the second pulse with respect to the first one, one can measure the entire time-dependence of the absorption changes. Nd:YAG, Ti-doped Sapphire and $\mathrm{Yb}: \mathrm{KGW}$ are popular laser sources for TAS, with controlled wavelengths for the desired sample. This tool was first applied by Furube et al. for measuring the decay time of photogenerated carriers in $\mathrm{K}_{4} \mathrm{Nb}_{6} \mathrm{O}_{17}$ photocathode thin film [122]. Moss et al. used TAS with three polymorphs of $\mathrm{TiO}_{2}$ and identified the carrier recombination dynamics with a microsecond laser [123]. Wan et al. investigated the dynamic process of the hot electron in $\mathrm{Pt} / \mathrm{SrNbO}_{3}$ with femtosecond time-resolved TAS [120].

\section{Toward Multi-Phase TM(D)C Co-Catalysts on Si}

The classic Volmer-Heyrovsky-Tafel mechanism on metal/electrolyte interfaces would explain HER activity. The hydronium ion reduction is, for example, described below:

$$
\begin{gathered}
\text { (Volmer step) } \mathrm{H}_{3} \mathrm{O}^{+}+\mathrm{e}^{-}+\mathrm{M} \rightleftharpoons \mathrm{M}-\mathrm{H}+\mathrm{H}_{2} \mathrm{O} \\
\text { (Heyrovsky step) } \mathrm{M}-\mathrm{H}+\mathrm{H}_{3} \mathrm{O}^{+}+\mathrm{e}^{-} \rightleftharpoons \mathrm{H}_{2}+\mathrm{H}_{2} \mathrm{O}+\mathrm{M} \\
\text { (Tafel step) } 2 \mathrm{M}-\mathrm{H} \rightleftharpoons \mathrm{H}_{2}+\mathrm{M}
\end{gathered}
$$

With the Tafel reaction possessing the ideal surface coverage, one can obtain the theoretical kinetic description to be an ideal Tafel slope of $\sim 30 \mathrm{mV} / \mathrm{dec}$. The ideal or dense coverage pertains to the moderate binding energy on metal surfaces, producing the so-called the volcano plot. However, the presence of hydrogen bubbles on (co-)catalysts also hinders the diffusion of $\mathrm{H}^{+} / \mathrm{H}_{3} \mathrm{O}^{+}$ions and the subsequent recombination by electrons. This may imply that dense layers of catalysts or co-catalysts are not necessary considering the (sub)micrometer-sized hydrogen gas bubbles at the stage of nucleation. Note that a very thin layer of electrolytes would exist between the bubble and the underlying catalyst, but the interdiffusion of electrolytes is also limited through it. Therefore, the multi-/mixed-phase co-catalysts could be ideal candidates of $\mathrm{Si} / \mathrm{TM}(\mathrm{D}) \mathrm{C}$ for efficient HER, although they do not offer dense, and the best, catalytic surfaces in that (1) it can protect the whole area of the absorber surfaces, and (2) it can alter or optimize the surface energetics by laterally re-arranging the material properties.

Consequently, Figure 14 shows a research direction in the field toward employing multi-phase TM(D)C co-catalysts on Si for efficient PEC HER. Modifying the semiconductor surface with a metal of high work functions $\left(\Phi_{\mathrm{w}}\right)$ are ideal (Figure 14a). However, noble metals are not wetting directly to Si and a thin layer of adhesion promoter is required. This paradoxically involves a catalytically inactive interlayer on Si photocathodes (Figure 14b). Employing multi-phase TM(D)C co-catalysts on Si would be beneficial in maximizing PEC performance (Figure 14c). In case of metal oxide photocatalysts (for example, $\mathrm{TiO}_{2}$ ), there are several reports that the mixture phase helps charge transfer, resulting in effective charge separation and suppressing the charge recombination [124]. However, whether the same mechanism is applied to TMD materials or not in terms of composition and phase structure needs further studies. Interestingly, much research is underway on phase engineering of TMD materials, 
and papers regarding the facilitated charge transfer between heterophases within TMD homojunction have been published which are drawing attention. Kappera et al. demonstrated the locally induced $1 \mathrm{~T} \mathrm{MoS} 2$ phase on $2 \mathrm{H}$ phase in plane, showing improved sharp atomic interface between two phases which enhance the 2D electronic device performance [125]. Cho et al. achieved a stable heterophase homojunction in $\mathrm{MoTe}_{2}$ by laser-derived phase patterning [126]. The homojunction heterophase exhibits ohmic contact in $\mathrm{MoTe}_{2}$ transistors, implying that the charge transfer between the interphase in the TMD materials can be facilitated. The result was confirmed by measuring the Arrhenius plot showing the conductance of the heterophase homojunction channel. Ho et al. successfully grew a mixed-phase and continuous $1 \mathrm{~T}$ and $2 \mathrm{H}$ homojunction $\mathrm{MoS}_{2}$ catalyst film on $\mathrm{Si}$, via ALD at low temperature $\left(250^{\circ} \mathrm{C}\right)$ [76]. The conduction band energy relative to vacuum level of $2 \mathrm{H}$ phase of $\mathrm{MoS}_{2}$ and the work function of $1 \mathrm{~T}$ phase are similar $(\sim 4.2 \mathrm{eV})$ [79] which secures band alignment, and in view of this, Joe et al. explained that mixed-phase $\mathrm{MoS}_{2}$ / silicon junction photocathode showed effective photocatalytic performance through the efficient charge transfer within the $\mathrm{MoS}_{2}$ homojunction heterophase [53]. The ALD-grown $\mathrm{MoS}_{2}$ layer functions as a monolithic structure for effective charge transport within the film and was shown that the effective barrier height reached up to $0.8 \mathrm{eV}$ with the optimized $\mathrm{MoS}_{2}$ thickness. The $p$-Si/MoS 2 heterojunction photocathode was confirmed to show effective PEC operation characteristics due to the inhomogeneous barrier heights induced from the embedded 1T-phase within the film. This structural characteristic was introduced to boosts the electron transfer pathway effectively compared to a conventional MIS electrode via the embedded and metallic 1T phase, which increases the overall intrinsic property of the film.
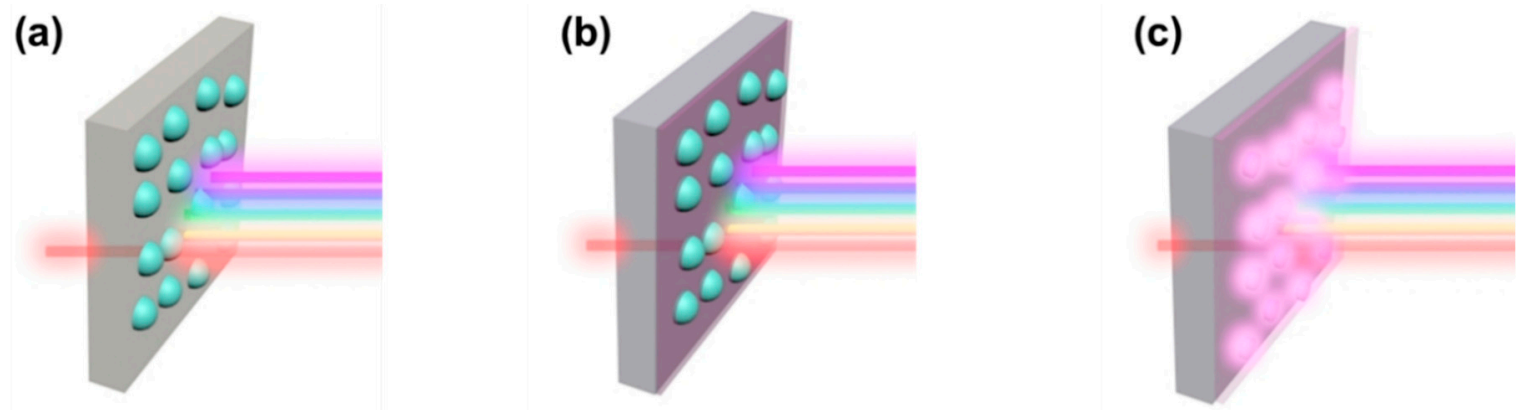

Figure 14. Developments of silicon photocathode with (a) co-catalysts, (b) adhesive junctions/ co-catalysts, and (c) overlayers of multi-/mixed-phase chalcogenides.

As shown Figure 15a, Chen et al. showed that a CoMoS $x$ composite display better electron accepting properties and HER catalytic activity compared with a-MoS $\mathrm{S}_{\mathrm{x}}$, proving that a bimetallic sulfide catalyst is highly efficient in extracting photogenerated electrons in reducing protons to hydrogen gas. The Si/a-CoMoS $S_{x}$ hybrid photocathode showed onset potential of $0.25 \mathrm{~V}$ vs. RHE and photocurrent $I_{\mathrm{sc}}$ of $17.5 \mathrm{~mA} \mathrm{~cm}^{-2}$ at $0 \mathrm{~V}$ vs. RHE in $\mathrm{pH}$ of 4.25 . Zhang et al. enhanced the PEC performance significantly by decorating $\mathrm{NiCoSe}_{\mathrm{x}}$ on $p$-Si nanopillars (Figure 15b). They proposed the possible reasons: (i) the effective light trapping capability of the nanopillars and the good optical transparency of $\mathrm{NiCoSe}_{x}$; (ii) the full coverage of the electrochemically active $\mathrm{NiCoSe}_{\mathrm{x}}$ material onto the pillars. In our previous work, Joe et al. demonstrated the energetically favorable path of photogenerated electrons from $p$-Si to electrolyte through the mixed-phase $\mathrm{MoS}_{2}$ catalyst layer and obtained the maximum $0.29 \mathrm{~V}$ onset voltage with the photocurrent density $J_{\mathrm{sc}}$ of $26.7 \mathrm{mAcm}^{-2}$ at $0 \mathrm{~V}$ vs. RHE (Figure 15c). In addition to the examples listed above, studies demonstrating that mixed phases, along with multiphase, are more effective for charge separation and transfer and improve PEC performance continue to emerge. 
(a)

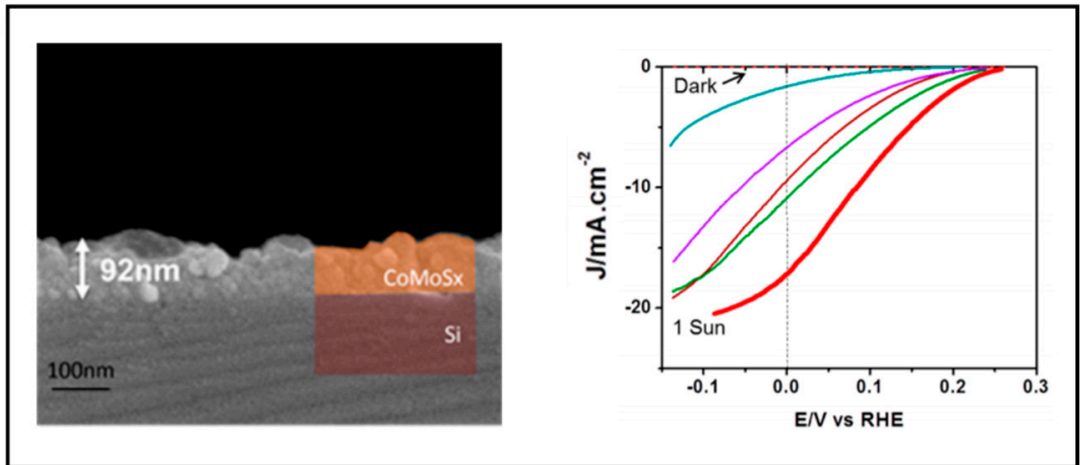

(b)
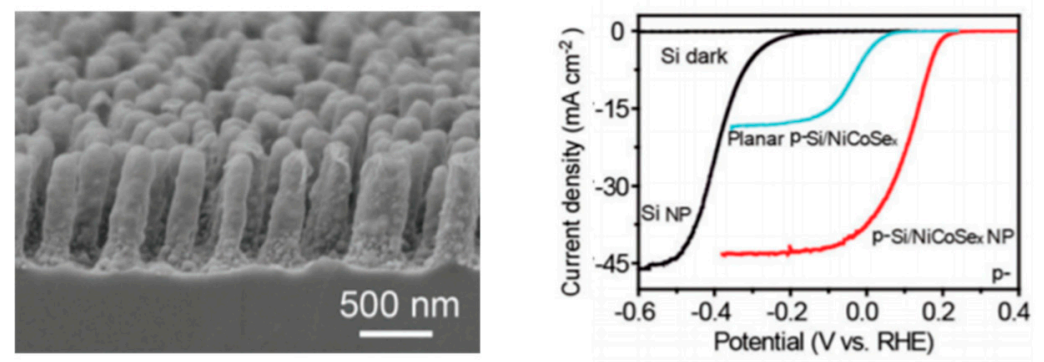

(c)
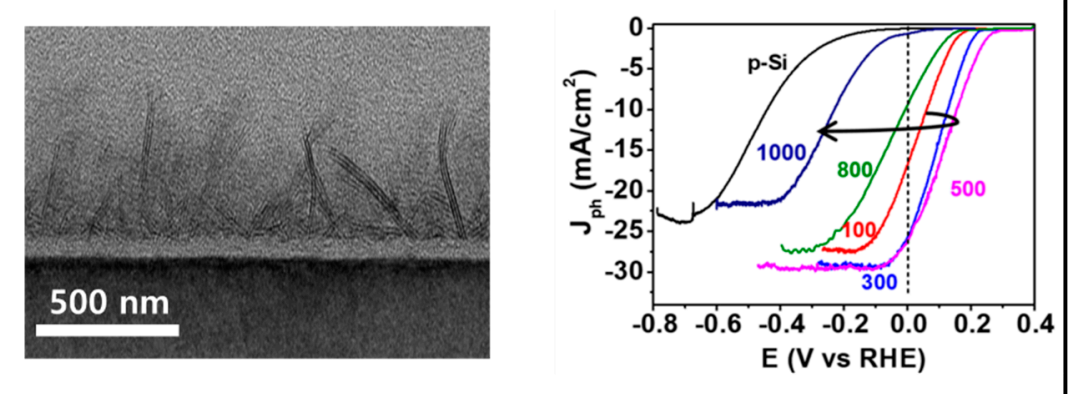

Figure 15. Experimental reports on multi-/mixed-phase $\mathrm{TM}(\mathrm{D}) \mathrm{C}$ co-catalysts on silicon. (a) Cross-section view taken by scanning electron microscope (SEM) (left) and characterizations of the $\mathrm{Si} / \mathrm{a}-\mathrm{CoMoS}_{\mathrm{x}}$ electrode with a catalyst loading (right), the PEC current density $(\mathrm{J})$ verses voltage $(\mathrm{V})$ plots. Adapted from reference [94]. Copyright (2015) American Chemical Society. (b) SEM image of $p$-Si/NiCoSe $e_{x}$ nanoparticle (NP) array-nanopillars (left) and the corresponding PEC current density verses potential plots (right). Adapted from reference. [93] with permission from The Royal Society of Chemistry. (c) Cross-section transmission electron microscope (TEM) image of Mixed-phase (1T and 2H) $\mathrm{MoS}_{2}$ on $p$-Si photocathode(left) and the corresponding J-V characteristics with different thickness of $\mathrm{MoS}_{2}$ layer(right) the number of $\mathrm{ALD}$ cycle for $\mathrm{MoS}_{2}$ deposition is denoted in different color. Adapted from reference [53].

To drive PEC WS effectively, three steps must be coherently operated as follows: (I) maximal photon absorption in the semiconductor; (II) exciton separation and the subsequent generation of mobile charges by minimal recombination; and (III) charge collection at opposite electrodes via good junction characteristics. The key recombination factors that prevent effective PEC WS are described in Figure 16. (1) $R_{\text {therm }}$ : photogenerated charge carriers that have excess energy due to absorb more solar energy than its band gap lose energy by thermalization. (2) $R_{\mathrm{scr}}$ : different concentration of charge form depletion region at the interface. The flowing charge is recombined until it is at equilibrium. (3) $R_{\text {quasi }}$ : carriers passing the space charge region passing through the quasi-neutral region. If diffusion length of the carrier is shorter than can reach the back metal, recombination occurs at the quasi-neutral region. (4) $R_{\text {back: }}$ recombination caused by ohmic contact which is formed between absorber and back contact metal. (5) $R_{\text {surf }}$ lattice imperfection at the surface form energy state which called surface state. This 
energy state can be recombination center at the surface. (6) $R_{\text {cat }}$ : the charge carrier travel through the catalyst layer can be recombined due to the delayed charge transfer process. (7) $R_{\mathrm{HL}}$ : Voltage drop caused by the Helmholtz layer which generated when electrodes immersed in the electrolyte, typical voltage drop of HL is known as 0.1 to $0.5 \mathrm{~V}$. $R_{\text {therm }}, R_{\text {back }}$ and $R_{\text {quasi }}$ are intrinsic properties of bulk semiconductor ( $\mathrm{Si}$ ) which cannot control with catalyst, while the $R_{\text {surf }}$ and $R_{\text {cat }}$ have room to be minimized via physical or chemically induced modification using the co-catalyst. Moreover, the overall performance of a PEC WS cell is determined by the voltage drop across the depletion region in contact with $\mathrm{TM}(\mathrm{D}) \mathrm{C}$ and / or within $\mathrm{TM}(\mathrm{D}) \mathrm{C}$. How the separated and mobile charges are transferred effectively with minimum number of recombination is of paramount importance. Recent studies also report that multi-phase $\mathrm{TM}(\mathrm{D}) \mathrm{C}$ layers exhibit superior properties for HER although the exact origins were not clarified to date.

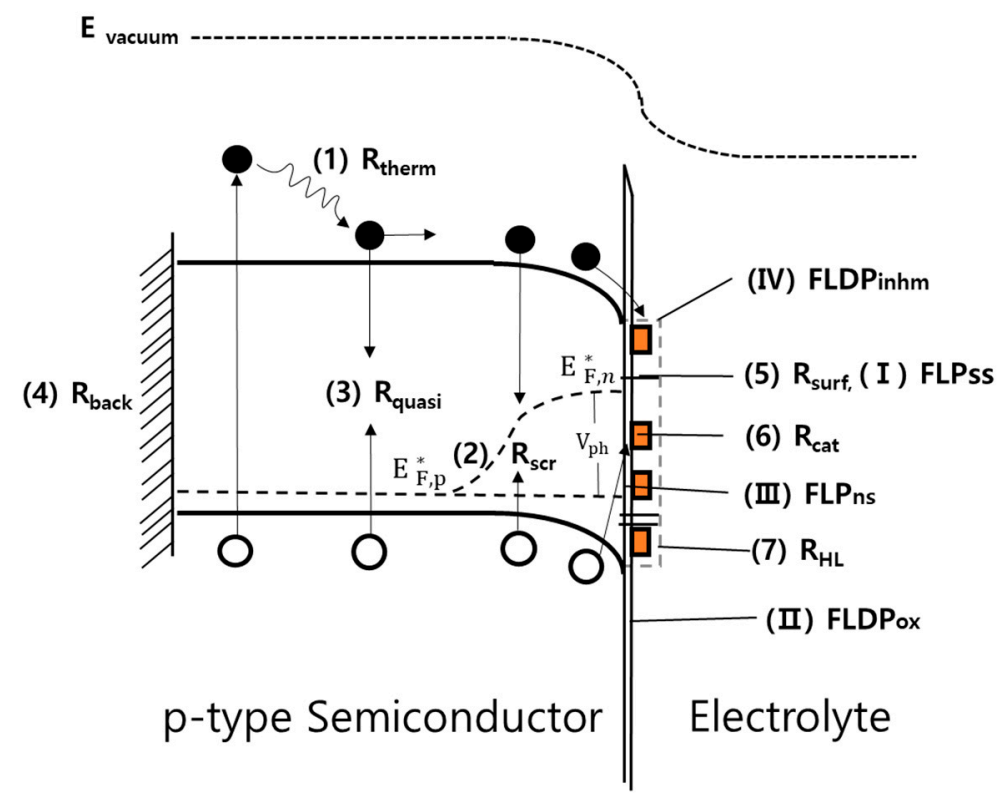

Figure 16. Basic recombination factors in PEC cells under illumination and the related effects. (1) $R_{\text {thermo }}$ is the thermalization loss of the excited electron, (2) $R_{\mathrm{scr}}$ is the recombination of the space charge region (SCR) (depletion layer) at the surface, (3) $R_{\text {quasi }}$ is the recombination at the quasi-neutral region of the semiconductor, (4) $R_{\text {back }}$ is the back Ohmic contact recombination, (5) $R_{\text {surf }}$ is the surface recombination induced from the surface states of $\mathrm{Si}$. (6) $R_{\text {cat }}$ is the recombination occur within the $\mathrm{MoS}_{2}$ film. (7) $R_{\mathrm{HL}}$ is Helmholtz layer recombination in the electrolyte. (I) FLP $P_{\mathrm{ss}}$ is the Fermi-level pinning induced from the surface states, (II) $F L D P_{\text {ox }}$ is the Fermi-level depinning due to the oxide (typically native oxide), (III) $F L P_{\mathrm{ns}}$ is the Fermi-level pinning induced from the nano Schottky junctions, (IV) $F L D P_{\text {inhm }}$ is the Fermi-level depinning results from the inhomogeneous Schottky junctions.

Here, we envision that employing continuous and multi-/mixed-phased metal chalcogenides on Si would be an ideal co-catalytic system in the application of PEC WS. We begin the discussion by highlighting our previous investigation on mixed-phase (1T and $2 \mathrm{H}) \mathrm{MoS}_{2}$ on Si. The resulting metal and semiconducting homo-junctions have negligible barrier along the catalytic overlayers. Note that hetero-junctions of TM(D)C could also have similar barrier-lowering effects by band structure hybridization at the interfaces [127]. Therefore, it is important to understand how the deposited $\mathrm{TM}(\mathrm{D}) \mathrm{C}$ material (here, $\mathrm{MoS}_{2}$ ) on Si surface affects the charge recombination. In the literature $[53,74,81]$, it was argued that depending on the thickness of the $\mathrm{MoS}_{2}$ catalyst layer, the Fermi-level pinning ( $F L P_{\mathrm{ss}}$ ) tends to be gradually relieved, possibly resulting in suppression of the $R_{\text {surf }}$. The reduced $R_{\text {surf }}$ leads to increasing the $V_{\mathrm{ph}}$, results in reducing the $R_{\mathrm{scr}}$ and the $R_{\text {quasi }}$. Moreover, when using ALD method which enables one continuous and conformal coating, the layer-dependent properties can be better observed. This differs from using metals that are deposited in the form of an island. Indeed, 
Thorne et al. studied that in the PEC WS of hematite $\mathrm{Fe}_{2} \mathrm{O}_{3}$, the overlayer of $\mathrm{NiFeO}_{\mathrm{x}}$, known as a co-catalyst led the slow surface hole transfer. However, it made the recombination rate slowed more at the interfaces, resulting in better water oxidation performance by intensity-modulated photocurrent spectroscopy [35]. Such a study implies that even in the co-catalytic systems, the pin-hole free surface overlayers should play a critical role in the efficient PEC WS.

Another consideration for the enhancement of PEC performance is $R_{\text {cat }}$ derived from the film characteristics. Based on the examples demonstrated in Figure 15, we believe that in our previous paper, a number of secured electron pathways through $1 \mathrm{~T}-\mathrm{MoS}_{2}$ to $2 \mathrm{H}-\mathrm{MoS}_{2}$ provide facilitate charge transfer within the catalyst film. We speculate that this might result in suppressing the recombination within the film and thus contributes to an improvement in the PEC performance. The $\mathrm{MoS}_{2}$ films with physical inhomogeneities in nanoscale dimensions smaller than the depletion width due to the coexistence of $1 \mathrm{~T}$ and $2 \mathrm{H}$ phase form inhomogeneous junctions with the $\mathrm{Si}$, accordingly.

What makes the continuous multi-/mixed-phased metal chalcogenides different is that the charge transfers take place at the whole interface areas. The inclusion of metallic (or degenerated) phases in the multi-/mixed-phased chalcogenides could form a nano-Schottky junction with Si. Thus, Fermi-level pinning $\left(F L P_{\mathrm{nS}}\right)$ is expected by nanoscale junctions as a result of so-called 'environmental Fermi-level pinning' at around the Schottky junction interfaces [128]. Note also that there exists Fermi-level depinning $\left(F L D P_{\text {ox }}\right)$ by the presence of oxide interfaces, e.g., $\mathrm{SiO}_{\mathrm{x}}$ between the metal and $\mathrm{Si}$ [129]. We also suspect that the presence of the continuously mixed phases would lead to ideal band edge pinning, indicative of facilitated charge transfer in the catalyst layer [53], reducing $R_{\text {cat }}$. Moreover, the catalysts with a lateral dimension less than the depletion width and with different work function values form inhomogeneous junctions to the absorber. These mechanisms were suspected to be offset from each other in the enhancement of $V_{\mathrm{ph}}$. The association of the physical inhomogeneous junction properties with $V_{\text {ph }}$ can be explained by the pinch-off effects, indicative of Fermi-level depinning $\left(F L D P_{\text {inhm }}\right)$ [130]. Together with stable interfaces by ALD and the multi-/mixed-phase overlayers, the ALD-grown TM(D)C/Si photocathodes should be capable of regulating the overall energy barriers and impedances of the total junctions and are expected for long-term operation in PEC WS.

\section{Conclusions and Outlook}

In summary, we have looked at the basic principles and the recent progress of Si-based photoelectrodes with $\mathrm{TM}(\mathrm{D}) \mathrm{C}$ co-catalysts as Earth-abundant candidates. Investigation of photoelectrodes using $\mathrm{Si}$ as one of the low band gap semiconductors and the mechanisms was also summarized with an emphasis on the exact role and the nature of catalysts. So far, TM(D)C materials are highly competitive Earth-abundant and inexpensive alternatives to noble metals due to the high durability in acid solution with catalytic activities. We provide an almost complete literature survey on both layered TMDC and non-layered TMC co-catalysts on Si photoelectrodes and different measurement tools for analyzing the effects of the TM (D) C catalyst on Si have been described. Various synthesis methods of TMD Catalysts and the corresponding performances were classified accordingly. Diverse approaches to the improved PEC performance and the proposed synergetic functions of co-catalysts on the underlying Si are reviewed. Among the various methods of depositing the catalyst, we focus on atomic layer deposition (ALD) which is prized for its conformal film deposition. Further on, the growth mechanism of TM(D)C material using ALD and its implication of low-temperature growth on defect chemistry are featured. We highlighted the multi-/mixed-phase TM(D)C overlayers on Si and the operation principles, and provided challenges and directions regarding future research for achieving the theoretical PEC performance of Si-based photoelectrodes. To support this, the band bending of the mixed-phase TM(D)C on Si and the related recombination mechanisms were discussed, which could provide a guideline for an efficient photoelectrode design to improve PEC performance. Despite the significant progress, the stable operation of photoelectrodes continues to be challenging which requires further improvement in optimizing the synthesis method as well as the overall system. 
Author Contributions: Conceptualization, C.B. and H.S.; Methodology, J.J. and H.Y.; Writing-Original Draft Preparation, C.B., J.J. and H.Y.; Writing-Review and Editing, C.B. and H.S.; Supervision, C.B. and H.S.

Funding: The authors acknowledge the grants by the National Research Foundation of Korea (NRF-2018R1D 1A1B07051059, NRF-2016M3D1A1027664, NRF-2018M3C1B7020716 and NRF-2018K1A3A1A32055268).

Conflicts of Interest: The authors declare no conflict of interest.

\section{References}

1. Walter, M.G.; Warren, E.L.; McKone, J.R.; Boettcher, S.W.; Mi, Q.; Santori, E.A.; Lewis, N.S. Solar Water Splitting Cells. Chem. Rev. 2010, 110, 6446-6473. [CrossRef]

2. Bocarsly, A.B.; Bookbinder, D.C.; Dominey, R.N.; Lewis, N.S.; Wrighton, M.S. Photoreduction at Illuminated p-Type Semiconducting Silicon Photoelectrodes. Evidence for Fermi Level Pinning. J. Am. Chem. Soc. 1980, 102, 3683-3688. [CrossRef]

3. Chu, S.; Li, W.; Yan, Y.; Hamann, T.; Shih, I.; Wang, D.; Zetian, M. Roadmap on solar water splitting: Current status and future prospects. Nano Futures 2017, 1, 022001. [CrossRef]

4. Kulkarni, A.; Siahrostami, S.; Patel, A.; Nørskov, J.K. Understanding Catalytic Activity Trends in the Oxygen Reduction Reaction. Chem. Rev. 2018, 118, 2302-2312. [CrossRef]

5. Thorne, J.E.; Li, S.; Du, C.; Qin, G.; Wang, D. Energetics at the Surface of Photoelectrodes and Its Influence on the Photoelectrochemical Properties. J. Phys. Chem. Lett. 2015, 6, 4083-4088. [CrossRef]

6. Zhong, D.K.; Choi, S.; Gamelin, D.R. Near-Complete Suppression of Surface Recombination in Solar Photoelectrolysis by Co-Pi Catalyst-Modified W: BiVO 4 . J. Am. Chem. Soc. 2011, 133, 18370-18377. [CrossRef]

7. Hu, S.; Xiang, C.; Haussener, S.; Berger, D.A.; Lewis, N.S. An analysis of the optimal band gaps of light absorbers in integrated tandem photoelectrochemical water-splitting systems. Energy. Environ. Sci. 2013, 6, 2984-2993. [CrossRef]

8. Abdi, F.F.; Han, L.; Smets, A.H.M.; Zeman, M.; Dam, B.; Van De Krol, R. Efficient solar water splitting by enhanced charge separation in a bismuth vanadate-silicon tandem photoelectrode. Nat. Commun. 2013, 4, 2195:1-2195:7. [CrossRef]

9. Urbain, F.; Wilken, K.; Smirnov, V.; Astakhov, O.; Lambertz, A.; Becker, J.P.; Rau, Y.; Ziegler, J.; Kaiser, B.; Jaegermann, W.; et al. Development of Thin Film Amorphous Silicon Tandem Junction Based Photocathodes Providing High Open-Circuit Voltages for Hydrogen Production. Int. J. Photoenergy 2014, 249317:1-249317:10. [CrossRef]

10. Benchamekh, R.; Nesoklon, M.; Jancu, J.-M.; Voisin, P. Semiconductor Modeling Techniques, 1st ed.; Springer: Berlin/Heidelberg, Germany, 2012; ISBN 978-3-642-43467-9.

11. Wang, S.; Tian, H.; Ren, C.; Yu, J.; Sun, M. Electronic and optical properties of heterostructures based on transition metal dichalcogenides and graphene-like zinc oxide. Sci. Rep. 2018, 8, 12009. [CrossRef]

12. Pfluger, E.; Savan, A. Modern Solid Lubricants, Especially Based on $\mathrm{MoS}_{2}$. Vak. Forsch. Prax. 1999, 11, 236-240. [CrossRef]

13. Bae, C.; Böhnert, T.; Gooth, J.; Lim, S.; Lee, S.; Kim, H.; Heimann, S.; Schulz, S.; Shin, H.; Nielsch, K. Thermopower Engineering of $\mathrm{Bi}_{2} \mathrm{Te}_{3}$ without Alloying: The interplay between nanostructuring and defect activation. Semicond. Sci. Technol. 2014, 29, 064003. [CrossRef]

14. Yang, E.; Ji, H.; Jung, Y. Two-Dimensional Transition Metal Dichalcogenide Monolayers as Promising Sodium Ion Battery Anodes. J. Phys. Chem. C 2015, 119, 26374-26380. [CrossRef]

15. Gu, X.; Cui, W.; Li, H.; Wu, Z.; Zeng, Z.; Lee, S.-T.; Zhang, H.; Sun, B. A Solution-Processed Hole Extraction Layer Made from Ultrathin $\mathrm{MoS}_{2}$ Nanosheets for Efficient Organic Solar Cells. Adv. Energy. Mater. 2013, 3, 1262-1268. [CrossRef]

16. Chhowalla, M.; Shin, H.S.; Eda, G.; Li, L.J.; Loh, K.P.; Zhang, H. The chemistry of two-dimensional layered transition metal dichalcogenide nanosheets. Nat. Chem. 2013, 5, 263-275. [CrossRef]

17. Guio, C.G.M.; Stern, L.A.; Hu, X. Nanostructured hydrotreating catalysts for electrochemical hydrogen evolution. Chem. Soc. Rev. 2014, 43, 6555-6569. [CrossRef]

18. Van de Krol, R. Principles of Photoelectrochemical Cells, 1st ed.; Springer: Boston, MA, USA, 2011; ISSN 978-1-4614-1380-6.

19. Rasmussen, A.F.; Thygesen, S.K. Computational 2D Materials Database: Electronic Structure of Transition-Metal Dichalcogenides and Oxides. J. Phys. Chem. C 2015, 119, 13169-13183. [CrossRef] 
20. Lu, Q.; Yu, Y.; Ma, Q.; Chen, B.; Zhang, H. 2D Transition-Metal-Dichalcogenide-Nanosheet-Based Composites for Photocatalytic and Electrocatalytic Hydrogen Evolution Reactions. Adv. Mater. 2016, 28, 1917-1933. [CrossRef]

21. Galicia-Hernandez, J.M.; Sanchez-Castillo, A.; Garza, L.M.; Cocoletzi, H.G. Two-dimensional cadmium selenide electronic and optical properties: First principles studies. Bull. Mater. Sci. 2017, 40, 1111-1119. [CrossRef]

22. Tamirat, A.G.; Rick, J.; Dubale, A.A.; Sub, W.N.; Hwang, B.J. Using hematite for photoelectrochemical water splitting: A review of current progress and challenges. Nanoscale Horiz. 2016, 1, 243-267. [CrossRef]

23. Mak, F.; Lee, C.; Hone, J.; Shan, J.; Heinz, F. Atomically Thin $\mathrm{MoS}_{2}$ : A New Direct Gap Semiconductor. Phys. Rev. Lett. 2010, 105, 136805:1-136805:4. [CrossRef]

24. Simon, T.; Bouchonville, N.; Berr, M.; Vaneski, A.; Adrovic, A.; Volbers, D.; Wyrwich, R.; Doblinger, M.; Susha, A.; Rogach, A.; et al. Redox shuttle mechanism enhances photocatalytic $\mathrm{H}_{2}$ generation on Ni-decorated CdS nanorods. Nat. Mater. 2014, 13, 1013-1018. [CrossRef]

25. Wiensch, J.D.; John, J.; Velazquez, J.M.; Torelli, D.A.; Pieterick, A.P.; McDowell, M.T.; Sun, K.; Zhao, X.; Brunschwig, B.S.; Lewis, N.S. Comparative Study in Acidic and Alkaline Media of the Effects of $\mathrm{pH}$ and Crystallinity on the Hydrogen-Evolution Reaction on $\mathrm{MoS}_{2}$ and MoSe 2 . ACS Energy Lett. 2017, 2, 2234-2238. [CrossRef]

26. Memming, R. Semiconductor Electrochemistry, 2nd ed.; Wiley: New York, NY, USA, 2000; ISBN 978-3-527-31281-8.

27. Lewis, N.S. A Quantitative Investigation of the Open-Circuit Photovoltage at the Semiconductor/Liquid Interface. J. Electrochem. Soc. 1984, 131, 2496-2503. [CrossRef]

28. Baglio, J.A.; Calabrese, G.S.; Harrion, D.J.; Kamieniecki, E.; Ricco, A.J.; Wrighton, M.S.; Zoski, G.D. Electrochemical characterization of p-type semiconducting tungsten disulfide photocathodes: Efficient photoreduction processes at semiconductor/liquid electrolyte interfaces. J. Am. Chem. Soc. 1983, 105, 2246-2256. [CrossRef]

29. Markovic, N.M.; Grgur, B.N.; Ross, R.N. Temperature-Dependent Hydrogen Electrochemistry on Platinum Low-Index Single-Crystal Surfaces in Acid Solutions. J. Phys. Chem. B 1997, 101, 5405-5413. [CrossRef]

30. Yang, J.; Wang, D.; Han, H.; Li, C. Roles of Cocatalysts in Photocatalysis and Photoelectrocatalysis. Acc. Chem. Res. 2013, 46, 1900-1909. [CrossRef]

31. Reichman, J. The current-voltage characteristic of semiconductor-electrolyte junction photovoltaic cells. J. Appl. Phys. Lett. 1980, 36, 574-576. [CrossRef]

32. Gartner, W.W. Depletion-Layer photoeffects in Semiconductors. Phys. Rev. 1959, 116, 84-87. [CrossRef]

33. Peng, K.Q.; Wang, X.; Wu, X.L.; Lee, S.T. Platinum Nanoparticle Decorated Silicon Nanowires for Efficient Solar Energy Conversion. Nano Lett. 2009, 9, 3704-3709. [CrossRef]

34. Bao, N.Z.; Shen, L.M.; Takata, T.; Domen, K. Self-Templated Synthesis of Nanoporous CdS nanostructures for Highly Efficient Photocatalytic Hydrogen Production under Visible Light. Chem. Mater. 2008, 20, 110-117. [CrossRef]

35. Thorne, J.E.; Jang, J.W.; Liu, E.Y.; Wang, D. Understanding the origin of photoelectrode performance enhancement by probing surface kinetics. Chem. Sci. 2016, 7, 3347-3354. [CrossRef]

36. Upadhyay, R.K.; Soinb, N.; Roy, S.S. Role of graphene/metal oxide composites as photocatalysts, adsorbents and disinfectants in water treatment: A review. RSC Adv. 2014, 4, 3823-3851. [CrossRef]

37. Li, H.; Hu, H.; Bao, C.; Guo, F.; Zhang, X.; Liu, X.; Hua, J.; Tan, J.; Wang, A.; Zhou, H.; et al. Forming heterojuction: An effective strategy to enhance the photocatalytic efficiency of a new metal-free organic photocatalyst for water splitting. Sci. Rep. 2016, 6, 29327. [CrossRef] [PubMed]

38. Sivula, K.; Van De Krol, R. Semiconducting materials for photoelectrochemical energy conversion. Nat. Rev. Mater. 2016, 1, 15010. [CrossRef]

39. White, J.R.; Fan, F.R.F.; Bard, A. Semiconductor Electrodes LVI. Principles of Multijunction Electrodes and Photoelectrosynthesis at Texas Instruments'p/n-Si Solar Arrays. J. Electrochem. Soc. 1985, 132, 544-550. [CrossRef]

40. Delahoy, A.E.; Gau, S.C.; Murphy, O.J.; Kapur, M.; JO’M, B. A one-unit photovoltaic electrolysis system based on a triple stack of amorphous silicon (pin) cells. Int. J. Hydrog. Energy 1985, 10, 113-116. [CrossRef]

41. Kronik, L.; Shapira, Y. Surface photovoltage phenomena: Theory, experiment, and applications. Surf. Sci. Rep. 1999, 37, 1-206. [CrossRef] 
42. Han, L.; Digdaya, I.A.; Buijs, T.W.; Abdi, F.F.; Huang, Z.; Liu, R.; Dam, B.; Zeman, M.; Smith, W.A.; Smets, A.H. Gradient dopant profiling and spectral utilization of monolithic thin-film silicon photoelectrochemical tandem devices for solar water splitting. J. Mater. Chem. A 2015, 3, 4155-4162. [CrossRef]

43. Sabba, D.; Kumar, M.H.; Wong, L.H.; Barber, J.; Grätzel, M.; Mathews, N. Perovskite-Hematite Tandem Cells for Efficient Overall Solar Driven Water Splitting. Nano Lett. 2015, 15, 3833-3839.

44. Li, F.; Fan, K.; Xu, B.; Gabrielsson, E.; Daniel, Q.; Li, L.; Sun, L. Organic Dye-Sensitized Tandem Photoelectrochemical Cell for Light Driven Total Water Splitting. J. Am. Chem. Soc. 2015, 137, 9153-9159. [CrossRef] [PubMed]

45. Chen, Z.; Dinh, H.N.; Miller, E. Photoelectrochemical Water Splitting standards, Experimental Methods, and Protocol, 1st ed.; Springer: New York, NY, USA, 2013; pp. 63-103.

46. Dos Santos, W.S.; Rodriguez, M.; Afonso, A.S.; Mesquita, J.P.; Nascimento, L.L.; Patrocínio, A.O.T.; Silva, A.C.; Oliveira, L.C.A.; Fabris, J.D.; Pereira, M.C. A hole inversion layer at the $\mathrm{BiVO}_{4} / \mathrm{Bi}_{4} \mathrm{~V}_{2} \mathrm{O} 11$ interface produces a high tunable photovoltage for water splitting. Sci. Rep. 2016, 4, 31406. [CrossRef] [PubMed]

47. Deutsch, T.G.; Koval, C.A.; Turner, J.A. III-V Nitride Epilayers for Photoelectrochemical Water Splitting: GaPN and GaAs PN. J. Phys. Chem. B 2006, 110, 25297-25307. [CrossRef] [PubMed]

48. Koster, L.J.A.; Mihailetchi, V.D.; Ramaker, R.; Blom, P.W.M. Light Intensity dependence of open-circuit voltage of polymer-fullerene solar cells. Appl. Phys. Lett. 2005, 86, 123509. [CrossRef]

49. Kumar, P.; Jain, S.C.; Kumar, H.; Chand, S.; Kumar, V. Effect of illumination intensity and temperature on open circuit voltage in organic solar cells. Appl. Phys. Lett. 2009, 94, 183505. [CrossRef]

50. Chegaar, M.; Hamzaoui, A.; Namoda, A.; Petit, P.; Aillerie, M.; Herguth, A. Effect of illumination intensity on solar cells parameters. Energy Procedia 2013, 36, 722-729. [CrossRef]

51. Yu, X.; Sivula, K. Photogenerated Charge Harvesting and Recombination in Photocathodes of Solvent-Exfoliated WSe ${ }_{2}$. Chem. Mater. 2017, 29, 6863-6875. [CrossRef]

52. Liu, B.; Li, X.-B.; Gao, Y.-J.; Li, Z.-J.; Meng, Q.-Y.; Tung, C.-H.; Wu, L.Z. A solution-processed, mercaptoacetic acid-engineered CdSe quantum dot photocathode for efficient hydrogen production under visible light irradiation. Energy. Envorn. Sci. 2015, 8, 1443-1449. [CrossRef]

53. Joe, J.; Bae, C.; Kim, E.; Ho, T.A.; Yang, H.; Park, J.H.; Shin, H. Mixed-Phase (2H and 1T) MoS $_{2}$ Catalyst for a Highly Efficient and Stable Si Photocathode. Catalysts 2018, 8, 580. [CrossRef]

54. Kornienko, N.; Gibson, N.A.; Zhang, H.; Eaton, S.W.; Yu, Y.; Aloni, S.; Leone, S.R.; Yang, P. Growth and Photoelectrochemical Energy Conversion of Wurtzite Indium Phosphide nanowire Arrays. ACS Nano 2016, 10, 5525-5535. [CrossRef]

55. Digdaya, I.A.; Han, L.; Buijs, T.W.F.; Zeman, M.; Dam, B.; Smets, A.H.M.; Smith, W.A. Extracting large photovoltages from a-SiC photocathodes with an amorphous $\mathrm{TiO}_{2}$ front surface field layer for solar hydrogen evolution. Energy Environ. Sci. 2015, 8, 1585-1593. [CrossRef]

56. Liu, C.; Wang, F.; Zhang, J.; Wang, K.; Qiu, Y.; Liang, Q.; Chen, Z. Efficient Photoelectrochemical Water Splitting by g- $\mathrm{C}_{3} \mathrm{~N}_{4} / \mathrm{TiO}_{2}$ Nanotube Array Heterostructures. Nano-Micro Lett. 2018, 10, 37. [CrossRef]

57. Digdaya, I.A.; Adhyaksa, G.W.P.; Trzes'niewski, B.J.; Garnett, E.C.; Smith, W.A. Interfacial engineering of metal-insulator-semiconductor junctions for efficient and stable photoelectrochemical water oxidation. Nat. Commun. 2017, 8, 15968. [CrossRef] [PubMed]

58. Ye, L.; Wang, D.; Chen, S. Fabrication and Enhanced Photoelectrochemical Performance of $\mathrm{MoS}_{2} / \mathrm{S}-\mathrm{Doped}$ g- $\mathrm{C}_{3} \mathrm{~N}_{4}$ Heterojunction Film. ACS Appl. Mater. Interfaces 2016, 8, 5280-5289. [CrossRef] [PubMed]

59. Tewary, V.k.; Jain, S.C. Open-Circuit Voltage Decay in Solar cells. Adv. Electron. Phys. 1986, 67, 319-414.

60. Wang, Q. Fast Voltage Decay in Perovskite Solar Cells Caused by Depolarization of Perovskite Layer. J. Phys. Chem. C 2018, 122, 4822-4827. [CrossRef]

61. Sekizawa, K.; Oh-ishi, K.; Kataoka, K.; Arai, T.; Suzuki, T.M.; Morikawa, T. Stoichiometric water splitting using a p-type $\mathrm{Fe}_{2} \mathrm{O}_{3}$ based photocathode with the aid of a multiheterojunction. J. Mater. Chem. A 2017, 5, 6483-6493. [CrossRef]

62. Bisquert, J.; Zaban, A.; Greenshtein, M.; Mora-Sero, I. Determination of Rate Constants for Charge Transfer and the Distribution of Semiconductor and Electrolyte Electronic Energy Levels in Dye-Sensitized Solar Cells by Open-Circuit Photovoltage Decay Method. J. Am. Chem. Soc. 2004, 126, 13550-13559. [CrossRef] [PubMed]

63. Su, J.Z.; Guo, L.; Bao, N.Z.; Grimes, C.A. Nanostructured $\mathrm{WO}_{3} / \mathrm{BiVO}_{4}$ Heterojunction Films for Efficient Photoelectrochemical Water Splitting. Nano Lett. 2011, 11, 1928-1933. [CrossRef] [PubMed] 
64. Yu, X.; Du, R.; Li, B.; Zhang, Y.; Liu, H.; Qu, J.; An, X. Biomolecule-assisted self-assembly of $\mathrm{CdS} / \mathrm{MoS}_{2}$ /graphene hollow spheres as high-efficiency photocatalysts for hydrogen evolution without noble metals. Appl. Catal. B Environ. 2016, 182, 504-512. [CrossRef]

65. Yang, Y.; Xu, D.; Wu, Q.Y.; Diao, P. Cu $\mathrm{Cu}_{2} \mathrm{O} / \mathrm{CuO}$ Bilayered Composite as a High-Efficiency Photocathode for Photoelectrochemical Hydrogen Evolution Reaction. Sci. Rep. 2016, 6, 35158. [CrossRef] [PubMed]

66. Hill, J.C.; Landers, A.T.; Switzer, J.A. An electrodeposited inhomogeneous metal-insulator-semiconductor junction for efficient photoelectrochemical water oxidation. Nat. Mater. 2015, 14, 1150-1155. [CrossRef] [PubMed]

67. Pawar, G.S.; Tahir, A.A. Unbiased Spontaneous Solar Fuel Production using Stable $\mathrm{LaFeO}_{3}$ Photoelectrode. Sci. Rep. 2018, 8, 3501:1-3501:9. [CrossRef]

68. Hu, D.; Xiang, J.; Zhou, Q.; Su, S.; Zhang, Z.; Wang, X.; Jin, M.; Nian, L.; Nözel, R.; Zhou, G.; et al. One-step chemical vapor deposition of $\mathrm{MoS}_{2}$ noanosheet on SiNWs as photocathodes for efficint and stable solar-driven hydrogen production. Nanoscale 2018, 10, 3518-3525. [CrossRef]

69. Zhou, J.; Dai, S.; Dong, W.; Su, X.; Fang, L.; Zheng, F.; Wang, X.; Shen, M. Efficient and stable MoS $_{2}$ catalyst integrated on Si photocathodes by photoreduction and post-annealing for water splitting. Appl. Phys. Lett. 2016, 108, 213905. [CrossRef]

70. Devarapalli, R.R.; Kamaja, C.K.; Shelke, M.V. Quantum dot-decorated silicon nanowires as efficient photoelectrodes for photoelectrochemical hydrogen generation. J. Mater. Chem. A 2014, 2, 133352-133358. [CrossRef]

71. Lopes, T.; Andrade, L.; Formal, F.L.; Gratzel, M.; Sivula, K.; Mendes, A. Hematite photoelectrodes for water splitting: Evaluation of the role of film thickness by impedance spectroscopy. Phys. Chem. Chem. Phys. 2014, 16, 16515-16523.

72. Lopes, T.; Andrade, L.; Ribeiro, H.A.; Medes, A. Characterization of photoelectrochemical cells for water splitting by electrochemical impedance spectroscopy. Int. J. Hydrog. Energy 2010, 23, 11601-11608. [CrossRef]

73. Fujishima, A.; Honda, K. Electrochemical photolysis of water at a semiconductor electrode. Nature 1972, 238, 37-38. [CrossRef]

74. Andoshe, M.D.; Jin, G.; Lee, C.; Kim, C.; Kwon, K.C.; Choi, S.; Sohn, W.; Moon, C.W.; Lee, S.H.; Suh, J.M.; et al. Directly Assembled 3D Molybdenum Disulfide on Silicon Wafer for Efficient Photoelectrochemical Water Reduction. Adv. Sustain. Syst. 2018, 2, 1700142. [CrossRef]

75. Ding, Q.; Meng, F.; English, C.R.; Acevedo, M.C.; Shearer, M.J.; Liang, D.; Daniel, A.S.; Hamers, R.J.; Jin, S. Efficient photoelectrochemical Hydrogen Generation Using Heterostructures of Si an Chemically Exfoliated Metallic MoS 2 . J. Am. Chem. Soc. 2014, 136, 8504-8507. [CrossRef] [PubMed]

76. Ho, T.A.; Bae, C.; Lee, S.; Kim, M.; Montero-Moreno, J.M.; Park, J.H.; Shin, H. Edge-On MoS 2 Thin Films by Atomic Layer Deposition for Understanding the Interplay between the Active Area and Hydrogen Evolution Reaction. Chem. Mater. 2017, 29, 7604-7614. [CrossRef]

77. Fan, R.; Mao, J.; Yin, Z.; Jie, J.; Dong, W.; Fang, L.; Zheng, F.; Shen, M. Efficient and Stable Silicon Photocathodes Coated with Vertically Standing Nano-MoS 2 Films for Solar Hydrogen Production. ACS Appl. Mater. Interfaces 2017, 9, 6123-6129. [CrossRef] [PubMed]

78. Oh, S.; Kim, J.B.; Song, J.T.; Oh, J.H.; Kim, S.H. Atomic layer deposited molybdenum disulfide on Si photocathodes for highly efficient photoelectrochemical water reduction reaction. J. Mater. Chem. A 2017, 5, 3304-3310. [CrossRef]

79. Du, P.; Zhu, Y.; Zhang, J.; Xu, D.; Peng, W.; Zhang, G.; Zhang, F.; Fan, X. Metallic 1T phase MoS $_{2}$ nanosheets as a highly efficient co-catalyst for the photocatalytic hydrogen evolution of CdS nanorods. RSC Adv. 2016, 6, 74394-74399. [CrossRef]

80. Kwon, K.C.; Choi, S.; Hong, K.; Moon, C.W.; Shim, Y.-S.; Kim, D.H.; Kim, T.; Sohn, W.; Jeon, J.-M.; Lee, C.H.; et al. Wafer-scale transferable molybdenum disulphide thin-film catalyst for photoelectrochemical hydrogen production. Energy Environ. Sci. 2016, 9, 2240-2248. [CrossRef]

81. Fujii, K.; Ono, M.; Iwaki, Y.; Sato, K.; Ohkawa, K.; Yao, T. Photoelectrochemical Properties of the p-n Junction in and near the Surface Depletion Region of n-Type GaN. J. Phys. Chem. C 2010, 114, 22727-22735. [CrossRef] 
82. Tran, D.P.; Pramana, S.S.; Kale, S.V.; Nguyen, M.; Chiam, T.S.; Batabyal, K.S.; Wong, H.L.; Barber, J.; Loo, J. Novel Assembly of an $\mathrm{MoS}_{2}$ Electrocatalyst onto a Silicon Nanowire Array Electrode to Construct a Photocathode Composed of Elements Abundant on the Earth for Hydrogen Generation. Chem. Eur. J. 2012, 18, 13994-13999. [CrossRef]

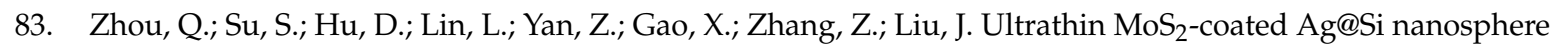
arrays as an efficient and stable photocathode for solar-driven hydrogen production. Nanotechnology 2018, 29, 105402-105410. [CrossRef]

84. Zeng, L.; Liu, Y.; Lin, S.; Qarony, W.; Tao, L.; Chai, Y.; Zhang, X.; Lau, P.S.; Tsang, H.Y. High photoelectrochemical activity and stability of $\mathrm{Au}-\mathrm{WS}_{2} /$ silicon heterojunction photocathode. Sol. Energy Mater. Sol. Cells 2018, 174, 300-306. [CrossRef]

85. Benck, D.J.; Lee, S.; Fong, D.K.; Kibsgaard, J.; Sinclair, R.; Jaramillo, F.T. Designing Active and Stable Silicon Photocathodes for Solar Hydrogen Production Using Molybdenum Sulfide Nanomaterials. Adv. Energy. Mater. 2014, 4, 1400739. [CrossRef]

86. King, L.A.; Hellstern, T.R.; Park, J.; Sinclair, R.; Jaramillo, T.F. Highly Stable Molybdenum Disulfide Protected Silicon Photocathodes for Photoelectrochemical Water Splitting. ACS Appl. Mater. Interfaces 2017, 9, 36792-36798. [CrossRef] [PubMed]

87. Huang, G.; Mao, J.; Fan, R.; Yin, Z.; Wu, X.; Jie, J.; Kang, Z.; Shen, M. Integrated MoSe 2 with n+p-Si photocathodes for solar water splitting with high efficiency and stability. Appl. Phys. Lett. 2018, 112, 013902. [CrossRef]

88. Zhang, L.; Liu, C.; Wong, B.A.; Resasco, J.; Yang, P. MoS 2 -wrapped silicon nanowires for photoelectrochemical water reduction. Nano Res. 2015, 8, 281-287. [CrossRef]

89. Chandra, G.; Roy, M.A.; Bhattacharya, S.S. Effect of n-Si on the Photocatalytic Production of Hydrogen by Pt-loaded CdS and CdS/ZnS Catalyst. Int. J. Hydrog. Energy 1996, 21, 19-23. [CrossRef]

90. Hou, T.; Abrams, L.B.; Vesborg, C.K.P.; Bjorketun, E.M.; Herbst, K.; Bech, L.; Setti, M.A.; Damsgaard, D.C.; Pedersen, T.; Hansen, O.; et al. Bioinspired molecular co-catalysts bonded to a silicon photocathode for solar hydrogen evolution. Nat. Mater. 2011, 10, 434-438. [CrossRef] [PubMed]

91. Hou, Y.; Zhu, Z.; Xu, Y.; Guo, F.; Zhang, J.; Wang, X. Efficient photoelectrochemical hydrogen production over p-Si nanowire arrays coupled with molybdenume-sulfur clusters. Int. J. Hydrog. Energy 2017, 42, 2832-2838. [CrossRef]

92. Huang, Z.; Wang, C.; Pan, L.; Tian, F.; Zhang, X.; Zhang, C. Enhanced photoelectrochemical hydrogen production using silicon nanowires@MoS 3 . Nano Energy 2013, 2, 1337-1346. [CrossRef]

93. Zhang, H.; Ding, Q.; He, D.; Liu, H.; Liu, W.; Li, Z.; Yang, B.; Zhang, X.; Lei, L.; Jin, S. A p-Si/NiCoSex core/shell nanopillar array photocathode for enhanced photoelectrochemical hydrogen production. Energy Environ. Sci. 2016, 9, 3113-3119. [CrossRef]

94. Chen, Y.; Tran, P.; Boix, P.; Ren, Y.; Chiam, Y.S.; Li, Z.; Fu, K.; Wong, H.L.; Barber, J. Silicon Decorated with Amorphous Cobalt Molybdenum Sulfide Catalyst as an Efficient Photocathode for Solar Hydrogen Generation. ACS Nano 2015, 9, 3829-3836. [CrossRef]

95. Chen, C.; Chen, P.; Basu, M.; Yang, K.; Lu, Y.; Dong, C.; Ma, C.; Shen, C.; Hu, S.; Liu, R. An integrated cobalt disulfide $\left(\mathrm{CoS}_{2}\right)$ co-catalyst passivation layer on silicon microwires for photoelectrochemical hydrogen evolution. J. Mater. Chem. A 2015, 3, 23466-23476. [CrossRef]

96. Chen, C.; Yang, K.; Basu, M.; Lu, T.; Lu, Y.; Dong, C.; Hu, S.; Liu, R. Wide Range pH-Tolerable Silicon@Pyrite Cobalt Dichalcogenide Microwire Array Photoelectrodes for Solar Hydrogen Evolution. ACS Appl. Mater. Interfaces 2016, 8, 5400-5407. [CrossRef] [PubMed]

97. Basu, M.; Zhang, Z.; Chen, C.; Chen, P.; Yang, K.; Ma, C.; Lin, C.; Hu, S.; Liu, R. Heterostructure of Si and $\mathrm{CoSe}_{2}$ : A Promising Photocathode Based on a Non-noble Metal Catalyst for Photoelectrochemical Hydrogen Evolution. Angew. Chem. Int. Ed. 2015, 54, 6211-6216. [CrossRef] [PubMed]

98. Bazri, B.; Lin, Y.; Lu, T.; Chen, C.; Kowsari, E.; Hu, S.; Liu, R. A heteroelectrode structure for solar water splitting: Integrated cobalt ditelluride across a $\mathrm{TiO}_{2}$-passivated silicon microwire array. Catal. Sci. Technol. 2017, 7, 1488-1496. [CrossRef]

99. Seger, B.; Laursen, B.A.; Vesborg, C.K.P.; Pedersen, T.; Hansen, O.; Dahl, S.; Chorkendorff, I. Hydrogen Production Using a Molybdenum Sulfide Catalyst on a Titanium-Protected n+p-Silicon Photocathode. Angew. Chem. Int. Ed. 2012, 51, 9128-9131. [CrossRef] [PubMed] 
100. Yadian, B.; Rao, Y.; Zhu, B.; Liu, Z.; Liu, Q.; Gan, L.C.; Chen, X.; Huang, Y. Metal-sulfide-decorated ZnO/Si nano-heterostructure arrays with enhanced photoelectrochemical performance. Mater. Res. Bull. 2017, 96, 503-508. [CrossRef]

101. Nie, X.; Zhuo, S.; Maeng, G.; Sohlberg, K. Doping of $\mathrm{TiO}_{2}$ Polymorphs for Altered Optical and Photocatalytic Properties. Int. J. Photoenergy 2009, 294042:1-294042:22.

102. Morgan, B.; Watson, G. Intrinsic n-type Defect Formation in $\mathrm{TiO}_{2}$ : A Comparison of Rutile and Anatase from GGA+U Calculations. J. Phys. Chem. C 2010, 114, 2321-2328. [CrossRef]

103. Fahey, P.; Griffin, P.; Plummer, J. Point defects and dopant diffusion in silicon. Rev. Mod. Phys. 1989, 61, 289-384. [CrossRef]

104. Scanlon, D.; King, P.; Singh, R.; Torre, A.; Walker, S.; Balakrishnan, G.; Baumberger, F.; Catlow, C. Controlling Bulk Conductivity in Topological Insulators: Key Role of Anti-Site Defects. Adv. Mater. 2012, 24, 2154-2158. [CrossRef]

105. Fuschillo, N.; Bierly, N.J.; Donahoe, F.J. Transport properties of the pseudo-binary alloy system $\mathrm{Bi}_{2} \mathrm{Te}_{3}-\mathrm{ySey}$. J. Phys. Chem. Solids 1959, 8, 430-433. [CrossRef]

106. Miller, G.R.; Li, C. Evidence for the existence of antistructure defects in bismuth telluride by density measurements. J. Phys. Chem. Solids 1965, 26, 173-177. [CrossRef]

107. Ghoshtagore, R.N. Self-Diffusion in Tellurium. I. Anisotropy and Impurity Effect. Phys. Rev. 1967, 155, 598-602. [CrossRef]

108. George, S.M. Atomic Layer Deposition: An Overview. Chem. Rev. 2010, 110, 111-131. [CrossRef]

109. Kim, H.; Lee, H.B.R.; Maeng, W.J. Applications of atomic layer deposition to nanofabrication and emerging nanodevices. Thin Solid Films 2009, 517, 2563-2580. [CrossRef]

110. Jin, Z.; Shin, S.; Kwon, D.H.; Han, S.J.; Min, Y.S. Novel chemical route for atomic layer deposition of $\mathrm{MoS}_{2}$ thin film on $\mathrm{SiO}_{2} / \mathrm{Si}$ substrate. Nanoscale 2014, 6, 14453-14458. [CrossRef]

111. Song, J.G.; Ryu, G.H.; Lee, S.J.; Sim, S.; Lee, C.W.; Choi, T.; Jung, H.; Kim, Y.; Lee, Z.; Myoung, J.M.; et al. Controllable synthesis of molybdenum tungsten disulfide alloy for vertically composition-controlled multilayer. Nat. Commun. 2015, 6, 7817. [CrossRef] [PubMed]

112. Yoo, H.; Bae, C.; Yang, Y.; Lee, S.; Kim, M.; Kim, H.; Kim, Y.; Shin, H. Spatial Charge Separation in Asymmetric Structure of $\mathrm{Au}$ Nanoparticle on $\mathrm{TiO}_{2}$ Nanotube by Light-Induced Surface Potential Imaging. Nano Lett. 2014, 14, 4413-4417. [CrossRef] [PubMed]

113. Polak, L.; Rector, J.; Slaman, M.; Wijngaarden, R. $\mathrm{NaTaO}_{3}$ Photoanode for Bias-Free Water Splitting: A Photo-Electrochemical and Kelvin Probe Surface Photovoltage Study. J. Phys. Chem. C 2016, 120, 23559-23565. [CrossRef]

114. Hu, Y.; Wu, Y.; Feng, J.; Huang, H.; Zhang, C.; Qian, Q.; Fang, T.; Xu, J.; Wang, P.; Li, Z.; et al. Rational design of electrocatalysts for simultaneously promoting bulk charge separation and surface charge transfer in solar water splitting photoelectrodes. J. Mater. Chem. A 2018, 6, 2568-2576. [CrossRef]

115. Almadori, Y.; Bendiab, N.; Grévin, B. Multimodal Kelvin Prove Force Microscopy Investigations of a Photovoltaic $\mathrm{WSe}_{2} / \mathrm{MoS}_{2}$ Type-ll interface. ACS Appl. Mater. Interfaces 2018, 10, 1363-1373. [CrossRef] [PubMed]

116. Li, Y.; Xu, C.-Y.; Wang, J.-Y.; Zhen, L. Photodiode-Like Behavior and Excellent Photoresponse of Vertical $\mathrm{Si} /$ Monolyer $\mathrm{MoS}_{2}$ Heterostructures. Sci. Rep. 2014, 4, 7186:1-7186:8.

117. Kim, J.; Kim, G.Y.; Moon, H.; Yoon, S.; Seo, I.W.; Lee, Y.; Moon, D.G.; Ahn, S.J.; Jo, W. Identification of marcasite in pyrite $\mathrm{FeS}_{2}$ fhim films and the films' carrier transport characeristics. RSC Adv. 2016, 6, 81394-81399. [CrossRef]

118. Chi, C.F.; Cho, H.W.; Teng, H.; Chuang, C.Y.; Chang, Y.M.; Hsu, Y.J.; Lee, Y.L. Energy level alignment, electron injection, and charge recombination characteristics in CdS/CdSe cosensitized $\mathrm{TiO}_{2}$ photoelectrode. Appl. Phys. Lett. 2011, 98, 012101. [CrossRef]

119. Fingerle, M.; Tengeler, S.; Calvet, W.; Mayer, T.; Jaegermann, W. Water Interaction with Sputter-Deposited Nickel Oxide on n-Si Photoanode: Cryo Photoelectron Spectroscopy on Adsorbed Water in the Frozen Electrolyte Approach. J. Electrochem. Soc. 2018, 165, H3148-H3153. [CrossRef]

120. Wan, D.; Zhao, Y.; Cai, Y.; Asmara, T.; Huang, Z.; Chen, J.; Hong, J.; Yin, S.; Nelson, C.; Motapothula, M.; et al. Electron transport and visible light absorption in a plasmonic photocatalyst based on strontium niobite. Nat. Commun. 2017, 8, 15070. [CrossRef] [PubMed] 
121. Liu, J.; Liu, Y.; Liu, N.; Han, Y.; Zhang, X.; Huang, H.; Lifshitz, Y.; Lee, S.; Zhong, J.; Kang, Z. Metal-free efficient photocatalyst for stable visible water splitting via a two-electron pathway. Science 2015, 347, 970-974. [CrossRef] [PubMed]

122. Furube, A.; Shiozawa, T.; Ishikawa, A.; Wada, A.; Domen, K.; Hirose, C. Femtosecond Transient Absorption Spectroscopy on Photocatalysts: $\mathrm{K}_{4} \mathrm{Nb}_{6} \mathrm{O}_{17}$ and $\mathrm{Ru}(\mathrm{bpy}) 3$ 2+-Intercalated $\mathrm{K}_{4} \mathrm{Nb}_{6} \mathrm{O}_{17}$ Thin Films. J. Phys. Chem. B 2002, 106, 3065-3072. [CrossRef]

123. Moss, B.; Lim, K.; Beltram, A.; Moniz, S.; Tang, J.; Fornasiero, P.; Barnes, P.; Durrant, J.; Kafizas, A. Comparing photoelectrochemical water oxidation, recombination kinetics and charge trapping in the three polymorphs of $\mathrm{TiO}_{2}$. Sci. Rep. 2017, 8, 2938:1-2938:7. [CrossRef] [PubMed]

124. Liu, J.; Dai, M.; Wu, J.; Hu, Y.; Zhang, Q.; Cui, J.; Wang, Y.; Tan, H.H.; Wu, Y. Electrochemical hydrogenation of mixed-phase $\mathrm{TiO}_{2}$ nanotube arrays enables remarkably enhanced photoelectrochemical water splitting performance. Sci. Bull. 2018, 63, 194-202. [CrossRef]

125. Kappera, R.; Voiry, D.; Yalcin, S.E.; Branch, B.; Gupta, G.; Mohite, A.D.; Chhowalla, M. Phase-engineered low-resistance contacts for ultrathin $\mathrm{MoS}_{2}$ transistors. Nat. Mater. 2014, 13, 1128-1134. [CrossRef]

126. Cho, S.; Kim, S.; Kim, J.H.; Zhao, J.; Seok, J.; Keum, D.H.; Baik, J.; Choe, D.-H.; Chang, K.J.; Suenaga, K.; et al. Phase patterning for ohmic homojunction contact in $\mathrm{MoTe}_{2}$. Science 2015, 349, 625-628. [CrossRef]

127. Li, M.Y.; Shi, Y.; Cheng, C.C.; Lu, L.S.; Lin, Y.C.; Tang, H.L.; Tsai, M.L.; Chu, C.W.; Wei, K.H.; He, J.H.; et al. Epitaxial growth of a monolayer $\mathrm{WSe}_{2}-\mathrm{MoS}_{2}$ lateral p-n junction with an atomically sharp interface. Science 2015, 349, 524-528. [CrossRef]

128. Agrawal, A.; Lin, J.; Barth, M.; White, R.; Zheng, B.; Chopra, S.; Gupta, S.; Wang, K.; Gelatos, J.; Mohney, S.E.; et al. Fermi level depinning and contact resistivity reduction using a reduced titania interlayer in n-silicon metal-insulator-semiconductor ohmic contactsn nanowire array electrode to construct a photocathode composed of elements abundant on the earth for hydrogen generation. Appl. Phys. Lett. 2014, 104, 112101-112105.

129. Smit, G.D.J.; Rogge, S.; Klapwijk, T.M. Scaling of nano-Schottky-diodes. Appl. Phys. Lett. 2002, 81, $3852-3854$. [CrossRef]

130. Rossi, R.C.; Lewis, N.S. Investigation of the Size-Scaling Behavior of Spatially Nonuniform Barrier Height Contacts to Semiconductor Surfaces Using Ordered Nanometer-Scale Nickel Arrays on Silicon Electrodes. J. Phys. Chem. B 2001, 105, 12303-12318. [CrossRef]

(C) 2019 by the authors. Licensee MDPI, Basel, Switzerland. This article is an open access article distributed under the terms and conditions of the Creative Commons Attribution (CC BY) license (http:// creativecommons.org/licenses/by/4.0/). 